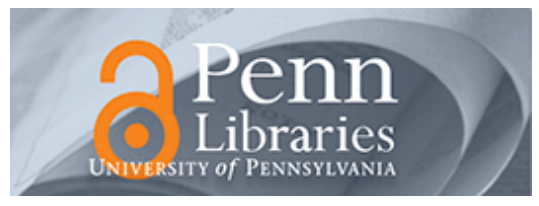

University of Pennsylvania

ScholarlyCommons

Accounting Papers

Wharton Faculty Research

$12-2010$

\title{
Understanding Earnings Quality: A Review of the Proxies, Their Determinants and Their Consequences
}

Patricia M. Dechow

Weili Ge

Catherine M. Schrand

University of Pennsylvania

Follow this and additional works at: https://repository.upenn.edu/accounting_papers

Part of the Accounting Commons

\section{Recommended Citation}

Dechow, P. M., Ge, W., \& Schrand, C. M. (2010). Understanding Earnings Quality: A Review of the Proxies, Their Determinants and Their Consequences. Journal of Accounting and Economics, 50 (2-3), 344-401. http://dx.doi.org/10.1016/j.jacceco.2010.09.001

This paper is posted at ScholarlyCommons. https://repository.upenn.edu/accounting_papers/124

For more information, please contact repository@pobox.upenn.edu. 


\title{
Understanding Earnings Quality: A Review of the Proxies, Their Determinants and Their Consequences
}

\author{
Abstract \\ its earnings quality is suggested as one area for future work.

\section{Keywords} \\ earnings quality, earnings management, review, survey \\ Disciplines \\ Accounting
}

Researchers have used various measures as indications of "earnings quality" including persistence, accruals, smoothness, timeliness, loss avoidance, investor responsiveness, and external indicators such as restatements and SEC enforcement releases. For each measure, we discuss causes of variation in the measure as well as consequences. We reach no single conclusion on what earnings quality is because "quality" is contingent on the decision context. We also point out that the "quality" of earnings is a function of the firm's fundamental performance. The contribution of a firm's fundamental performance to 


\title{
Understanding earnings quality:
}

\section{A review of the proxies, their determinants and their consequences}

\author{
Patricia Dechow \\ Weili Ge \\ Catherine Schrand
}

\begin{abstract}
Over the years, researchers have devised various measures of "earnings quality" to represent decision usefulness in specific decision contexts. These measures, however, have become proxies for "earnings quality" in a generic sense, absent a decision context. The result is that some papers use a proxy for earnings quality that does not match the hypothesized form of decision usefulness in their study, but they nonetheless find results that are consistent with their hypothesis. Other papers are intentionally agnostic and find robust results across multiple proxies for earnings quality. The fact that researchers find consistent and robust results across proxies suggests that there is common component to the various measures of quality, which is the firm's fundamental earnings process. Existing research does not clearly distinguish the impact of a firm's fundamental earnings process on the decision usefulness ("quality") of its earnings from the impact of the application of accounting measurement to that process. Research attention has focused on earnings management that reduces the reliability of earnings rather than on the ability of specific features of an accrual-based accounting system to provide a more decision-useful measure, conditional on the firm's fundamental earnings process.
\end{abstract}

September 2009

Thanks to Michelle Hanlon (the editor), Shiva Rajgopal, Terry Shevlin, Nemit Shroff, Richard Sloan, and Rodrigo Verdi for helpful comments. The framework for this review is based on Schrand's discussion of earnings quality at the April 2006 CARE Conference sponsored by the Center for Accounting Research at the University of Notre Dame. 


\section{Understanding earnings quality:}

\section{A review of the proxies, their determinants and their consequences}

We begin with a definition of "earnings quality" that sets the scope of our review. Higher quality earnings more faithfully represent the features of the firm's fundamental earnings process that are relevant to a specific decision made by a specific decision-maker. Our definition implies that the term "earnings quality" is meaningless without specifying the decision context, because the relevant features of the firm's fundamental earnings process differ across decisions and decision makers. Consistent with this broad definition, we review approximately 350 published papers on earnings. ${ }^{1}$ We do not require that the researcher use the term earnings quality.

This broad scope is motivated by the varied and often imprecise use of the term "earnings quality" by practitioners (including regulators, enforcement agencies, and courts), the financial press, and academic researchers. Lev (1989) popularized the adjective "quality" as a descriptive characteristic of earnings for academic researchers when he stated that one explanation for low $\mathrm{R}^{2} \mathrm{~s}$ in earnings/returns models is that: "No serious attempt is being made to question the quality of the reported earnings numbers prior to correlating them with returns." Lev's statement implicitly suggests that he defines earnings quality as decision-usefulness in the context of equity valuation decisions.

This use of the term "quality" is consistent with O'Glove's practitioner-oriented financial statement analysis textbook, Quality of Earnings, published in 1987, and even with Graham and Dodd's use of the term in Security Analysis, published in 1934. Graham and Dodd describe the Wall

\footnotetext{
${ }^{1}$ We searched four journals starting with the first issue (in parentheses) through 2008: Contemporary Accounting Research (1984), Journal of Accounting and Economics (1980), Journal of Accounting Research (1964), and Review of Accounting Studies (1996). We searched The Accounting Review from 1970 through 2008. We added articles from other journals and working papers to the extent we are aware of them, but we did not perform a systematic review to find them.
} 
Street equity valuation model as earnings per share times a "coefficient of quality" where the quality coefficient reflects firm-specific characteristics such as dividend policy, as well as "size, reputation, financial position and prospects," the nature of the firm's operations, and macro factors including "temper of the general market."

Accounting researchers continue to use the descriptor quality in reference to the decision-usefulness of earnings in equity market valuation, but use of the term has been extended to other contexts as well, likely because of our conversational understanding of the term quality as an indication of superiority or excellence. This evolution of a term such as earnings quality to its current state of ambiguity is not unique. Schelling (1978) describes the phenomenon:

Each academic profession can study the development of its own language. Some terms catch on and some don't. A hastily chosen term that helps meet a need gets initiated into the language before anybody notices what an inappropriate term it is. People who recognize that a term is a poor one use it anyway in a hurry to save thinking of a better one, and in collective laziness we let inappropriate terminology into our language by default. Terms that once had accurate meanings become popular, become carelessly used, and cease to communicate with accuracy.

Our approach in this review is to embrace the fact that earnings quality is a multi-faceted term. We therefore expand the scope of the review beyond studies of the decision-usefulness of earnings in an equity valuation context. We identify the various proxies that have been used to measure earnings quality, evaluate the various attributes of decision usefulness (i.e., "quality") that researchers have measured, and point out the strengths and weaknesses of each measure. We also identify circumstances where researchers obtain conflicting results because of ambiguity in what is meant by "quality" or differences due to the choice of earnings quality proxy. ${ }^{2}$

\footnotetext{
${ }^{2}$ A number of survey papers of earnings quality and/or earnings management predate this review: Healy and Wahlen (1999); Dechow and Skinner (2000); McNichols (2000); Fields, Lys, and Vincent (2001); Imhoff (2003); Penman (2003); Nelson, Elliott, and Tarpley (2003); Schipper and Vincent (2003); Dechow and Schrand (2004); Francis, Olsson,
} 
An important feature of our review is the method we use to organize our discussion of the papers. We apply the approach that Chronbach and Meehl (1955) suggest to assess the validity of a latent construct in general to the specific case of earnings quality. For each paper, we identify its proxy for earnings quality. We use three broad earnings quality (EQ) categories: (i) statistical properties of earnings; (ii) investor responsiveness to earnings; and (iii) external indicators of financial reporting quality. The properties of earnings category includes: a) persistence and accruals, b) earnings smoothness, c) asymmetric timeliness and timely loss recognition; and d) benchmarking, in which the distance of earnings from a benchmark is viewed as a measure of its quality (e.g., small profits). The investor responsiveness to earnings category includes papers that use an earnings response coefficient (ERC) as a measure of earnings informativeness or earnings quality. The category for external indicators of financial reporting quality includes: AAERs, restatements, and internal control procedure deficiencies reported under SOX. Table 1, Panel A, lists the EQ proxies and the sections of this survey in which we discuss them. Exhibit 1 provides a brief summary of the intuition behind each measure and comments on its use as a proxy for earnings quality. By juxtaposing the papers against other papers that examine the same EQ proxy, we are able to draw conclusions about the contexts in which the proxy is decision-useful.

We then classify the papers into two groups according to whether they provide evidence on 1) the determinants of the earnings quality proxy, or 2) the consequences of the earnings quality proxy. Table 1, Panels B and C, list the categories of determinants and consequences. The determinants papers propose or test theories about features of the firm (or the firm's environment) that cause an earnings outcome; the earnings quality proxy is the dependent variable in the analysis. The consequences papers propose or test theories about earnings quality that cause an outcome; the context and discuss only the literature related to that definition. 
earnings quality proxy is the independent variable in the analysis. ${ }^{3}$ We perform a second sort of the papers by either the hypothesized determinant or the hypothesized consequence of earnings quality. Juxtaposing the papers against other papers that examine the same determinant (or the same consequence) provides an efficient means to informally assess the convergent and divergent validity of the proxies. That is, we can examine whether determinants that should be related to the various proxies in the same way are, and whether the proxies that should not be related are not. The double sorting therefore allows us to more easily identify patterns of mixed and missing evidence. Figures 1 and 2 provide an overview of the studies we have reviewed.

In Section 2, we summarize our key findings about the literature taken as a whole and our conclusions for each specific earnings quality proxy. We also provide a list of ten additional findings, some of which offer suggestions for future research. The detailed discussions of the papers that support the conclusions follow in Sections 3 through 6. Readers that want to view the evidence organized by the EQ proxy should read Sections 3 and 4. Readers that want to view the evidence organized by determinant or consequence should read Sections 5 and 6. Section 7 concludes.

\section{Summary of findings}

Figure 1 (Figure 2) reports the number of papers that examine the various determinants (consequences) of each earnings quality proxy. Figure 3 combines the information in Figures 1 and 2 to give a quick preview of the various links that have been examined by researchers. Figure 4 provides a graphical representation of whether researchers validated their earnings quality proxy by showing that the proxy was also correlated with another proxy (e.g., documenting that SEC

\footnotetext{
${ }^{3}$ Chronbach and Meehl (1955) describe the determinants and consequences as part of the nomological network in which a construct occurs. The nomological network is the interlocking system of laws which may relate $(a)$ observable properties or quantities to each other; or $(b)$ theoretical constructs to observables; or $(c)$ different theoretical constructs to one another which set forth the laws in which the construct occurs.
} 
enforcement firms have high discretionary accruals). The conclusions below are based on the review of the literature represented in Figures 1 through 4.

\subsection{Overall conclusions}

A somewhat unsatisfying feature of this survey for readers is that we do not suggest that there is a single best proxy for earnings quality that is appropriate for all decision contexts. In fact, an overriding message of the survey is that earnings quality is context-specific, and thus our assessment of the ability of each measure to capture decision usefulness is also context specific. The commonly used proxies for EQ, however, vary with respect to the degree to which they measure decision-usefulness across different types of decisions, and hence there is no overall best measure. Our review of the proxies provides evidence on which types of useful information each EQ proxy captures.

All of the proxies for earnings quality that involve earnings (i.e., properties such as persistence as well as the ERCs) have at their core the reported accrual-based earnings number. Reported accrual-based earnings are a function of "fundamental" earnings (X), which are unobservable, as well as the accounting system that imperfectly measures X:

Reported Earnings $=$ Function of $(X)+$ error induced by accounting system (e)

Fundamental earnings $(\mathrm{X})$ represents the output of the firm's production function or business model and can be thought of as the expected cash flows generated during the period that could be annuitized to obtain the fundamental value of the firm, alternatively referred to as perpetual earnings. Throughout the review, we use the term "fundamental earnings process" to represent X. The quality 
of fundamental earnings will be a function of the operating cycle, macro business condition, investment opportunity set, managerial skill, and other features of the firm. The "error" term represents the ability of the accounting system to measure the firm's fundamental earnings process. There may be a feedback loop: the accounting measurement system could influence management's behavior that in turn changes "fundamental" earnings and its quality. For example, not requiring the expensing of stock options could result in greater stock option usage than otherwise would occur, which could affect risk taking behavior, which will in turn affect the fundamental earnings process.

Since all of the EQ proxies involve reported earnings, they all are affected by both the fundamental earnings process as well as the ability of the accounting system to measure the process. There are multiple reasons that the accounting measurement system captures the fundamental process with error. The standard setters are working with a different measurement system in mind (e.g., focusing on fair valuing assets and liabilities and measuring earnings as the change in wealth). Management make poor forecasts that affect accrual estimation (e.g., forecasting the level of returns incorrectly) or that affect real decisions (e.g., overinvesting in inventory or PPE, requiring a subsequent write down). Items that should be expensed are ignored (e.g., expected environment liabilities, bad investments). Firms structure transactions to get around undesirable accounting implications (leasing, securitizations, stock options).

As accountants, one important area of research should evaluate the ability of the accounting system to measure different types of earnings processes. That is, we should focus on the "e" term. Another important area of research should examine when reported earnings, in total, are of higher quality. Both types of research are important for understanding earnings quality.

Our point is that the current research does not adequately recognize the distinction between the fundamental earnings process and the measurement of the process, which limits the conclusions 
we can make, as a profession, to statements about the quality of the earnings as a whole rather than about the contribution of accounting measurement to the quality of reported earnings. We turn to Graham and Dodd for a lucid characterization of this issue and to emphasize the essential nature of the problem:

Most important of all, the analyst must recognize that the value of a particular kind of data varies greatly with the type of enterprise which is being studied. The five-year record of gross or net earnings of a railroad or a large chain-store enterprise may afford, if not a conclusive, at least a reasonably sound basis for measuring the safety of the senior issues and the attractiveness of the common shares. But the same statistics supplied by one of the smaller oil-producing companies may well prove more deceptive than useful, since they are chiefly the resultant of two factors, viz., price received and production, both of which are likely to be radically different in the future than in the past. (p. 33/34)

To better understand this deficiency in the literature, we estimate correlations between the commonly used earnings quality proxies. ${ }^{4}$ Table 2 shows that the correlations between most of the EQ proxies are positive and statistically significant, but they are not generally economically significant. For example, the correlation between timely loss recognition and persistence is less than two percent. Moreover, all EQ proxies have a negative correlation with the smoothness proxies.

These correlations suggest that there is a common driver of the EQ proxies, which at least in part will be the firm's unobservable fundamental earnings process. The degree to which the unobservable fundamental earnings process affects each proxy varies, as does the degree to which the proxy is affected by the accounting measurement system. All of the proxies reflect both elements, but the proxies are not equally affected by these two factors.

Given the fundamental component of the proxies, studies that examine determinants and consequences of the EQ proxies, measured using reported earnings, cannot identify the unique

\footnotetext{
${ }^{4}$ For illustrative purposes, we measure each variable using a common specification. All proxies are defined to be increasing in "quality." For example, we use the additive inverse of the Dechow/Dichev abnormal accruals measure because, in the literature, larger absolute errors are assumed to represent lower quality.
} 
contributions of the fundamental component from the ability of the accounting system to measure the process. For example, studies predict and find a negative relation between large absolute discretionary accruals and both the number of independent directors of a firm and auditor size, suggesting that both independent variables are determinants of earnings quality. The prediction assumes that these parties affect EQ through their influence on the financial reporting process. While the studies make various attempts to control for the fundamental earnings process, they generally cannot reject the hypothesis that they are finding a correlation between their hypothesized determinant or consequence and the fundamental component of quality.

For example, the most significant area of research in terms of the sheer volume of published papers is on the determinants and consequences of abnormal accruals derived from accrual models. Exhibit 2 provides a summary of the most commonly used approaches to measuring abnormal accruals. The accruals models attempt to control for the accruals that are related to the firm's fundamental earnings process, calling them normal, non-discretionary, or innate accruals. But, many of the controls that are used are measured by reported accrual-based earnings associated with the process (growth in sales revenue, for example). Thus, the accruals models may distinguish normal accruals from the component that represents discretion, but the normal or innate accruals do not necessarily adequately capture the fundamental earnings process.

Researchers could make positive predictions about how determinants would differentially affect specific quality proxies or about different consequences of the proxies. The testable hypotheses are generally derived from decision models and the models suggest a specific form of decision usefulness (i.e., earnings quality). Most theories would not predict a relation with all proxies, or at least would not predict an equally strong relation with all. But researchers typically do not conduct such analyses. In fact, the studies that test theories by examining multiple proxies for 
earnings quality often suggest that the study's findings are robust to alternative specifications of earnings quality. The results are consistent across the proxies, but we question whether they should be.

In summary, our wide-ranging finding across all the EQ proxies is that we have not adequately separated the unobservable dimension of quality related to the fundamental earnings process from the ability of the accounting measurement process to contribute to the quality of reported earnings. The research attempts to separate abnormal accruals from normal accruals, but the distinction between the normal accruals and $\mathrm{X}$ as a source of reported earnings quality is still an open question.

In the remainder of this section, we summarize our specific findings on each individual EQ proxy (Sections 2.2.1 through 2.2.3). Detailed discussions of the papers and justification for the conclusions are discussed in the survey section noted. Exhibit 1 provides an overview of each proxy, its strengths and its weakness, and how fundamentals and measurement error in the accounting system are likely to affect the proxy. In Section 2.3, we outline additional conclusions based on our survey of the entirety of the network of studies, with some suggestions of future research opportunities.

\subsection{Specific findings on each EQ proxy}

\subsubsection{Properties of earnings}

Earnings persistence and accruals (Section 3.1.1): A considerable number of studies provide evidence on the ability of reported earnings, and various components of earnings, to predict future cash flows relative to cash flows or other earnings metrics. Another set of studies examines earnings persistence directly, typically using an approach that measures the incremental contributions of 
accruals, in total or individually, and cash flows to earnings persistence. Researchers have partitioned the accruals in many ways in an attempt to characterize the effect of accruals on persistence. For example, researchers have examined normal vs. abnormal accruals, extreme accruals (in magnitude), more vs. less reliable accruals, operating vs. investment accruals, short-term vs. long-term accruals, and even specific accounts. A broad summarization of the findings is that the cash flow component is more persistent than the accrual component of earnings, and that the abnormal accrual component is less persistent than the normal accrual component of earnings. (See Section 3.1.1.)

The research on persistence does not generally separate the contributions of the fundamental earning process $(\mathrm{X})$ and the measurement of the process (e) to the persistence of reported earnings. The studies that examine the incremental persistence of accruals to cash flows are not sufficient to segregate the effects of "X" from " $\mathrm{C}$ " because current cash flows do not represent the fundamental earnings process, and in fact, the premise of accrual-based accounting is that accrual-based earnings should provide better information about fundamental earnings than current cash flows. Several studies do provide direct evidence on how the application of accounting measurement rules to specific earnings processes (or features of a process) affects EQ outcomes. Penman and Zhang (2002), for example, show that expensing costs that have future benefits will lead to higher future earnings as the future benefits are "realized" in earnings, but the slowing of these expensed "investments" can lead to transitory boosts in earnings. As a consequence, increases in capitalized investments will likely lead to errors such that the currently observed return on assets is not sustainable. Lev and Sougiannis (1996) suggest that the expensing of R\&D can lead to an earnings stream that does not reflect growth in the fundamental earnings process. 
In summary, while we may be able to characterize earnings persistence and conclude that firms with more persistent earnings have more accurate equity valuations, which implies greater decision usefulness, we have relatively less to say about the importance of the measurement process in reaching these conclusions. By clarifying and distinguishing between fundamentals and the accounting measurement system, more insights could be obtained about the role of the measurement system itself.

Earnings smoothness (Section 3.1.2): As noted in the introduction, the commonly-used smoothness proxies are negatively correlated with the other EQ proxies (Table 1). Because smoothness is based on the reported earnings number, it will have a fundamental component that represents the smoothness of the firm's fundamental earnings process. The other EQ proxies such as persistence, timeliness, or value-relevance, however, also are affected by the fundamental earnings process and the application of the measurement system to that process. Hence, the negative correlation suggests that the application of accounting measurement to the fundamental process does not have the same impact on resulting smoothness properties of reported earnings as it does for the other proxies. ${ }^{5}$ Another finding that is different for smoothness than for the other EQ proxies is that the limited literature that has examined the use of discretionary accruals to artificially smooth earnings (by U.S. firms) suggests that smoothing is value-relevant rather than opportunistic (e.g., Subramanyam, 1996, and Tucker and Zarowin, 2005).

\footnotetext{
${ }^{5}$ Ewert and Wagenhofer (2009) just recently distributed a working paper that models a firm's accounting choices over a single earnings process and measures various properties of the reported earnings including smoothness, persistence, and value relevance. Each of these commonly used proxies for earnings quality is evaluated relative to an unobservable but known construct in their model that represents the reduction in the variance of the terminal value in an equity valuation model associated with reported earnings. Likewise, Basu (1997) shows that persistence, asymmetric timeliness, and ERCs are related properties.
} 
While we identify these contradictions between smoothness and the other EQ proxies, we are short on explanations. There is little research that attempts to ascertain the "normal" component of smoothness that results from unbiased application of an accrual process to the firm's unobservable fundamental earnings process. As shown in Figure 1, only three papers in our database examine fundamental firm characteristics and smoothness proxies and one finds negative evidence. Smoothness has generated more consistent results as a proxy for earnings quality, and in particular for earnings management, in cross-country studies. The international evidence suggests that there is a significant component of smoothness that is artificial and that represents opportunistic earnings management. This finding, which contrasts with the limited findings in the U.S., may result from the ability to create a smoothness proxy that captures cross-sectional variation in artificial smoothing or earnings management. In international studies, researchers typically benchmark earnings smoothness against the smoothness of operating cash flows (e.g., Leuz, Nanda, and Wysocki, 2003). In these settings, the cross-sectional variation in the discretionary component of smoothness may dominate the measurement error in the fundamental component of smoothness, which makes the "abnormal smoothness" measure a reasonable proxy for earnings management. More research could be done to explain the inconsistencies between the firm-level results in the U.S. versus the country level results.

In summary, the ability of smoothness to capture 1) the smoothness of a firm's fundamental earnings process, 2) the smoothness induced by the unbiased application of an accounting measurement system to that process, and 3) the effect of intentional distortions on smoothness, is still very much an open question. 
Timely loss recognition/Asymmetric timeliness (Section 3.1.3): Timely loss recognition measures get more at the heart of the distinction between the quality of the fundamental earnings process (X) and the ability of the accounting system to measure the process (e) than the other EQ proxies. A stronger association of earnings with negative stock returns is more likely to be related to the application of financial reporting rules to a fundamental earnings process than to be a feature of the process itself (since stock returns are not an output of the accrual accounting system). However, differences in timely loss recognition within countries (or regions) with the same standards or legal origin suggest that timely loss recognition has an endogenous component related to firms' reporting incentives. It is not driven purely by a country's accounting system.

Using the returns-based measure of timely loss recognition as proxies for quality, however, requires that the researcher consider two significant issues. First, variation in asymmetric timeliness may reflect variation in the ability of earnings to capture value relevant information, as generally predicted, or it may be evidence of variation in the ability of returns to reflect value relevant information. The assumption of market efficiency that underlies the interpretation of returns-based metrics as a measure of earnings informativeness is not likely to hold equally across markets, which will induce omitted correlated variables bias. This issue is of particular concern in cross-country studies due to significant differences in market microstructure and macroeconomic conditions. ${ }^{6}$ Second, returns reflect all information, not just information in earnings. If more conservative accounting, conditional or unconditional, is correlated with the production or dissemination of alternative information sources (e.g., Gigler and Hemmer, 2001), then again the researcher faces an omitted correlated variables problem.

\footnotetext{
${ }^{6}$ Ball, Robin, and Wu (2003) emphasize the benefits of their sample - within East Asia - to mitigate the concern that cross-country variation in ERCs reflects variation in the return generating process rather than differences in earnings quality.
} 
Proxies for asymmetric timeliness based on the tendency of accruals to reverse avoid the above noted problems associated with returns-based metrics. (Section 3.1.3 discusses these metrics, proposed by Basu, 1997, and implemented in studies such as Ball and Shivakumar, 2005.) Similar to the concern raised about accruals models, this attempt to control for the fundamental earnings process is based on reported accrual-based earnings associated with the process (growth in sales revenue, for example).

Benchmarking (Section 3.1.4): The benchmarking studies use small positive differences between reported earnings and any benchmark as a measure of earnings quality. This literature includes studies that examine the "kink" in the distribution of reported earnings around zero (e.g., Burgstahler and Dichev, 1997), as well as studies of firms that report small positive profits or avoid small losses, or "meet or beat" forecasts.

A common but controversial interpretation of the kink in the earnings distribution around zero is that firms with small (unmanaged) losses intentionally manage earnings just enough to report a small profit. The evidence on whether the kink in earnings around zero implies that small profits likely contain a managed component is mixed at best. The relation between small profits and earnings management proxies is supported mostly in accrual-specific studies. Taken together, these results suggest that the use of small profits as a proxy for earnings management is setting-specific and not generalizable.

Evidence that earnings are likely managed when firms just meet or beat an external target is more persuasive. An important caveat to this evidence is that firms that are constrained in their ability to manage earnings may not meet or beat a target (Barton and Simko, 2002). Thus, meeting 
or beating a target represents a censored measure of earnings management. In addition, the analyst forecast target can also be managed.

The evidence on the quarterly patterns in earnings distributions are somewhat conflicting. Kerstein and Rai (2007) and Jacob and Jorgensen (2007) find that the kink in earnings around zero is strongest in the fourth quarter. Both papers emphasize their finding as evidence that the kink implies earnings management because the incentives to manage earnings are greatest in Q4. Brown and Pinello (2007), however, find that avoiding small negative analyst forecast errors is strongest in interim quarters. They emphasize their result as evidence of greater earnings management in interim quarters when the opportunities are greatest. The first two studies examine small profit firms while Brown and Pinello (2007) examine firms that avoid missing analyst forecast targets. Differences in the incentives and opportunities to meet these targets may explain the seemingly conflicting results.

\subsubsection{Earnings response coefficients (Section 3.2)}

Liu and Thomas (2000) conclude that the ERC can be viewed as a measure of higher quality earnings (p. 73) based on the finding that the observed ERC will be high when the correlation between unexpected earnings and forecast revisions is high. Their conclusion about the ERC as a proxy for earnings quality is in the sense of Graham and Dodd (1934) in that a higher ERC is associated with predictability of the fundamental earnings process. However, researchers should not take the Liu and Thomas (2000) conclusion out of their context and assume they can use the ERC, or the $\mathrm{R}^{2}$ from the ERC regression, as a proxy for quality in any context. Liu and Thomas (2000) indicate, for example, that the degree to which the ERC captures quality is sensitive to the degree of heterogeneity of the correlation between unexpected earnings and forecast revisions within the 
sample. Hence, sample specific characteristics that affect within-sample heterogeneity, such as growth, are important.

For three reasons, researchers must be cautious when using the ex post observed ERC (or the regression $\mathrm{R}^{2}$ ) as a proxy for ex ante earnings quality, interpreted as the ability of the financial reporting system to capture relevant economic activities. First, because of the relation between earnings quality and voluntary disclosure, the observed ERC does not reflect the cross-sectional variation in ex ante earnings quality. This same criticism was discussed for asymmetric timeliness

and returns-based metrics in general. Second, the prediction that a more precise earnings report will yield higher ERCs (Holthausen and Verrecchia, 1988) does not anticipate sources of variation in investor estimates of precision unrelated to the earnings number, such as the heightened uncertainty during a proxy contest (Collins and DeAngelo, 1990) or variation in the ability of equity markets to assess quality (i.e., markets are not equally efficient). Finally, returns, which are the other element of ERCs besides earnings, can exhibit cross-sectional and time-series variation (Johnson, 1999; Hoitash, Krishnan, and Sankaraguruswamy, 2002). Hence, ERCs may work as a proxy for earnings quality in a differences-in-differences analysis that can control for these alternative sources of variation in the ERCs, but these problems generally pose significant challenges in most research settings/designs.

\subsubsection{External indicators of financial reporting quality (Section 3.3)}

Studies using AAERs, restatements, and SOX internal control deficiency reports as proxies for earnings quality help to validate various proxies for earnings quality. They are also a useful setting to validate the theoretical determinants and consequences of quality that are investigated in other contexts. Each sample, however, has limitations as a measure of earnings quality, in general, 
or of earnings management. The AAER sample includes earnings management cases that are typically outside of GAAP and are identified by the SEC. This sample is likely to contain only the most egregious misstatements and excludes many firms that are likely to be managing earnings. The restatement sample includes some immaterial misstatements, corrections of unintentional errors, and applications of some new pronouncements (e.g., SAB 101 required retroactive restatement). The sample of firms that disclose internal control deficiencies could be affected by manager and auditor incentives to discover and disclose the weaknesses. The restatement sample offers an opportunity to explore variation in the implications of unintentional versus intentional misstatements in various decision-making contexts, although that variation has not been exploited, with the exception of Hennes, Leone, and Miller (2008).

The relation between internal control procedures and external auditors is not adequately explored. An exception is Hogan and Wilkins (2008), who document that audit fees in the year prior to the disclosure of an internal control deficiency are higher than the fees for a matched sample that does not report deficiencies. One explanation for this finding is that auditors charge higher fees for the extra audit effort required to audit firms with weak controls. In this case, we would observe an association between fees and weak internal controls, but not necessarily between fees and earnings quality. Another explanation is that auditors charge higher fees when the assessed audit risk is higher, and weak controls are correlated with audit risk assessments (i.e., the fees represent a pure risk premium). In this case, we would observe a relation between internal controls and earnings quality. Hogan and Wilkins emphasize the second explanation while admitting that they cannot rule out the risk premium story.

The studies that investigate the determinants and consequences of the external indicators of financial reporting quality emphasize the incentives and opportunities for intentional and 
unintentional misstatements, which are two of the three elements of the fraud triangle, but they do not investigate the third element: attitude. Recently, several studies have tried to examine the role of executive characteristics in financial reporting decisions, including accounting fraud (Hribar and Yang, 2007; Schrand and Zechman, 2009; Ge, Matsumoto, and Zhang, 2009).

\subsection{Overview of the network and research opportunities}

This section summarizes ten additional research-related conclusions.

1) Some studies treat the earnings quality proxies as substitutes and test hypothesized predictions about a determinant or consequence of "earnings quality" using a proxy for earnings quality that does not appropriately measure the theoretical construct. That is, not all studies carefully register that the testable hypotheses about the determinants and consequences of earnings quality come from decision models and the models suggest a specific form of decision usefulness (i.e., earnings quality). We observe some mixed results that appear to be driven by a mismatch between the theoretical construct for decision-usefulness and the proxies. A good example is the studies of accrual quality (see Section 2.1.1.4). There is strong (mixed) [weak] evidence that internal control procedures (audit quality) [governance characteristics] affect accrual quality. The order of the strength of the evidence is consistent with the order of construct validity. Internal control procedures are meant to detect and/or prevent both the ability to manipulate earnings as well as mistakes or errors, and the accrual proxies used in these studies generally represent the types of errors that internal controls could prevent. An auditor's responsibility, however, is only to report on whether the financial statements conform to GAAP, and the prediction that audit quality (typically measured by a proxy for independence) would be associated with abnormal accruals is less compelling. Finally, the predicted association between governance quality and accrual quality is particularly tenuous. It is not clear why some commonly used indicators of governance quality, for example 
number of outside directors, should, can, or will have a detectable influence on the accounting reporting system, in general, and the accrual process, in particular.

This construct validity issue extends to all the measures of earnings quality. When a paper provides a model of the accrual process, or of persistence, or of ERCs as a direct proxy for earnings quality, and states that the proxy exhibits "high quality" characteristics, researchers from that point forward use the measure as a proxy for "quality" and it becomes accepted. The researchers that originally developed the measure typically emphasize its short comings and conclude on its decision-usefulness in a specific decision context, but the use of the proxy gets extended inappropriately. Interestingly, Ball and Foster (1982) expressed a similar concern about the use of size as a proxy for political costs.

(2) Two facts that are independently recognized in the literature are that (i) firms face multiple objectives associated with reported earnings but they are constrained to report only one earnings number, ${ }^{7}$ and (ii) firms can choose a set (or portfolio) of accounting choices to meet their objectives. Equity markets are an obvious source of incentives, but research on the determinants of accounting choices recognizes the financial reporting incentives that result from explicit or implicit contracts with parties other than equity holders such as litigation, debt contracting, proprietary costs, compensation, and internal information needs. Studies that recognize these non-equity market incentives for financial reporting, however, typically examine their effects on accounting choices independently, and predict an accounting choice, rather than examining the trade-offs among multiple objectives.

\footnotetext{
${ }^{7}$ See Sivakumar and Waymire (2003) for a well-articulated discussion of this issue. Theory that incorporates multiple users predicts variation in accounting choice or contracting arrangements in the presence of financial statement users with different information needs (e.g., Demski, 1973; Evans and Sridhar, 1996; Chen, Hemmer, and Zhang, 2007).
} 
Empirical studies have examined multiple incentives (most commonly financial reporting, tax and regulatory objectives for financial institutions), but they typically examine accounting choice related to one particular account (e.g., loan loss provisions). The studies do not consider the alternative mechanisms that firms might use to achieve the firm's multiple earnings objectives. On the flip side, empirical studies have examined multiple accounting choices to achieve a single objective (e.g., real earnings management vs. discretionary accruals), although studies of this type are relatively limited.

There is almost no evidence on whether firms optimize over a set of accounting choices to meet multiple objectives, despite variation across accounting choices, such as methods and accrual estimations, with respect to their ability to meet a firm's objectives. ${ }^{8}$ Certain accrual choices, for example, may be sufficient to avoid debt covenant violation, but they also may produce a less persistent earnings number, which affects the decision usefulness of earnings for equity markets.

Theory papers seem more progressive on this dimension than the empirical studies (e.g., Evans and Sridhar, 1996; Liang, 2004; Chen, Hemmer, and Zhang, 2007), including variations on the optimal contracts with outsiders that affect the choice (Sridhar and Magee, 1996). However, even these models are generally concerned with the implications of multiple objectives on a single accounting choice, and they do not also address the issue that the firm makes a portfolio of choices that in the aggregate affect earnings. Christensen, Feltham, and Sabac (2005), however, recognize this issue: "Increasing the persistent components and reducing the reversible components are generally desirable for valuation, but not for contracting. Eliminating transitory components of earnings is generally desirable for valuation, but not necessarily for contracting." Kirschenheiter

\footnotetext{
${ }^{8}$ Notable exceptions are Beatty, Chamberlain, and Magliolo (1996) and Hunt, Moyer, and Shevlin (2000) examines both multiple tools and multiple incentives.
} 
and Melumad (2002) similarly emphasize the important trade-off between reporting high "real" levels of income, which are suggested to be more informative, and earnings smoothness.

(3) A consistent finding across studies that test a variety of theories in different settings and using different proxies for EQ is that when investors are able to observe, or rationally infer, increased estimation error (intentional or unintentional), they internalize its effect on price. Therefore, where the manipulation is more transparent or where the incentives are more obvious, investors will anticipate and discount potential earnings management or accounting distortions.

Numerous examples support this statement. For example, investors discount upward earnings management when banks are highly levered and close to capital market constraints. Investors discount downward earnings management when they are aware that managers will be issued with repriced options. Investors discount the discretionary accrual component of earnings when information on accruals is disclosed at the earnings release. Investors in the property and casualty insurance industry understand and correctly price the accrual related to future payouts because there are extensive disclosures related to this accrual's errors and corrections. Meeting or beating analyst forecasts on an ad hoc basis does not lead to higher valuations, but meeting or beating regularly does. See additional examples in the discussion of equity market consequences in Section 3.1.1.5.

(4) Taken together, the previous two observations - that firms might tailor accounting mechanism choices to specific earnings objectives and that equity investors can rationally infer or observe earnings management - suggests predictable patterns in the portfolio of a firm's accounting choices. If firms want to influence debt contracting outcomes but not at the expense of their cost of equity, 
there are (in theory) predictable accounting choices that can meet both objectives. For example, in a world of imperfect debt contracting, many types of gains can prevent covenant violation, but if they are made transparent, equity investors can undo their effect on earnings and they will not affect "information quality." This observation represents a research opportunity, but it also suggests that it is difficult to interpret the evidence of studies that focus on only one determinant of an accounting choice.

Recognizing that the single reported earnings number is the outcome of a complicated number of choices, motivated by multiple incentives, has implications for understanding the consequences of earnings quality. If equityholders understand a firm's incentives for reporting earnings, and if they understand its constraint to report only one earnings number, and if they have the ability to interpret reported earnings and/or to substitute other information for reported earnings, then we may not observe positive market responses to earnings that are of high quality with respect to equity valuation decisions. In fact, equity markets might respond negatively to firms that do not report a number that maximizes firm value, even if it distorts the ability of earnings to capture the firm's fundamental earnings process. In contrast, if equityholders do not recognize the earnings management to meet non-equity market objectives, accounting choices will have a spillover effect to the equity markets. Studies of accounting choice generally do not emphasize the trade-off between the short-term benefits of opportunistic accounting choices at the time of an event (e.g., an IPO) and the potential long-term reputation loss due to these one-off earnings management decisions.

(5) As noted previously, the determinants and consequences of abnormal accruals have received the most attention. The literature tends to validate accruals models by showing that the abnormal accrual is correlated with hypothesized predicted determinants or consequence of abnormal accruals. 
Other studies attempt to validate discretionary accruals from accruals models using external indicators of financial reporting quality such as restatements, SEC enforcement actions, and SOX internal control deficiency reports. The type II error rate in these samples, however, is extremely high (most high discretionary accrual firms are not members of these samples). Therefore, positive correlations are supportive evidence but far from conclusive.

Few papers, however, validate the accruals models by examining the "normal" component of accruals. Our understanding of earnings quality would benefit from more direct evidence on how an imperfect measurement system, when applied without intentional bias, distorts the measurement of a firm's fundamental earnings process. Examples of research along these lines include Landsman and Shakespeare (2005) who put securitizations back on the balance sheet; Lev and Sougiannis (1996) who capitalizes and expenses R\&D; Ge (2007) who capitalizes operating leases; and Dutta and Reichelstein (2005) who provide theoretical work on optimal capitalization policies.

(6) While it has long been recognized that accounting choices can be motivated by opportunism or efficient contracting, we still do not have sufficient evidence on this issue (see Christie and Zimmerman, 1994, Bowen et al., 2008). Again, the issue of multiple objectives arises, because a single accounting choice may appear opportunistic if hypothesized to be related to one objective, while the inference is invalid when allowing firms to have multiple objectives but constraining them to choose only one earnings number. This issue was raised in studies that use properties of earnings, accruals, and ERCs as proxies for EQ, yet the research is inconclusive.

(7) We are not aware of studies about a firm's earnings-related accounting choices when the anticipated impact of the choice on earnings properties is expected to be limited because the property 
is primarily driven by the firm's fundamental earnings process. In other words, if the firm cannot produce a persistent earnings number given the nature of operations, does it bother to make choices to produce the most persistent number possible? Or, does the firm give up on producing a persistent earnings stream and instead optimize according to another goal? Does the firm substitute for fundamentally low quality earnings with additional disclosure, along the lines examined in Francis, Nanda, and Olsson (2008)?

(8) Few papers attempt classical construct validity analyses. In fact, our database of papers contains only one study that employs classical methods for construct validation: Ecker, Francis, Kim, Olsson, and Schipper (2006), who perform a construct validity analysis of their "e-loading" proxy for accrual (earnings) quality. Several studies run "horse races" across accruals models (e.g., Guay, Kothari, and Watts, 1996), or consider extensions and improvements to specific models (e.g., Dechow, Sloan and Sweeney (1996) and Leone, Kothari, and Wasley (2005) of the Jones model; McNichols (2002), Francis, LaFond, Olsson and Schipper (2005), and Wysocki (2008) on the Dechow/Dichev model). These studies improve our understanding of the models, but additional analysis on construct validity would be useful.

(9) Most of the theory-testing papers test a prediction about either a determinant of quality or a consequence of quality, but not both. Figures 1 and 2 show that researchers have individually established links between the various determinants and the EQ proxies, and separately between the EQ proxies and the consequences. However, there is limited evidence on how a particular determinant affects earnings quality and then on the consequences of the resulting earnings quality. Bowen, Rajgopal, and Venkatachalam (2008) provide a good example of this type of research. They 
examine both determinants (i.e., governance) and consequences (i.e., future performance) of earnings management to disentangle two alternative explanations for earnings management: unexpected managerial opportunism versus efficient contracting. Their "complete path" approach offers insights that are not available from studies that examine only one side (i.e., determinant or consequence) of earnings quality. In other words, external auditors and internal controls may both affect abnormal accruals, and abnormal accruals may affect the cost of capital, but is the impact of accruals on the cost of capital the same when the source is external auditors rather than controls? Other good examples are Xie (2001) and Liu and Thomas (2000).

(10) Our survey indicates a number of inconsistencies in the tests of the determinants or consequences of earnings quality. (Figures 1 and 2 reveal these inconsistencies.) We highlight several in the following table:

\begin{tabular}{|l|l|l|}
\hline Research question & \multicolumn{1}{|c|}{ Yes } & \multicolumn{1}{c|}{ No } \\
\hline $\begin{array}{l}\text { Does incentive equity compensation provide } \\
\text { incentives to manipulate earnings? }\end{array}$ & Efendi et al., 2007 & Armstrong et al., 2009 \\
\hline $\begin{array}{l}\text { Is better corporate governance associated with higher } \\
\text { earnings quality? }\end{array}$ & Klein, 2002 & Larcker et al., 2007 \\
\hline Does nonaudit service compromise audit quality? & Frankel et al., 2002 & Ashbaugh et al., 2003 \\
\hline Are SOX 404 disclosures informative to investors? & $\begin{array}{l}\text { Ashbagh-Skaife et } \\
\text { al., 2009 }\end{array}$ & Ogneva et al., 2007 \\
\hline $\begin{array}{l}\text { Does managerial opportunism or efficient contracting } \\
\text { drive earnings management? }\end{array}$ & $\begin{array}{l}\text { Becker et al., 1998 } \\
\text { (opportunism) }\end{array}$ & $\begin{array}{l}\text { Bowen et al., 2008 } \\
\text { (efficient contracting) }\end{array}$ \\
\hline
\end{tabular}

As shown in Figures 1 and 2, studies that examine a particular consequence or determinant frequently use the same EQ proxy, so it is not differences in the quality proxy that lead to these mixed results. A significant source of the differences appears to be differences in sample or 
methodology. Studies could make unique predictions across proxies. The predictions may be in degrees: determinant $\mathrm{X}$ is predicted to have a stronger impact on quality proxy $\mathrm{Y}$ than on $\mathrm{Z}$. Or, the tests may be designed to assess divergent validity (i.e., counterfactual examples): determinant $\mathrm{X}$ is predicted to be associated with quality proxy Y but not with Z. A greater focus on stronger identification strategies in research designs could help sort out the mixed evidence given the various methodological issues associated with distinguishing the fundamental component of earnings quality from the process.

\section{Proxies for earnings quality}

This section juxtaposes the studies according to the proxy they use for earnings quality (see Table 1, Panel A). We define three categories of proxies: 1) Properties of earnings; 2) Earnings response coefficients (ERCs); and 3) External indicators of financial reporting quality (FRQ).

\subsection{Properties of earnings}

We distinguish four groups of earnings properties: Persistence, asymmetric timeliness and timely loss recognition, smoothness of earnings, and "benchmarking." Section 3.1.1 discusses research that examines the persistence of earnings and accrual models. Studies that use the term predictability and examine earnings usefulness to predict future cash flows are included in this section as well. Section 3.1.2.examines research on earnings smoothness and variability. The benchmarking category (Section 3.1.4) includes measures of earnings relative to any benchmark. 


\subsubsection{Persistence of earnings and models of accruals}

Studies of earnings persistence and cash flow predictability are motivated by an assumption that persistence (or predictability) improves decision-usefulness in an equity valuation context, in particular in models that are variants of neoclassical discounted dividend (DD) models. Model variants based on dividends, cash flows, and earnings are theoretically equivalent under specific assumptions about the relations between dividends, cash flows, and earnings (Penman, 1998; Penman and Sougiannis, 2000; Lundholm and O'Keefe, 2001). While theoretically equivalent, the models deviate in their ability to predict fundamental firm value in practice. The deviations depend on the degree of conformity of observable model inputs with the model's underlying assumptions and on the sensitivity of the valuation to this conformity. In particular, the computation of the terminal value, which is a significant component of the valuation, depends critically on assumptions about growth and persistence.

Penman and Sougiannis (1998) provide evidence on the comparative decision usefulness of the models, which in turn has implications for assessing the benchmark that should be used to evaluate the decision usefulness of an earnings number. In summary, they conclude that over various time horizons, in models with and without a terminal value assumption, models that apply simple forecasting assumptions to earnings provide a better forecast of current market value than models based on cash-flow or dividend forecasts. However, the point is that an assessment of whether cash flow predictability or earnings persistence is a better measure of decision usefulness in equity valuation depends as much on the proxy as it does on the decision model. In other words, being able to predict one-year-ahead cash flows may be an irrelevant measure of quality if cash flow based equity valuation models produce high prediction errors. 
The discussion of earnings persistence and predictability is organized as follows. Section 3.1.1.1 discusses research that examines the usefulness of earnings and accrual components to predict expected future cash flows, where future cash flows are measured in a variety of ways, such as one year-ahead cash flows, or market value. Section 3.1.1.2 discusses research that examines earnings persistence, motivated by the notion that it is important to understand earnings persistence as an input to equity valuation. The determinants and consequences of persistence are discussed in Sections 3.1.1.3 and 3.1.1.4. Finally, Sections 3.1.1.5 and 3.1.1.6 discuss accruals models and interpretation issues related to these models, as the resulting measures of abnormal accruals are a large and distinct part of the literature. We leave a detailed discussion of the determinants and consequences of abnormal accruals to later sections of the paper.

\subsubsection{The usefulness of earnings and accrual information to predict future cash flows}

Research that characterizes the predictive ability for future cash flows is motivated by the assumption that the prediction of cash flows as inputs to equity valuation models will be useful. Hence, a common measure of cash flow is one-year or two-year-ahead cash flows. The researcher compares the $\mathrm{R}^{2} \mathrm{~s}$ or the coefficients from models that include current earnings to those of models that include other measures of performance such as dividends, cash from operations, or earnings excluding various accruals (e.g., earnings before depreciation and taxes).

Barth, Cram, and Nelson (2001) find that cash flows are superior to earnings at predicting future cash flows, and Bowen et al. (1986) find that earnings are at least not superior. Greenberg et al. (1986), however, find that the predictive ability of aggregate earnings is superior to cash flows. Finger (1994) finds that earnings and cash flow have similar predictive ability for longer horizons, but cash flow is slightly superior to earnings for short horizons. A cash flow prediction model that 
disaggregates the working capital and other accrual components of earnings results in lower cash flow forecast errors and improved predictability (Dechow, Kothari, and Watts, 1998; Barth et al., 2001).

\subsubsection{The usefulness of earnings to predict future earnings}

Research that characterizes the persistence of earnings is motivated by the assumption that more persistent earnings will yield better inputs to equity valuation models. A simple model specification estimates earnings persistence as:

$$
\text { Earnings }_{t+1}=\alpha+\beta_{1} \text { Earnings }_{t}+\varepsilon_{t}
$$

Researcher can add other financial statements elements or variables outside the financial statements (e.g., market based measures or disclosures from the footnotes) to examine to examine their incremental explanatory power to predict future earnings:

$$
\text { Earnings }_{t+1}=\alpha+\beta_{1} \text { Earnings }_{t}+\beta_{2} \text { components of financial statements or other information }_{t}+\varepsilon_{t}
$$

If $\beta_{2}$ is significant in either direction, then the researcher has identified a determinant of future earnings that provides incremental information beyond current earnings. Alternatively, researchers can decompose earnings into its components and examine whether the components have different implications for future earnings. For example, Sloan (1996) examines two components of earnings:

$$
\text { Earnings }_{t+1}=\alpha+\beta_{1} C F_{t}+\beta_{2} \text { Accrual }_{t}+\varepsilon_{t}
$$

\footnotetext{
${ }^{9}$ Some studies use this framework, measuring relative predictive ability, but model future earnings. These studies consistently find that special items as a subset of accruals do not improve the ability of accrual earnings to predict future earnings relative to cash based earnings (e.g., Barth et al., 2001; Dechow and Ge, 2006). Other studies model contemporaneous stock returns (Ball and Brown 1968, Dechow 1994) or market value (Penman and Sourgiannis 1998). Stock based measures generally find that accruals help improve earnings ability to reflect value (except if earnings includes large write-downs or special items).
} 
and documents that $\beta_{2}<\beta_{1}$, which implies that the cash flow component of earnings is more persistent than the accrual component.

As noted in the introduction, reported earnings represents the firm's fundamental earnings process $(\mathrm{X})$ and the measurement of that process (e). Thus, when researchers add financial statement ratios to the incremental predictability model above, the ratios they add are generally computed using reported accounting numbers. Thus, they do not disentangle the unobservable fundamental earnings process $(\mathrm{X})$ from the measurement of the process. Likewise, any decomposition of accruals into its components decomposes them based on their reported amounts. Clearly, we recognize the constraint that researchers face when they attempt to measure an unobservable construct like the fundamental earnings process. By highlighting this issue, we hope that researchers can search for better instruments than reported numbers to capture the effects of the persistence of " $\mathrm{X}$ " on the persistence of earnings.

\subsubsection{Determinants of persistence}

This section discusses studies 1) that model the incremental explanatory power of variables over current earnings for future earnings, and 2) that document the predictive ability of earnings components as determinants of persistence. While it was just noted that predictability of future earnings is likely to be driven to a large extent by the business in which the firm operates, there is little work that uses the approach above to test for such determinants. Lev (1983) associates persistence with product type, industry competition, capital intensity, and firm size, generally motivating these variables as proxies for uncertainty of the business process. Baginski, Lorek, Willinger, and Branson (1999) find that the relations documented in Lev (1983) are weak using persistence metrics from lower-order time series models but exist when the measure of persistence is 
a differenced, higher order model. ${ }^{10}$ Several studies predict and find that firms that differentiate their products (measured by higher margins and lower turnover) have more persistent earnings than firms following a cost leadership strategy (i.e., lower margins and higher turnover). See, for example, Nissim and Penman (2000), Fairfield and Yohn (2001), and Soliman (2008). These results suggest that creating barriers to entry by having a technology such that the firm can sell its product at lower cost is more sustainable than creating a unique product to satisfy consumer desires. However, the benefits of cost leadership are likely to be highly contextual.

Accruals, in various forms, as a component of earnings are the most studied determinant of persistence. Sloan (1996) documents that the accrual component of earnings is less persistent than the cash flow component of earnings. His definition of accruals is non-cash working capital accruals plus depreciation. Richardson, Solimon, Sloan, and Tuna (2005) provide a more comprehensive measure of accruals (intuitively, the change in net operating assets or the difference between earnings and free cash flows) and show that this measure of "total accruals" is less persistent than cash flows.

There have been further break-downs of accruals into various components, using similar methodologies to assess predictability for future earnings. ${ }^{11}$ For example, Lev and Thiagarajan (LT, $1993)$ and Abarbanell and Bushee (AB, 1997) focus on inventory and accounts receivable. With respect to inventory accruals, the quality metric, which measures poor quality, is significantly negatively associated with future changes in EPS (AB, 1997) and contemporaneous returns (LT,

\footnotetext{
${ }^{10}$ Early studies that analyzed the statistical process that underlies earnings include Foster, 1977; Watts and Leftwich, 1977; Albrecht, Lookabill, and McKeown, 1977; Beaver, 1970; and Griffin, 1977. Baginski, Lorek, Willinger, and Branson (1999) emphasize that time-series modeling assumptions can create significant differences in parameter estimates, and lead to different economic conclusions about persistence.

${ }^{11}$ Melumad and Nissim (2008) provide an analysis of earnings quality by looking at specific accrual line items. We discuss these examples to emphasize the conflicting evidence.
} 
1993). ${ }^{12}$ The studies find conflicting evidence on accounts receivable accruals. LT (1993) find a negative relation between abnormal accounts receivable (receivables changes less sales changes) and contemporaneous returns, and they interpret this result as evidence that disproportionate $\mathrm{A} / \mathrm{R}$ changes indicate difficulties in selling the firm's products, related credit extensions, and premature revenue recognition. ${ }^{13} \mathrm{AB}$ (1997), however, find an unexpectedly positive relation between abnormal receivables and one-year ahead earnings changes, which they interpret as evidence that receivables growth indicates sales growth and not reliability or customer collection problems. More research is needed to resolve these conflicting findings.

Dechow and Ge (2005) suggest that large negative accruals are less persistent than cash flows because large negative accruals often reflect write-offs and impairment charges that "correct" the balance sheet (see also Fairfield, Sweeney and Yohn 1996). They show that low accrual firms have proportionally greater levels of special items, and that these non-recurring charges play an important role in the lower earnings persistence for these firms. Nissim and Penman (2001) also suggest that unusual items affect earnings persistence.

Researchers also suggest that the sources and uses of cash flows affect earnings persistence. Dechow, Richardson, and Sloan (2005) show that retained cash flows have very similar implications for persistence to accruals. Cash flows related to the payment or issuances of equity are the major determinant of the higher persistence of the cash flow component of earnings relative to accruals. Nissim and Penman (2003) decompose return on assets into an operating leverage component and a financial leverage component. They suggest that an increase in operating leverage is likely to

\footnotetext{
${ }^{12}$ Thomas and Zhang (2002) do not assess whether changes in inventory are a less persistent component of earnings directly. However, the do find that the change in inventory is the strongest driver of accrual anomaly hedge returns. LaFond (2005) also documents that inventory accruals explain hedge returns in 13 out of 17 countries. Allen, Larson, and Sloan (2009) do show that growth in inventory result in less persistent earnings. Their results suggest that measurement error plays an important role since write-downs of inventory is a key driver of the lower persistence.

${ }^{13} \mathrm{LT}$ also find no relation between the abnormal component of the provision for doubtful receivables and contemporaneous returns, which they describe as surprising.
} 
depress current earnings but lead to future improvements in earnings. An increase in financial leverage, however, tends to have an incrementally negative effect on future earnings (scaled by equity).

Fairfield, Whisenant, and Yohn (2003a) suggest that growth and conservatism in accruals could be determinants of the lower persistence of the accrual component of earnings. They show that the change in PPE has similar implications for persistence as working capital accruals. However, the measurement of PPE is itself a product of the accrual accounting system and the growth in this variable could also reflect accounting measurement problems (see Zhang, 2007). Richardson et al. (2005) further investigate growth. They decompose the change in net operating assets (total accruals) into a growth component (proxied by sales growth) and an efficiency component (net operating asset turnover ratio) and an interaction effect. They show that declines in efficiency and growth both play a role in the lower persistence of the accrual component. While their paper suggests that growth is not a complete explanation for the low persistence parameter on accruals, it suffers from the same criticism that sales growth, as a proxy for growth, is itself a product of the accrual accounting system.

Researchers have also attempted to directly examine whether forecast errors made by management (that will affect the magnitude of accruals) and their subsequent corrections have implications for earnings persistence. Dechow and Dichev (2002) develop a measure of accrual quality based on accruals modeled as a function of past, present, and future cash flows (discussed later in this section). Holding the magnitude of accruals constant, earnings persistence is negatively associated with the Dechow/Dichev accruals quality measure. In contrast, holding the accruals quality measure constant, the association between persistence and the magnitude of accruals is much weaker. 
Xie (2001) uses the Jones model (discussed later in this section) to decompose accruals into a normal and abnormal component. The abnormal component is likely to contain more measurement error and managerial discretion. He finds the persistence parameters on cash flows, normal accruals, and discretionary accruals are $0.73,0.7$, and 0.57 . This result indicates that discretionary accruals are less persistent than either normal accruals or cash flows, consistent with reliability and measurement issue concerns. Richardson et al. (2005) develop a model of reliability and argue that operating assets and liabilities are less reliably measured than financial assets and liabilities.

Consistent with their predictions, they find that working capital (operating) accruals have the lowest reliability, accruals related to financial assets and liability have the highest, and long-term operating accruals are in the middle. Broadly speaking, they find a positive relation between their ex ante reliability rankings and return on assets.

Internal control violations under the Sarbanes Oxley act are suggestive of measurement error and problems with the accounting system. Doyle, Ge, and McVay (2007a) find that firms that disclose they have at least one material weakness during the 2002-2005 period, have less persistent earnings. Finally, Wang (2006) finds a positive association between founding family ownership and proxies for accrual quality and earnings persistence.

\subsubsection{Consequences of persistence}

The vast majority of papers on consequences of persistence examine equity market consequences. A few papers discuss consequences that we refer to collectively as other-than-equitymarket consequences.

Equity market consequences: Researchers hypothesize two distinct equity market consequences of persistence. The first prediction is that more persistent earnings will yield a higher equity market 
valuation and, therefore, that increases in estimates of persistence will yield positive (contemporaneous) equity market returns. Early research by Komendi and Lipe (1987), Collins and Kothari (1989), and Easton and Zmijewski (1989) provide evidence that more persistent earnings have a stronger stock price response and association.

However, subsequent research on the accrual anomaly suggests that investors do not fully price the implications of the cash and accrual components for future earnings. (See Richardson, Tuna, and Wysocki, 2009, for a complete review.) Sloan (1996) documents that a hedge strategy that is long in low accrual firms and short in high accrual firms earns approximately a 12 percent return per year. Subsequent studies have provided several explanations for the hedge returns including (i) investor misunderstanding of abnormal accruals (Xie, 2001); (ii) investor misunderstanding the extent of errors in accruals or reliability (Richardson, Sloan, Soliman, and Tuna, 2005; Hirshleifer and Teoh, 2003); (iii) investor misunderstanding of the growth reflected in accruals (Desai, Rajgopal, and Venkatachalam, 2004; Fairfield, Whisenant, and Yohn, 2003a; and Zhang, 2007); and (iv) mismeasurement of expected returns or other research design issues (Khan, 2008; Kraft, Leone, and Wasley, 2006).

Researchers have also examined whether equity market consequences to the persistence of accruals varies with an investor's information processing ability or with the availability of outside information. Louis and Robinson (2005) find that stock split announcements add credibility to accruals. Levi (2008) finds that the accrual anomaly exists only for firms that delay the release of accrual information to their 10-Q and do not include cash flow and balance sheet information in press releases. Collins, Gong, and Hribar (2003) find that firms with a high level of institutional investors and a minimum threshold level of active institutional traders have stock prices that more accurately reflect the persistence of accruals. While Collins et al. (2003) suggest that these 
sophisticated investors do understand differences in accrual quality, Richardson (2003) finds no evidence that short-sellers are clustered in high-accrual firms, which one would expect if they understand that high accrual firms have less persistent earnings and lower future returns. However, his sample period is 1990 to 1998 , and the accrual anomaly did not become widely known until after the publication of Sloan in 1996.

Researchers have also investigated how investors respond to investments that are expensed rather than capitalized (such as R\&D) since these decisions will have differing implications for future earnings. The results suggest that investors do view $R \& D$ expenditures as assets but they do not perfectly price the full implications of the R\&D investment on future earnings (Lev and Sougiannis, 1996, and Penman and Zhang, 2002). Similarly, off-balance sheet items such as leases are valued by investors, but their implications for future earnings are not perfectly incorporated into prices $(\mathrm{Ge}, 2007)$. This line of research suggests that investors appear to react to predictable changes in earnings induced by different accounting treatments for investments.

There is also an extensive line of research examining the implications of write-offs (i.e., large negative special items) that are transitory and hence reduce earnings persistence. Bartov, Lindahl, and Ricks (1998) summarize the findings from the literature on write-offs through 1998. The early research documented negative stock market reactions to the announcement of special items, but the negative reactions were small (around one percent) and announcement period returns were positive if the write-off was associated with a restructuring or an operational change. Bartov et al. (1998) question the small stock price response at the announcement date and examine a sample of 317 write-offs in 1984 and 1985. They find annualized negative abnormal returns of $-21 \%$ over a twoyear period following the announcements of the write-off, robust to various risk adjustments. As previously discussed, Dechow and Ge (2006), however, find that firms with large negative accruals 
driven by special items have positive future returns, which suggests that investors overweight these accruals.

Several studies also examine the consequences related to industry-specific loss accruals. Beaver and Engel (1996) find that the normal component of banks' allowances for loan loss reserves is negatively priced and the abnormal component is incrementally positively priced. They interpret the positive coefficient on abnormal accruals as follows: “...positive effects on security prices can occur because discretionary behavior alters the market's assessment of the expected net benefits of discretionary behavior or conveys management's beliefs about the future earnings power of the bank." McNichols and Beaver (2001) find that investors correctly price the loss reserve accrual even though they incorrectly price other accruals in a manner consistent with Sloan (1996). Their finding suggests that the extensive disclosures about loss reserve accruals of $\mathrm{P} \& \mathrm{C}$ insurers help investors to estimate the persistence and valuation implications of this component.

Finally, Francis et al. (FLOS, 2005) find that firms with more persistent earnings have a lower cost of debt and equity capital. FLOS use multiple earnings proxies and so for ease of exposition and to reduce repetition, we provide an extensive review of the literature that predicts the cost of capital as a consequence of earnings quality in Section 6 .

Other than-equity-market consequences: Two papers examine compensation decisions as a function of earnings persistence. Baber, Kang, and Kumar (1998) find that earnings persistence increases the positive relation between unexpected earnings and the annual change in various components of compensation. Nwaeze, Yang, and Yin (2006) find that firms with less persistent earnings have lower weight placed on earnings relative to cash flows in compensation. Both papers attempt to distinguish persistence driven by firm fundamentals from persistence associated with accounting 
measurement. Nwaeze, Yang, and Yin (2006) measure earnings persistence relative to cash flow persistence. Baber et al. (1998) include stock returns in the model.

Evidence on other consequences is limited. Bradshaw, Richardson, and Sloan (2001) document that sell-side analysts' forecasts do not fully incorporate the predictable earnings declines associated with high-accrual firms. In addition, high-accrual firms are not more likely to get qualified audit opinions or to have auditor changes. Bradshaw et al. confirm that the high-accrual firms indeed have subsequent earnings declines. Thus, they interpret their findings as evidence that analysts and auditors do not appear to be aware of quality issues for high-accrual firms. Bhojraj and Swaminathan (2007) find that bond investors misprice high and low accrual firms in a similar manner to equity investors.

Related to persistence: $\operatorname{Li}(2008)$ documents that firms that have more readable financial reports have more persistent earnings. Li recognizes causality as an unanswered question, and acknowledges that the explanation for the relation is beyond the scope of his paper. It is an interesting question, and one that the developing text analysis software may help us to resolve. Researchers also have investigated the role of management guidance and earnings sustainability. The results generally suggest that managers of firms with more volatile earnings are less likely to provide guidance (see, for example, Verrecchia, 1990; Waymire, 1985, and Tucker, 2008).

\subsubsection{Models of the accrual process}

The objective of accruals models is to dissect accruals into a component that measures accrual-based earnings that will be associated with the firm's fundamental earnings process from abnormal accruals, which are assumed to represent accruals that are discretionary or that are the 
result of intentional or unintentional accounting errors. Higher levels of accruals that are not associated with the firm's fundamental earnings process are assumed to reduce the quality of earnings. As reported in Figures 1, 2, and 3, abnormal accruals have been used as a proxy to test predictions in almost all of the determinants and consequences categories, hence we discuss the models. Exhibit 2 summarizes the most widely used accruals models.

Jones (1991) explains working capital accruals and depreciation as a function of sales growth and PP\&E. The explanatory power of the Jones model is low, explaining only about $10 \%$ of the variation in accruals. Consistent with the assumption that the residual represents greater discretion, as mentioned earlier, Xie (2001) documents that the residuals from the Jones model have lower predictive ability for year-ahead earnings than the non-discretionary (i.e., "normal") accruals. On the downside, the residuals are highly $(80 \%)$ positively correlated with total accruals (Dechow, Richardson, and Tuna, 2005), and they are positively correlated with earnings performance and negatively correlated cash flow performance (Dechow, Sloan, and Sweeney, 1995). These correlations are an important concern when the residuals are used to test theories of the determinants or consequences of earnings quality, in which performance is an important potential omitted correlated variable. In addition, Dechow, Larson, Ge, and Sloan (2009) show that discretionary accruals are generally less powerful than total accruals at detecting earnings management in SEC enforcement releases. This finding suggests that the discretionary accruals modeling process could include some accruals representing earnings management in "normal" accruals.

Dechow, Sloan, and Sweeney (1995) modify the Jones model to adjust for growth in credit sales. Credit sales are frequently manipulated, thus this modification increases the power of the Jones' model to yield a residual that is uncorrelated with expected (i.e., normal) revenue accruals 
and better reflects revenue manipulation. ${ }^{14}$ However, this model suffers from the same performancerelated problems as described above for the Jones model.

Holthausen, Larcker and Sloan (1995) and Leone, Kothari, and Wasley (2005) suggest ways to combat concerns about the correlation between performance and the residuals from the Jones model and modified Jones model. They both suggest controlling for the normal level of accruals conditional on ROA. Leone et al. (2005) identify a firm from the same industry with the closest level of ROA to that of the sample firm and deduct the control firm's discretionary accruals (i.e., residuals) from those of the sample firm to generate "performance-matched" residuals. Because the models of normal accruals that generate the residuals explain only $10 \%-12 \%$ of the variation in accruals, this approach is likely to add noise to the measure of discretionary accruals and it is best applied when correlated performance is an important concern. In addition, the performance matching can extract too much discretion when earnings are being managed, resulting in low power tests. $^{15}$

Dechow and Dichev (2002) view the matching function of accruals to cash flows as being of primary importance and thus model accruals as a function of current, past, and future cash flows because accruals anticipate future cash collections/payments and reverse when cash previously recognized in accruals is received/paid. The $\mathrm{R}^{2} \mathrm{~s}$ from their specification are higher than those of the modified Jones model ( $47 \%$ at the firm-level, $34 \%$ at the industry level, and $29 \%$ at the pooled level). The standard deviation of the residuals from the model is their proxy for earnings quality.

\footnotetext{
${ }^{14}$ The modified Jones model has many variants and adaptations. DeFond and Subramanyam (1998) estimate the regression by industry rather than by firm to lessen firm-year requirements. Chambers (1999) suggests adding lagged accruals to the model to capture predictable reversals. Dechow, Richardson, and Tuna (2003) estimate the normal relation between credit sales and total sales to control for nondiscretionary credit sales. They also add future sales growth to capture accruals made in anticipation of future growth. Their adjustments increase the $\mathrm{R}^{2}$ from around $9 \%$ to $20 \%$. Guay, Kothari, and Watts (1996) provide a comparison of various models.

${ }^{15}$ For example, assume ROA is $20 \%$ for firm A and B, with firm A using discretionary accruals to boost its ROA by $2 \%$ to report $20 \%$. Firm B is not manipulating earnings; it has achieved $20 \%$ ROA because it has higher non-discretionary accruals than firm A. Matching firm B to firm A would suggest that firm A's level of non-discretionary accruals should be the same as firm B, but this match is incorrect since the correct match should be a firm with ROA of $18 \%$.
} 
They show that firms with larger standard deviations have less persistent earnings, longer operating cycles, larger accruals, and more volatile cash flows, accruals and earnings. They are smaller firms and the firms are more likely to report a loss. They suggest that these firm characteristics are indicative of a greater likelihood of estimation error in accruals and thus lower accrual quality.

Francis, LaFond, Olsson, and Schipper (2005) modify and extend the Dechow and Dichev model in two ways. First, as suggested by McNichols (2002), they add growth in revenue and PP\&E to the model of normal accruals. Second, they decompose the regression residual into firm-level measures of innate estimation errors and discretionary estimation errors, such that the discretionary error is meant to represent the outcome of "managerial choices" (i.e., intentional errors). Specifically, FLOS (2005) estimate their accruals prediction model by industry-year and calculate the standard deviation of the residuals for each firm $j$ in year $t\left[\sigma\left(\varepsilon_{\mathrm{j}}\right)_{\mathrm{t}}\right]$ based on the value of $\varepsilon_{\mathrm{j}}$ in year's $t-4$ through year $t$ (five years). The standard deviation of the residuals $\sigma\left(\varepsilon_{\mathrm{j}}\right)_{\mathrm{t}}$ is a measure of accrual quality (AQ); higher standard deviations are lower quality. To decompose AQ into an innate component and a discretionary component, FLOS model AQ as a function of firm characteristics identified in Dechow and Dichev (2002):

$$
\sigma\left(\varepsilon_{\mathrm{j}}\right)_{\mathrm{t}}=\lambda_{0, \mathrm{j}}+\lambda_{1, \mathrm{j}} \operatorname{Size}_{\mathrm{j}, \mathrm{t}-1}+\lambda_{2, \mathrm{j}} \sigma(\mathrm{CFO})_{\mathrm{j}, \mathrm{t}}+\lambda_{3, \mathrm{j}} \sigma(\text { Sales })_{\mathrm{j}, \mathrm{t}}+\lambda_{4, \mathrm{j}} \mathrm{OperCycle}_{\mathrm{j}, \mathrm{t}}+\lambda_{5, \mathrm{j}} \operatorname{NegEarn}_{\mathrm{j}, \mathrm{t}}+v_{\mathrm{j}, \mathrm{t}}
$$

The predicted value of $\sigma\left(\varepsilon_{\mathrm{j}}\right)_{\mathrm{t}}$ represents the quality of accruals associated with the inherent ability of an accrual system to capture the firm's fundamental earnings process, and the residual $\left(v_{\mathrm{j}, \mathrm{t} .}\right)$ represents discretionary accrual quality. An argument can be made that each of the innate characteristics could also reflect estimation errors and corrections that would reduce the power of $v_{\mathrm{j}, \mathrm{t}}$ (or induce bias) as a proxy for discretion. 
All of the accruals models can be estimated at the firm-level, which allows variation across firms in the determinants of normal accruals. Firm-level estimation, however, assumes timeinvariant parameter estimates and typically imposes sample survivorship biases. The models often are estimated at the industry-level. This specification assumes constant coefficient estimates within the industry. Thus, some firms may have large residuals because of variation induced by industry classification rather than because of earnings management or errors. Measurement error in the residual will be related to industry characteristics, which can be a concern in some contexts. For example, the model may have a poorer fit in growth industries and growth may be correlated with the hypothesized determinant or consequence.

Several studies develop models of specific accruals and for homogeneous samples in order to test the determinants or consequences of accrual quality. The motivation behind the research design is that a better model of the normal component of an accrual generates a less noisy estimate of the abnormal component (i.e., model residual), resulting in more powerful tests. As an example, Miller and Skinner (1998) and Schrand and Wong (2003) both model the economic determinants of the valuation allowance for deferred tax assets (DTAs) required under SFAS 109. Miller and Skinner (1998) do not find much evidence of earnings management using the residual from their model estimated for firms with large DTAs. Schrand and Wong (2003), however, are able to find evidence of earnings management using a model of the DTA allowance specifically designed for banks. Of course, the construct validity benefits of modeling specific accruals, especially within specific industries, come at the expense of generalizability. 


\subsubsection{Determinants and consequences and interpretation of discretionary accruals proxies}

If "normal" accruals are the predicted value from a regression model of accruals associated with the firm's fundamental earnings process, then abnormal accruals represent estimation errors, which can be intentional or unintentional. Almost one hundred papers in our database use abnormal accruals as a measure of earnings quality and test predicted determinants or consequences. These studies test the joint hypothesis that the residual from an accruals model reflects earnings management and that the predicted determinant induces earnings management or that earnings management has a predicted consequence. For ease of exposition and to reduce the amount of repetition in this survey, we discuss the results of such tests in the relevant determinant or consequence section.

In this section, however, we emphasize several general findings. First, while abnormal accruals are less persistent than normal accruals, they do have positive persistence. Xie (2001) finds that discretionary accruals have a significantly positive persistence coefficient of 0.57 . In addition, Subramanyam (1996) uses the modified Jones model to measure abnormal accruals and finds incremental information content in abnormal accruals, which he interprets as evidence that abnormal accruals are not opportunistic but that they communicate private information about equity value. Also using the modified Jones model to measure abnormal accruals, Chaney, Jeter, and Lewis (1996) suggest that discretionary accruals smooth earnings and they interpret their finding as evidence that discretionary accruals are not opportunistic but that they communicate information about the firm's long-term (permanent) earnings to equity markets. Subramanyam (1996) and Chaney et al. (1996) assume that investors are able to isolate the abnormal accrual component. If investors are naïve and fixate on earnings, then a positive stock price reaction could be documented even if the accrual component is not value relevant. 
Second, investors seem to recognize the distinction between abnormal accruals and normal accruals, but they do not fully incorporate the implications into price. DeFond and Park (2001), find that abnormal accruals suppress the magnitude of market reactions to earnings surprises, suggesting that investors do not find them as reliable as normal accrual components. However, even though investors realize that abnormal accruals are less reliable, they still overreact to the information (i.e., the abnormal accrual component is negatively associated with future stock returns). Xie (2001) finds that the accrual anomaly hedge returns are stronger for hedge portfolios based on abnormal accruals measured using the Jones model.

Third, research that examines the complete path from a determinant of abnormal accruals through to the consequences for future period earnings comes to a different conclusion than most studies that independently study the links. Bowen, Rajgopal, and Venkatachalam (2008) find an association between lax governance and abnormal accruals, ${ }^{16}$ where governance quality is measured by an overall governance score and by the "usual suspects" of individual governance characteristics. Bowen et al. (2008) also find, however, that the accounting discretion associated with lax governance is positively related to future performance (ROA), which they interpret as evidence that abnormal accruals reflect future performance expectations, not opportunism.

\subsubsection{Smooth earnings}

Earnings smoothness or its inverse, variability, is a firm-specific time-series construct. ${ }^{17}$ While the concepts statements do not state that "smoothness" is a desirable property of earnings or an objective of the accruals process, SFAC No. 1 does recognize that accrual earnings help mitigate problems associated with a "mismatch" of cash receipts and payments when reporting accounting

\footnotetext{
${ }^{16}$ Bowen et al. (2008) use an aggregate index of accounting discretion. The use of abnormal accruals is one component of the index, along with a measure of accrual-based smoothing and the tendency to avoid negative earnings surprises.

${ }^{17}$ Early discussions and analyses of smoothing include Beidleman (1973) and Ronen and Sadan (1975).
} 
information for finite periods, and it concludes that accrual earnings will provide “...a better indication of an enterprise's present and continuing ability to generate favorable cash flows than information limited to the financial effects of cash receipts and payments." Hence, predictability is the objective, not smoothness, but the concepts statement suggests that the earnings process is smoother than the cash collection/payment process. In other words, smoothness is a means to an end.

Smoothness that improves predictability of fundamental earnings is of higher quality, ceteris paribus, in an equity valuation context. The term "smooth" however, comes with baggage. Earnings that are smooth relative to uninformative cash flow variation are more decision useful under the assumption that the firm's fundamental earnings process is smoother than the cash receipt/payment process. But smoothed earnings or "artificial" smoothness in which the reported earnings have less volatility than the fundamental earnings process, represent distortions. Theories suggest that firms have incentives to make accounting choices that create smooth earnings including choices of real activities (Lambert, 1984) or accruals (Demski, 1998; Kirschenheiter and Melumad, 2002).

\section{Determinants of smoothness:}

Beidleman (1973), Barefield and Comiskey (1971), and Dharan (1987) document how unbiased application of specific GAAP methods affects earnings smoothness. Beidleman (1973) measures smoothness as the difference between reported earnings and "normal" earnings, where normal earnings is an average earnings level, estimated based on historical earnings and a constant growth rate. Dharan (1987) is a simulation analysis that uses the variance of the simulated earnings stream as a measure of smoothness. These papers suggest methods for which accrual earnings in 
fact improve predictability relative to cash earnings assuming, like the concepts statement, that the fundamental earnings process is smoother than the cash receipt/payment process.

Most studies, however, explore the relation between incentives for smoothing and specific accounting choices (or real activity choices) that generate smoother earnings. The focus is on the mechanisms used to smooth earnings, but the analyses are joint tests of the incentives and of the mechanism choice (e.g., White, 1970; Barnea, Ronen, and Sadan, 1976; Moses, 1987; Chaney, Jeter, and Lewis, 1998; Hand, 1989). Studies of accrual choices frequently investigate specific accounts, or even employ industry-specific small sample case studies (e.g., Dascher and Malcolm, 1970; McNichols and Wilson, 1988; Kanagaretnam, Lobo, Yang, 2004). Smoothing is treated as a periodspecific accounting choice, thus these papers typically measure smoothing as the negative correlation between a proxy for unmanaged earnings (e.g., non-discretionary accruals), and the "discretionary accrual" that is being used to smooth earnings.

\section{Consequences of smoothness:}

The majority of the consequences studies examine the implications of smoothness in a crosscountry context. Section 4.2 discusses these studies. The advantage of the cross-country analyses is the researcher's ability to create a smoothness proxy that represents artificial smoothing or earnings management. Smoothness has both a fundamental component, which is predicted to increase quality, and an artificial component, which is predicted to decrease quality. The predicted consequences of the two components are different, thus the research necessitates distinguishing nondiscretionary (normal) smoothness from discretionary (abnormal) smoothness. In the cross-country studies, the notion is that the measurement error in the model of the fundamental component of 
smoothness is dominated by the cross-sectional variation in the discretionary component, which makes the "abnormal smoothness" measure a reasonable proxy for earnings management.

Within the U.S., studies of the consequences of smoothness, artificial or otherwise, are limited. Tucker and Zarowin (2006) find that smoothness improves earnings informativeness. The analysis splits firms into a high smoothing group, defined as firms that have a stronger negative correlation between discretionary accruals and unmanaged earnings (total earnings - discretionary accruals), and a low smoothing group. Their measure of earnings informativeness is the extent to which changes in current stock returns are reflected in future earnings, following Collins, Kothari, Shanken, and Sloan (CKSS, 1994). The high smoothing group has a stronger CKSS relation. This result holds after various controls for the smoothness of the fundamental earnings process. Their conclusion is that the net smoothing effect of accrual accounting, which they predict would lead to greater informativeness if accruals smooth noise but to reduced informativeness if managers artificially smooth earnings relative to the fundamental process, is to improve informativeness and not to garble earnings.

\subsubsection{Asymmetric timeliness and timely loss recognition}

We include in this section any studies that measure separately the timeliness of loss recognition and profit recognition. A more timely recognition of losses is often associated with a “conservative" accounting system (Basu, 1997; Pope and Walker, 1999). More recent studies distinguish conditional conservatism, which is more timely recognition of bad news than of good news in earnings, from unconditional conservatism, which describes an ex ante policy that results in 
lower book values of assets (higher book values of liabilities) in the early periods of an asset or liability life. $^{18}$

The most frequently used measure of timely loss recognition is the reverse earnings-returns regression from Basu (1997).

$$
\text { Earnings }_{t+1}=\alpha_{0}+\alpha_{1} D_{t}+\beta_{0} \operatorname{Ret}_{t}+\beta_{1} D_{t} \operatorname{Ret}_{t}+\varepsilon_{t}
$$

where $D=1$ if $\operatorname{Ret}<0$, and a higher $\beta_{1}$ implies more timely loss recognition. The specification is reported in Exhibit 1. Basu (1997) provides a second measure that is not based on returns.

$$
\Delta N I_{\tau}=\alpha_{0}+\alpha_{1} N E G D U M+\alpha_{2} \Delta N I_{\tau_{-} 1}+\alpha_{3}\left(N E G D U M^{*} \Delta N I_{\tau_{-} 1}\right)+\varepsilon_{\tau}
$$

where $\Delta \mathrm{NI}_{\mathrm{t}}$ is the change in income from year $\mathrm{t}-1$ to $\mathrm{t}$, scaled by beginning book value of total assets, and NEGDUM is an indicator variable equal to one if $\Delta \mathrm{NI}_{\mathrm{t}-1}$ is negative. If bad news is recognized on a more timely basis than good news, negative earnings changes will be less persistent and will tend to reverse more than positive earnings changes. This translates into a prediction that $\alpha_{3}<0$, and Basu (1997) finds support for this prediction. This tendency-to-reverse measure is used in some papers when equity returns are not available (e.g., Ball and Shivakumar, 2005), and it is used in other papers to check the robustness of the results. ${ }^{19}$

Our review of the asymmetric timeliness literature focuses on studies of the determinants and consequences of asymmetric timeliness, specifically when it is a suggested measure of quality. Ryan (2006) provides a recent and thorough review of the literature on conservatism, more generally including measurement issues.

\footnotetext{
${ }^{18}$ Basu (1997) uses the term conditional to describe his measure of conservatism, but he does not specifically call it "conditional conservatism."

${ }^{19}$ The use of this measure to check the robustness of the results based on the Basu (1997) reverse regression measure has increased since the publication of Dietrich, Muller, and Riedl (2007), which suggests that the reverse regression measure is biased. Ryan (2006) questions the magnitude of the bias, but also provides some possible solutions.
} 
Determinants of asymmetric timeliness and timely loss recognition: ${ }^{20}$ The first determinant we discuss is accounting standards. Loss recognition is more timely in common law than code law countries (Ball, Kothari, and Robin, 2000, BKR). Using the Basu (1997) reverse regression, BKR find that the $\mathrm{R}^{2}$ of the regression is higher and the $\beta_{1}$ coefficient is lower in common law countries, which suggests greater asymmetric timeliness recognition. Within bad news observations, loss recognition is more timely in common law countries.

Loss recognition is more timely for firms that use IAS (Barth, Landsman, and Lang, 2008). Using logit analysis, Barth et al. (2008) compare IAS adopters to non-adopters. The model includes a dummy explanatory variable for large negative reported earnings and control variables for other determinants of the choice to follow IAS. The coefficient on the indicator variable is positive. Barth et al. (2008) also estimate a logit regression within the sample of IAS adopters with the dependent variable equal to one if the observation is post IAS adoption and equal to zero pre-adoption. The coefficient estimate on the indicator variable is positive, so IAS adoption is associated with a greater frequency of reported losses within the same sample of firms across time.

Loss recognition is more timely when equity market incentives demand it. This conclusion is based on four studies. Ball and Shivakumar (2005), using the Basu (1997) tendency-to-reverse measure, find that loss recognition is more timely in U.K. public companies than U.K. private companies. Ball, Robin, and Sadka (2008), using the $\mathrm{R}^{2}$ and $\beta_{1}$ coefficient estimate from the Basu (1997) reverse regression (as in BKR), find that loss recognition is more timely for firms in countries with greater prominence of debt markets relative to equity markets. Ball, Robin, and $\mathrm{Wu}$ (2003), also using the BKR metrics, find that East Asian countries, which share a common law origin but are asserted to have lower equity capital markets incentives, do not have more timely loss recognition

\footnotetext{
${ }^{20}$ Many of the studies of the determinants of asymmetric timeliness are cross-country studies, which also are discussed in Section 4.
} 
than code law countries. The differences in timely loss recognition within countries (or regions) with the same standards or legal origin suggest that timely loss recognition has an endogenous component related to firms' reporting incentives. It is not driven purely by a country's accounting system. Pae, Thornton, and Welker (2005), also using the BKR metrics, find that firm-level priceto-book ratios are a determinant of timely loss recognition and that the negative association is correlated with the accrual component of earnings, which again supports the conclusion that equity incentives, and not just mechanical application of accounting principles, are associated with observed timely loss recognition.

Loss recognition is more timely when enforcement, either internal or external, is stronger. Francis and Wang (2008) find that the positive association between common law countries as a proxy for greater investor protection and timely loss recognition is higher only for firms with Bigfour auditors. García Lara, García Osma, and Penalva (2009) find a positive association between commonly used governance proxies for effective monitoring and timely loss recognition. Chung and Wynn (2008) find that D\&O liability insurance coverage for Canadian firms is negatively associated with timely loss recognition. One paper provides negative evidence: within a sample of U.S. firms, Ruddock, Taylor, and Taylor (2006) find no relation between non-audit services, which could impede independence and reduce auditor monitoring, and timely loss recognition. All four studies use the Basu (1997) reverse regression to measure timely loss recognition; Chung and Wynn (2008) and García Lara, García Osma, and Penalva (2009) additionally check the robustness of the results to the use of the Basu (1997) tendency-to-reverse measure. 


\subsubsection{Benchmarking}

This section covers studies that use small positive differences between reported earnings and any benchmark as a measure of earnings quality. A significant component of this literature is related to the "kink" in the distribution of reported earnings around zero: a statistically small number of firms with small losses and a statistically large number of firms with small profits (Hayn, 1995; Burgstahler and Dichev, 1997). A common but controversial interpretation of this pattern is that firms with unmanaged earnings just less than the heuristic target of zero intentionally manage earnings just enough to report a small profit. Thus, small profits (or avoiding small losses) are a de facto indication of earnings management. Likewise, small earnings increases are a proxy for earnings management based on the finding in Burgstahler and Dichev (1997) of a statistically unusual number of firms with small decreases in earnings, and meeting or beating an analyst forecast is a proxy for earnings management based on the finding in Dechow, Richardson, and Tuna (2001) of a "kink" in earnings around consensus analyst forecasts.

The consequences studies frequently use small positive surprises (or avoidance of negative surprises) as a proxy for managed earnings, and the authors make predictions about the consequences of the assumed diminished quality. In the determinants studies, the most common research question is whether the assumption that is made in the consequences studies - that small positive surprises are more likely to represent managed earnings - is justified.

Determinants of small positive profits: Several studies suggest that small profits are not evidence of earnings management. Dechow, Richardson, and Tuna (2003), in a large-sample study, find no relation between realizations of small profits and increases in discretionary accruals. Beaver, McNichols, and Nelson (2007) suggest that asymmetric taxes, rather than opportunistic choices, can 
explain the kink. Durtschi and Easton (2005) suggest that the kink is due to statistical and sample bias issues.

Several types of results, however, suggest a relation between small profits and other recognized proxies for earnings management. First, there is a correlation between small profits and discretionary accruals in industry-specific and/or account-specific studies. Beaver, McNichols, and Nelson (2003) find a positive correlation between earnings management of loss reserves and small profit realizations at P\&C insurers. Phillips, Pincus, and Rego (2003) find an association between deferred tax expense and avoiding losses. In both studies, the results are subject to the caveat that neither the accruals metric nor small profits represent earnings management, but the two variables are correlated, perhaps as explained in Beaver et al. (2007). Firms that were able to use more aggressive revenue recognition techniques, which might provide greater opportunities for earnings management, are more likely to report small profits and are less likely to report small losses (Altamuro, Beatty, and Weber, 2005). Second, the kink is strongest in the fourth quarter when studies assert that the incentives for earnings management are predicted to be higher (Kerstein and Rai, 2007; Jacob and Jorgensen, 2007). Third, low audit effort measured by hours worked, which might mitigate opportunities for earnings management, is associated with small positive profits (Caramanis and Lennox, 2008).

Determinants of meeting or beating targets: The literature on the determinants of meeting or beating analyst forecasts and reporting small earnings increases includes three types of analyses. In the first type, the study focuses on the mechanisms/tools that firms use to produce earnings that just meet or beat a target. Firms make accounting choices such as managing tax expense (Dhaliwal, Gleason, and Mills, 2004); managing the classification of items within the income statement (McVay, 2006); and managing the creation and reversal of restructuring charge accruals/cushions 
(Moehrle, 2002). Firms also make real decisions such as repurchasing stock (Hribar, Jenkins, and Johnson, 2006) or selling fixed assets or marketable securities (Herrmann, Inoue, and Thomas, 2003) or repurchasing shares (Bens, Nagar, Skinner, and Wong, 2003). Ayers, Jiang, and Yeung (2006), following the basic approach of Dechow, Richardson, and Tuna (2003), assess the relation between discretionary accruals and meeting or beating analyst forecasts and reporting small earnings increases. They find some evidence consistent with an association between earnings management through the use of accruals and these targets.

In the second type of analysis, the study focuses on firms' equity market incentives to meet or beat a target. Matsumoto (2002) finds that firms with greater incentives, primarily given their ownership structure, are more likely to just meet or beat a target. ${ }^{21}$ Beatty, Ke, and Petroni (2002) find that public banks are more likely to use discretionary bank-specific accruals to report small profit increases. Cheng and Warfield (2005) find that managers with high equity incentives are more likely to just meet or beat a target, and McVay, Nagar, and Tang (2006) find insider trading subsequent to just meeting or beating. Abarbanell and Lehavy (2003) indirectly link earnings management activities to equity market incentives assuming that analyst stock recommendations not meeting or beating a forecast - proxy for incentives.

In the third type of analysis, the study focuses on opportunities to meet or beat a target. Frankel, Johnson, and Nelson (2002) find a positive (negative) correlation between non-audit (audit) fees as proxies for auditor quality and independence and small earnings increases and the likelihood of meeting or beating analyst forecasts. Brown and Pinello (2007) show that firms are more likely to avoid negative earnings surprises relative to an analyst forecast at interim quarters when they hypothesize the greatest opportunities to manage earnings. Barton and Simko (2002) find that firms

\footnotetext{
${ }^{21}$ She supports this indirect evidence with direct tests that the firms appear to meet or beat via abnormal accruals and by managing the forecast down.
} 
with overstated net asset values are constrained in their opportunities to manage earnings and are less likely to meet or beat analyst forecasts.

Consequences of small earnings surprises: Three papers suggest that meeting or beating targets has positive market consequences. Two papers document that firms that consistently report earnings increases relative to the prior year or relative to the same quarter of the prior year receive a price premium (e.g., Barth, Elliott, and Finn, 1999; Myers, Myers, and Skinner, 2007). These studies do not provide evidence on whether the strings are achieved by artificial smoothing. Bartov, Givoly, and Hayn (2002) find that meeting or beating analyst forecasts is associated with a higher contemporaneous quarterly return. Bhattacharya et al. (2003) find that greater opacity, which he measures as an increasing function of loss avoidance, is associated with a higher average cost of equity and a lower level of trade, however, the loss avoidance proxy alone is not a significant determinant.

The positive market consequences are mitigated if earnings management is suspected. Kasznik and McNichols (2002) find that meeting or beating on an ad hoc basis does not lead to higher valuations, but that meeting or beating regularly does. Gleason and Mills (2008) show that when earnings management is more obvious and detectable, and thus investors are more able to differentiate meeting or beating that represents earnings management from that which represents value-relevant good news, there is a market discount for beating. Patterns in analyst forecasts/stock recommendations as a consequence of meeting or beating targets, however, suggest that analysts do not detect/anticipate earnings management to meet or beat targets (Abarbanell and Lehavy, 2003; Burgstahler and Eames, 2003).

A final consequence paper uses a unique measure of "surprise." Affleck-Graves, Callahan, and Chipalkatti (2002) compute an earnings predictability "score" based on analyst forecast errors 
and analyst forecast dispersion at the timing of the filing of the year $y-110-\mathrm{K}$ filing. The paper predicts and finds that the high category of "surprise" firms has a greater conditional increase in abnormal adverse selection costs measured using functions of short window bid-ask spreads around quarterly earnings announcements.

\subsection{Earnings response coefficients (ERCs)}

Prior to Ball and Brown (1968) academic accounting research focused on evaluating the "quality of earnings" in terms of conformity to a consistent measurement system or conceptual framework. $^{22}$ Beaver (1968), Ball and Brown (1967; 1968), and Martin (1971) changed the perspective of academic research in terms of how "quality" was evaluated. They showed that earnings news was correlated with various equity market attributes (long-window returns and volume and volatility changes around earnings announcements). Because these outcomes result when investors change their equity valuations, they conclude that information in earnings is correlated with the information used by investors in their valuation decisions. Thus, it is not surprising that a returns-based earnings response coefficient is a candidate proxy for decisionusefulness or earnings quality. (See Exhibit 2 for the regression model commonly used to estimate the ERC).

In this section, we examine the robustness of the earnings response coefficient (ERC) as a direct proxy for earnings quality. We make a distinction between these studies and studies that use returns to infer the quality of earnings. The studies that use the ERC as a direct proxy for earnings quality test a theory that predicts a determinant of quality (e.g., governance characteristics) or a consequence of it (e.g., voluntary disclosure). The analyses are joint tests of market efficiency and

\footnotetext{
${ }^{22}$ Much of the debate focused on whether earnings should be measured using historical cost with matching (e.g., Daines, 1929; Littleton, 1956; Paton and Littleton, 1940); replacement cost or entry values (e.g., Sterling, 1970); future discounted cash flows (e.g., Fisher, 1907, 1930); or net realizable values or exit costs (e.g., Chambers, 1956, 1965).
} 
earnings quality. The studies specifically state (or at least strongly imply) that the ERC is a direct proxy for earnings quality.

The studies commonly cite Holthausen and Verrecchia (HV, 1988) as the theoretical basis for their prediction that ERCs are positively correlated with earnings quality. In the HV model, an information signal communicates the true value of a firm's liquidating dividend with noise, and the variance of the noise term reflects the "quality" (HV's term) of the information signal.

The assertion that ERCs measure precision of earnings information has some empirical support. Imhoff and Lobo (1992) find a negative relation between ERCs and analyst forecast dispersion, which they interpret as evidence that higher quality earnings are associated with lower ex ante inherent uncertainty about earnings and the information the firm has provided to analysts. Kinney, Burgstahler, and Martin (2002) also find a negative association between analyst forecast dispersion and ERCs.

Liu and Thomas (2000) specifically state that the ERC can be viewed as a measure of higher quality earnings (p. 73). They show that the ERC (coefficient estimate) and the $\mathrm{R}^{2}$ of the ERC regression are affected by the relation between unexpected earnings (UE), measured as actual earnings for $\mathrm{t}$ minus the forecast of period $\mathrm{t}$ earnings in $\mathrm{t}-1$, and earnings forecast revisions for future periods (FR), measured using information available at time t. When the correlation between UE and FR is high, the observed ERC will be high. They attribute low values of the regression $R^{2}$ to heterogeneity of the correlation between UE and FR within the sample. Hence, the ERC captures the notion of earnings quality in the sense of Graham and Dodd (1934), in that a higher ERC is associated with predictability of the fundamental earnings process. 


\section{Determinants of ERCs:}

\subsubsection{Accounting methods}

Five papers examine the cross-sectional or longitudinal relation between earnings measured under alternative methods and the resulting ERCs. ${ }^{23}$ Altamuro, Beatty, and Weber (2005) show that firms that are required to significantly change their revenue recognition policies because of SAB 101 exhibit a decline in earnings informativeness. In the pre-adoption period, the SAB 101 firms have significantly higher ERCs than matched sample firms with similar revenue generation processes. The post-adoption ERCs do not appear to be different. Loudder and Behn (1995) compare ERCs for a sample of R\&D intensive firms that capitalized R\&D costs pre-SFAS No. 2 and were forced to expense after SFAS No.2 to the ERCs of a matched sample of firms that expensed R\&D both preand post-SFAS No. 2. The capitalizing firms have significantly higher ERCs relative to the matched sample in the pre-adoption period. Their ERCs decline when they are forced to expense. Collins and Salatka (1993) document an increase in ERCs of multinational firms after adoption of SFAS No. 52 (accounting for translation gains and losses), which they suggest made earnings less noisy, but not necessarily more or less aggressive.

Dharan and Lev (1993) find that firms that move to income-increasing methods have lower $\mathrm{R}^{2} \mathrm{~s}$ and ERCs in the year of the change relative to a control sample of non-change firms and a sample of firms that move to income-decreasing methods. Pincus (1993) characterizes a portfolio of accounting choices related to inventory, depreciation, investment tax credits, and leases with respect

\footnotetext{
${ }^{23}$ Early papers examined differences in market responses to earnings measured under different accounting methods (Mlynarczyk, 1969; Gonedes, 1969; Ball, 1972; Cassidy, 1976), with a general notion of exploring the degree of market efficiency. They did not assert that the earnings number under one method or another was more decision useful. Rather, they assumed that both earnings numbers were different representations of the same firm performance and the research question was whether markets understood this. These studies generally did not control for endogeneity of method choice.
} 
to conservatism, which is defined as whether the methods are primarily income-accelerating. ${ }^{24}$ While there is some evidence that the ERCs of conservative and non-conservative firms differ, Pincus acknowledges that it cannot be attributed to the methods per se.

The standard academic debate is whether managerial discretion over accounting method choice, in the presence of information asymmetry, improves efficient capital allocation because managers use the discretion to convey private information to investors (e.g., Healy and Palepu, 1993) or whether the discretion decreases efficiency because managers use it to bias financial reporting. The papers discussed above provide inconclusive evidence on this debate. Dharan and Lev (1993) interpret their evidence as suggesting that changing to income-increasing methods may be a warning sign that there are fundamental problems at the firm that are being masked by the accounting methods, which supports the bias story. Loudder and Behn (1995) and Altamuro et al. (2005), however, suggest that earnings measured under the more "aggressive" policy, in the sense that earnings recognition is earlier rather than later or expense recognition is delayed, is associated with a higher market response. These studies challenge the premise that earnings aggressiveness should be viewed as de facto evidence of lower quality.

Many studies examine whether ERCs have changed over time for the US economy. The general finding is that the value relevance of earnings has declined over time. ${ }^{25}$ Conservatism in accounting standards associated with intangible assets, and the increase in intangible-intensive firms, is one explanation (e.g. Lev and Zarowin 1999). Another explanation is the increase in fair value accounting (e.g. asset impairments, the recognition of pension liabilities), which results in the

\footnotetext{
${ }^{24}$ Pincus (1993) is an example of a paper that specifically motivates his paper as one that investigates the "quality of earnings" and cites Lev (1989) as the source of his inspiration.

${ }^{25}$ See Collins, Maydew, and Weiss (1997); Francis and Schipper (1999); Lev and Zarowin (1999); Brown, Lo, and Lys (1999); Givoly and Hayn (2000); Francis, Schipper, and Vincent (2002); Landsman and Maydew (2002); Core, Guay, and VanBuskirk (2003); Ryan and Zarowin (2003); Dontoh, Radhakrishnan, and Ronen (2004); Beaver, McNichols, and Rhie (2005); Kim and Kross (2005); Collins, Li, and Xie (2007); Jorion, Shi, and Zhang (2007); Dichev and Tang (2008).
} 
recognition of more transitory losses in earnings (e.g., Givoly and Hayn 2000). Johnson (1999)

however, shows that the association between earnings and stock returns is larger in economic expansions and smaller in economic recessions. This result raises the question of whether it is the "return" component of ERCs or the "earnings" component of ERCs that is changing. If market structures and asset pricing patterns are time-variant, one might observe time variation in ERCs in the presence of stable earnings quality (Hoitash, Krishnan, and Sankaraguruswamy, 2002).

\subsubsection{Firm characteristics}

Governance characteristics: Using both short and long-window ERCs, Francis, Schipper, and Vincent (2005) find that earnings are less informative for firms with dual class shares. Further analysis suggests that markets view the earnings of firms with a dual class structure as less credible primarily because of the separation of voting rights from cash flow rights, although the firms with dual class shares also tend to have greater managerial ownership. Using long-window ERCs, Wang (2006) finds a positive association between founding family ownership and earnings informativeness, measured as the regression coefficient in an annual returns-earnings model. ${ }^{26}$ Debt Characteristics: Our database includes Dhaliwal, Lee, and Fargher (1991) and Core and Schrand (1999), which find that leverage is associated with non-linearities in ERCs. Both papers recognize that equity is a call option on the value of the firm and predict the shape of the earningsreturns relation as a function of the firm's debt structure. These papers present researchers with a measurement issue to consider when using ERCs as a measure of quality.

Auditors: Teoh and Wong (1993) report higher ERC coefficients for firms with Big-8 auditors, which they use as a proxy for audit quality. Francis and Ke (2006) find that non-audit fees, which

\footnotetext{
${ }^{26}$ Warfield, Wild, and Wild (1995) document a similar relation between managerial ownership and an identical specification of the ERC, based on the same theoretical arguments. Warfield et al., however, use the term "earnings informativeness" rather than "earnings quality" to motivate the test.
} 
they assert proxy for lower independence, are negatively related to ERCs. Hackenbrack and Hogan (2002) find that the average short window (2-day) ERC for the two annual earnings announcements after an auditor change that likely indicates a credibility decrease (e.g., to lower fees, because of a disagreement over fees, or because of a disagreement with the auditors) is lower than the ERC for the two annual pre-change earnings announcements. However, the average ERC is higher for firms that switch for reasons that the authors classify as service related. Manry, Tiras, and Wheatley (2003) report that quarterly returns have a stronger association with contemporaneous earnings levels for firms that have timely auditor reviews of their interim earnings, but they have a stronger relation with lagged earnings for firms that have retrospective auditor reviews. ${ }^{27}$

\subsubsection{Information environment}

Concurrent disclosure of non-earnings information generally improves the earnings-returns relation for firms with poor earnings informativeness (e.g., Lougee and Marquardt, 2004). Baber, Chen, and Kang (2006) reach a similar conclusion based on a finding that the market discount that investors apply to earnings that are likely to be upwardly managed declines when balance sheet information is disclosed concurrent with the earnings announcement. ${ }^{28}$ Amir and Lev (1996) confine the analysis to an industry in which financial information "informativeness" is likely low independent cellular companies - and document that non-financial indicators (e.g., POPS, which is a measure of population density) are value-relevant. Amir, Harris, and Venuti (1993), however, characterize their evidence as "mixed" on whether 20-F earnings reconciliations improve earnings informativeness using both long and short-window ERCs.

\footnotetext{
${ }^{27}$ Due to data constraints, sample size limits the power of the tests. There are 328 observations with timely reviews and 84 retrospective reviews. The authors are unable to address selection issues and the authors acknowledge that the results are "mixed" across quarters and specification of the earnings variable in levels or changes.

${ }^{28}$ This analysis incorporates the findings of Chen, DeFond, and Park (2002), which models the firm's decision to voluntarily disclose balance sheet information in earnings announcements.
} 
Francis, Schipper, and Vincent (2002) find a significant positive cross-sectional association between abnormal returns to analyst announcements (aggregated over all announcements prior to the earnings announcement) and the market response to subsequent quarter earnings. Evidence on the association between mean abnormal returns and ERCs, however, is mixed. They interpret the totality of their evidence as providing little support for the view that competing information from analysts erodes the informativeness of earnings.

Collins and DeAngelo (1990) find that the market is more responsive to earnings during a proxy contest. This finding rejects one proposed hypothesis which is that earnings during this period are less precise because they are likely to be opportunistically managed. Rather, they interpret their finding as evidence that a proxy contest is a period of heightened uncertainty and that the earnings number is especially useful for valuation.

In summary, firms appear to supplement poor fundamental earnings informativeness with additional information (Lougee and Marquardt, 2004; Chen, DeFond, and Park, 2002). However, management forecasts are associated with historically stronger earnings informativeness (higher ERCs), so the relation between disclosure and ERCs is not generalizable.

\section{Consequences of ERCs}

Figure 2 indicates that the only examined consequence of ERCs as a proxy for earnings quality is voluntary disclosure. Two papers find that firms voluntarily disclose non-earnings information when earnings are less informative. Chen, DeFond, and Park (2002) find that when earnings informativeness is low or uncertain, firms have a greater propensity to voluntarily disclose balance sheet information in earnings announcements. Lougee and Marquardt (2004) document that firms with low historical ERCs are more likely to voluntarily disclose pro forma earnings. One 
paper, however, finds that firms are more likely to issue management forecasts of earnings when earnings are more informative (Lennox and Park, 2006). Their explanation for the result is that managers' propensity to forecast is increasing in the manager's confidence about forecast accuracy, given reputation concerns.

\subsection{External indicators of financial reporting quality (FRQ)}

The external indicators of financial reporting quality that we review are: 1) SEC Accounting and Auditing Enforcement Releases (AAERs), 2) Restatements, and 3) Internal controls. We term these external measures of financial reporting quality because the researcher does not measure a characteristic of earnings to determine its quality, but rather obtains evidence from an outside source (the SEC, or the management team themselves in the case of restatements, or the auditor in the case of internal control disclosures). Two important distinctions of these variables as proxies for EQ is that they often provide information about the quality of the financial statements as a whole, not just earnings, and that they each involve potentially significant selection issues, as discussed below.

\subsubsection{AAERs as a proxy for earnings management}

The SEC issues accounting and auditing enforcement releases (AAERs) after it completes an investigation and takes action against a firm, manager, or the auditor of the firm. Samples of AAERs used in accounting research typically consist of cases where the SEC alleges that the firm has misstated or overstated earnings. Samples usually exclude cases against auditors and pure disclosure cases. Almost half of the AAER firms have overstated revenue, but overstatements of inventory and other assets are also common (Dechow, Ge, Larson, and Sloan 2009). In most AAER cases, the SEC typically accuses managers of intentionally misstating financial statements, which is 
the definition of fraud in SAS No. 99. In some cases, however, the SEC alleges that managers were negligent (i.e., "reckless in not knowing" of the misstatement).

Because the AAER sample includes cases of egregious and intentional misstatements (i.e., earnings management), it is likely to have a lower Type I error rate than samples identified using

other methods such as abnormal accruals models. One issue of concern, however, is the potential for selection bias related to how the SEC identifies the misstating firms. Given a constrained budget, the SEC may not pursue cases that involve ambiguity and that it does not expect to win. The SEC states that it will scrutinize firms that restate earnings because the firm has already admitted to making a mistake. The SEC also states that it is concerned with market impact because their role is to protect investors. Therefore, they scrutinize firms with large market capitalizations as well as IPO firms and firms raising public debt or equity.

\section{Determinants of AAERs}

Managerial compensation: Dechow et al. (1996) and Beneish (1999) do not find an association between the existence of an earnings-based bonus plan and the likelihood of accounting manipulations. Johnson, Ryan, and Tian (2009) find that AAER managers face stronger incentives from unrestricted stocks than those of control firms, however, Erickson, Hanlon, and Maydew (2006) and Armstrong, Jagolinzer, and Larcker (2009) do not find a positive association between stock-based incentive compensation and the likelihood of accounting fraud. Dechow et al. (1996) do not find abnormally higher stock sale activities for the officers and directors of the AAER firms during the manipulation years, but two subsequent studies find that insiders of fraud firms tend to engage in more stock sales during the manipulation period (Summers and Sweeney, 1998; Beneish, 1999). 
Debt covenants: Dechow et al. (1996) find that manipulation firms have higher leverage ratios and are more likely to violate debt covenants during and after the manipulation period than control firms. Beneish (1999), however, does not find statistically significant differences between manipulation firms and control firms in either leverage ratios or default risk. ${ }^{29}$

Capital market incentives: Dechow et al. (1996) find that manipulation firms have higher ex ante external financing demands and higher ex post external financing activities than non-manipulation firms. Beneish (1999) again provides conflicting evidence, but Dechow et al. (2009) confirm the result using a more comprehensive sample of AAER firms.

Board of directors and CEOs: AAER firms tend to have a smaller percentage of outside members on the board of directors, are more likely to have a CEO who also serves as chairman of the board or founder of the company and are less likely to have an outside blockholder than control firms (e.g., Dechow et al, 1996; Beasley, 1996; Farber, 2005). In addition, Feng, Ge, Luo, and Shevlin (2009) provide evidence suggesting that CFOs become involved mainly under CEO pressure rather than for their own immediate financial benefits.

Audit committees and auditors: Dechow et al. (1996) find that AAER firms are less likely to have an audit committee, but Beasley (1996) does not find a significant association. Farber (2005) shows that fraud firms tend to have fewer audit committee meetings and fewer financial experts on the audit committee. ${ }^{30}$ He does not, however, find an effect of audit committee independence on accounting fraud. Neither Dechow et al. (1996) nor Beneish (1999) finds a significant difference between the auditor quality of misstatement firms and control firms, using Big 4 status as an

\footnotetext{
${ }^{29}$ Dechow et al. (1996) and Beneish (1999) find conflicting results in several cases. A possible explanation is the difference between the samples. Beneish's sample includes 10 "fraud" firms identified from a search of the financial press that were not the subject of AAERs (yet, he argues). Dechow et al.'s sample consists of just over 90 AAER firms, all of which overstate earnings.

${ }^{30} \mathrm{McDaniel}$, Martin, and Maines (2002) in an experimental setting find that financial experts help audit committees focus on monitoring more important financial reporting issues.
} 
indication of audit firm quality, but Farber (2005) finds that fraud firms are less likely to have Big-4 audit firms using a more recent sample. Geiger, Lennox, and North (2008) do not find empirical evidence that auditor independence is associated with fraud, while Joe and Vandervelde (2007), in an experimental setting, suggest that it is.

\section{Consequences of AAERs}

Manager turnover: Feroz et al. (1991) find that 42 of 58 AAER firms between 1982 and 1989 (72.4 percent) have management turnover (i.e., firing or resignation) after the public disclosure of the misstatement. Beneish (1999) documents that only 35.9 percent of misstatement firms have CEO turnover subsequent to the discovery of accounting misstatements (during the year of discovery and four years following the discovery) for AAER firms between 1987 and 1993. Karpoff, Lee, and Martin (2008) find that 93 percent of the individuals identified by the SEC as the responsible party leave the company by the end of the enforcement period, and these culpable individuals suffer serious legal penalties (e.g., criminal charges) and monetary losses.

Firm value: Feroz et al. (1991) and Dechow et al. (1996) find a stock return of -9 to -10 percent on the first announcement day of the accounting misstatements (see also Miller, 2006a). Dechow et al. (1996) document a significant increase in bid-ask spreads and a significant decline in analyst following after the discovery of accounting misstatements. Karpoff, Lee, and Martin (2008b) find that the enforcement firms on average lose a total of 38 percent of their market values measured over all announcement dates related to the enforcement action. They suggest that two thirds of the decline represents lost reputation, which they define as "the decrease in the present value of future cash flows as investors, customers, and suppliers are expected to change the terms of trade with which they do business with the firm." The remaining one-third represents legal penalties, and 
readjustments in valuations associated with the "restated" financial information. Farber (2005) finds that only firms that improve their corporate governance (e.g., by increasing the percentage of outside members on the board) experience improved stock market performance in the three-year postdetection period after controlling for changes in operating performance.

Auditors: Feroz et al. (1991) find that large auditors of the AAER firms are less likely to be censured by the SEC and suffer lighter penalties than small auditors. They suggest two explanations: large auditors are associated with less extreme cases and/or large auditors can afford more resources to negotiate with the SEC to lower penalties. Bonner, Palmrose, and Young (1998) document that auditors face litigation in 38 percent of AAER firms in their sample. The litigation risk for auditors is higher when the type of fraud occurs frequently across companies (i.e., common frauds) or when the fraud is caused by fictitious transactions.

\section{Conclusions based on studies of AAERs}

AAER firms would seem to be a powerful place for researchers to investigate incentives to manipulate earnings, but the evidence on the determinants of AAERs, and in particular on the role of governance in monitoring manipulations, is mixed and weak. One explanation is large type II errors. That is, firms that manage earnings for similar reasons are not identified by the SEC or firms manage earnings just within the boundaries of GAAP and avoid SEC selection. This problem inhibits proper matching. Other explanations include (i) small sample sizes that lack power, (ii) differences in sample composition over time; or (iii) endogeneity of contracting variables (e.g., Armstrong et al., 2009).

There is consistent and compelling evidence that investors react negatively to discovery of a misstatement, but it is less clear how to interpret this result. Keeping in mind that most samples of 
AAERs consist of overstatement of earnings, there are at least four explanations for a negative market reaction. First, investors could adjust their forecasts of future cash flow because the forecasts are based on historical earnings and the AAER reveals that historical earnings are lower than previously reported. Second, investors could reassess the multiplier (persistence parameter) they apply to the firm's fundamental earnings process (growth prospects) as well as change the discount rate. Third, investors could increase the discount rate if the AAER causes them to revise downward their expectations about the precision of the firm's accounting information. Finally, investors might revise their expectations of future cash flows because they expect the AAER to create additional costs that the firm would otherwise not have incurred, such as litigation or reputation loss.

The third potential source of negative returns - that investors change their assessment of the precision of the accounting measurement and reporting system - should be of particular interest to accountants, but it is difficult to disentangle this explanation from the others. The AAER reactions, however, have advantages for documenting revaluations due to changes in information risk. Many of the announcements are a surprise, the event window is fairly short, and the events are not clustered in calendar time. Karpoff et al. took a useful first step toward differentiating among the possible explanations for the negative stock market reactions, and we would encourage the use of this sample to identify the pricing of earnings quality.

\subsubsection{Restatements as a proxy for earnings quality}

There are four important differences between firms that restate earnings and the AAER firms. ${ }^{31}$ First, restatement samples are significantly larger than samples of AAER firms in any given year, which adds power to the empirical tests. Second, the restatement sample includes a wider

\footnotetext{
${ }^{31}$ See Dechow et al. (2009) for a detailed discussion of the comparison between different databases related to accounting misstatements.
} 
range of misstatements and they are primarily earnings restatements. Third, many restatements are caused by internal errors in applying accounting rules rather than intentional misreporting, and the proportion of such restatements in the database has increased in recent years (Plumlee and Yohn, 2008; Hennes, Leone, and Miller, 2008). Fourth, the selection problem in the restatement sample differs from that in the AAER sample, although it is not clear which is a bigger concern. Different selection criteria across the multiple sources that identify restatements might suggest that the selection problem simply creates noise in the analysis rather than bias, but knowing that the SEC selects the AAER cases may make it easier to control for the potential bias.

\section{$\underline{\text { Determinants of restatements }}$}

Managerial compensation: Burns and Kedia (2006) find that the sensitivity of the CEO's option portfolio to stock price is significantly positively associated with the likelihood of restatements, but the sensitivity of other components of CEO compensation, (i.e., equity, restricted stock, long-term incentive payouts, and salary plus bonus) is not related. Efendi et al. (2007) find that the likelihood of restatements increases when the CEO has considerable holdings of in-the-money stock options. ${ }^{32}$ However, Armstrong et al. (2009) do not find any significant association between CEO equity incentives and restatements after controlling for the compensation contracting environment.

Board of directors and auditors: Restatement firms tend to have CEOs who serve as chairman of the board or have founder status, and have board or audit committee directors with financial expertise (Agrawal and Chadha, 2005; Efendi et al., 2007). Independence of the board or audit committee is not a determinant of the likelihood of restatement (Agrawal and Chadha, (2005). Larcker, Richardson, and Tuna (2007) find that only two out of fourteen dimensions of governance (insider

\footnotetext{
${ }^{32}$ Efendi et al. (2007) also find that restatements are more likely when firms are constrained by an interest-coverage debt covenant and when they raise external financing. This paper is the only one in our database that examines debt contracting and equity market incentives as determinants of restatements.
} 
power such as percentage of insiders on board, and debt variables such as the ratio of book value of debt to the market value of equity) are associated with restatements.

Non-audit fees, which are presumed to affect auditor independence and hence may compromise auditor quality, are not associated with restatements on average (Agrawal and Chadha, 2005). Kinney, Palmrose, and Scholz (2004) also find no association between fees for financial information systems design and implementation or internal audit services and restatements, but they find some association between fees for unspecified non-audit services and restatements. When using a sample of U.K. firms, Ferguson, Seow, and Young (2004) find a positive association between nonaudit fees and restatements.

\section{Consequences of restatements}

Managers/Directors: Managers at restatement firms experience significantly higher turnover (Desai, Hogan and Wilkins, 2006; Hennes et al., 2008) and director turnover (Srinivasan, 2005) than control firms. Desai et al. (2006) also find that it is more difficult for these displaced managers to find subsequent employment than displaced managers of control firms. Srinivasan (2005) finds that director turnover rate is higher for more severe restatements and for audit committee directors. Firm value: Palmrose, Richardson, and Scholz (2004) document an average market-adjusted return of -9.2 percent over a two-day restatement announcement window; the average is -20 percent for restatements associated with fraud. ${ }^{33}$ Lev, Ryan, and $\mathrm{Wu}(2008)$ document that the restatements that

\footnotetext{
${ }^{33}$ Desai, Krishnamurthy, and Venkataraman (2006) find that short sellers accumulate positions in restatement firms before restatement announcements and unwind these positions after stock prices decline due to the restatement. Their finding suggests that short sellers are able to identify firms that will likely restate in advance of the restatement announcement. It does not, however, explain their assumptions regarding market efficiency. One possibility is that the short sellers believe the stock is overpriced due to the valuation implications of the misstated earnings, they expect the restatement to reveal the mispricing and the price to correct. Another possibility is that the short-sellers anticipate that markets will react negatively to restatements on average, regardless of the implications of the restatement for valuation. More research is needed to interpret the implications of this evidence for earnings quality.
} 
significantly change the historical pattern of earnings (e.g., shortening histories of earnings growth) have more negative stock market consequences. Gleason, Jenkins, and Johnson (2008) find that restatement announcements cause stock price declines for non-restatement firms in the same industry. Hribar and Jenkins (2004) document a significant increase in a firm's cost of equity capital, measured based on the residual income model, in the month following a restatement. Kravet and Shevlin (2009) document a significant increase in the pricing of information risk after restatement announcements.

Litigation: Palmrose and Scholz (2004) find that 38 percent of restatements are associated with litigation, including litigation actions against the company, officers, directors, and auditors. They document that the likelihood of litigation increases with the impact of restatements on earnings (magnitude) and the fraudulent nature of restatements. Restatements of core earnings (i.e., recurring earnings from primary operations) and restatements that involve a greater number of accounts tend to result in a higher likelihood of lawsuits and larger payments by defendants. Lev et al. (2008) find that restatements that curtail histories of earnings growth or positive earnings have a higher likelihood of class action lawsuits than other restatements.

\section{Conclusions based on studies of restatements}

Restatements measure both intentional and unintentional errors; they are not a good proxy for intentional earnings management. In support of this conclusion, the compensation variables, that would provide incentives for intentional earnings management, and the monitors that would constrain such behavior, are not consistently associated with restatements. Support for this conclusion also comes from a related study by Kinney and McDaniel (1989), which finds that firms that correct previously announced quarterly earnings are smaller, are less profitable, have higher 
debt, are more slowly growing, and face more serious uncertainties. They interpret their evidence as suggesting that accounting errors are the outcome of a weak accounting system (i.e., weak internal control procedures) rather than opportunistic earnings management. The mixed results about the determinants of restatements, however, could be due to selection bias associated with detection of the accounting irregularity and the firm's decision to report it.

Restatements reflect errors that cause investors to revise their beliefs about information precision associated with the firm's earnings (e.g., Hribar and Jenkins, 2004; Kravet and Shevlin, 2009). We found no studies that provide similar evidence about the effects of AAERs on investor beliefs.

The restatement samples might be useful to examine the complete path from a predicted determinant (i.e., weak internal control procedures) to a particular type of earnings quality and then to a predicted consequence because of the variation in the types of errors reflected in the restatements. For example, one could address whether the market consequences of a misstatement are different if an internal control weakness rather than an agency problem causes it.

\subsubsection{Internal control procedures quality as a proxy for earnings quality ${ }^{34}$}

Under Section 302 of the Sarbanes Oxley Act of 2002 (SOX), which became effective on August 29, 2002, management is required to certify in its 10-Qs and 10-Ks their conclusions about the effectiveness of the firms' internal control procedures. Section 404 of SOX, which became effective on November 15, 2004 for accelerated filers, requires companies to include management's assessment of the effectiveness of the internal control structure and procedures in its annual report;

\footnotetext{
${ }^{34}$ Studies that examine whether internal control procedures are a determinant of another earnings quality proxy (e.g., discretionary accruals or persistence) are discussed in Section 5.2.3.
} 
the firm's public accountants must attest to this assessment. ${ }^{35}$ Prior to these reports, companies (with the exception of the banking industry) were required to disclose significant internal control deficiencies in 8-Ks only when disclosing a change in auditors (Ge and McVay, 2005; Krishnan, 2005; Altamuro and Beatty, 2009). Earlier research consisted primarily of case studies or analysis of survey data. For example, Willingham and Wright (1985) survey audit firm partners and do not find an association between auditors' assessment of internal control effectiveness and financial statement errors detected by auditors. ${ }^{36}$ A couple of studies have shown a positive association between internal control quality and various earnings quality measures such as discretionary accruals and earnings persistence (e.g., Doyle et al., 2007b; Ashbaugh-Skaife et al., 2008). These studies provide some justification for using the internal control deficiencies reported under SOX as an indication of earnings quality.

Determinants of internal control procedures: Krishnan (2005) finds that independent audit committees and audit committees with financial expertise are significantly less likely to be associated with the incidence of internal control problems. Ashbaugh-Skaife et al. (2007) and Doyle et al. (2007a) find that firms with higher control risk associated with organizational complexity and significant organizational changes are more likely to have internal control deficiencies. The weakness firms also appear to be more constrained in their resources to invest in internal control systems (i.e., firm size, financial strength).

Consequences of internal control procedures: Hammersley, Myers, and Shakespeare (2008) and Beneish, Billings, and Hodder (2008) find that disclosures of internal control weaknesses under

\footnotetext{
${ }^{35}$ Internal control disclosures under Section 404 are available in machine readable form from Audit Analytics. The early papers collected the reports from Compliance Week.

${ }^{36}$ Kinney (2000) also notes that lack of access to data was a barrier to research on internal control procedures. Some very early work analyzed the design and tests of internal control system (e.g., Cushing, 1974; Kinney, 1975).
} 
Section 302 are associated with negative stock price reactions. In addition, Beneish et al. (2008) find that Section 302 disclosures are associated with a decrease in analyst forecast revisions and an increase in cost of equity capital. However, disclosures of internal control weaknesses under Section 404 are not associated with a negative stock price reaction, a decrease in analyst forecast revisions, or an increase in cost of equity capital (Ogneva, Subramanyam and Raghunandan, 2007; Beneish et al. 2008). Only one study by Ashbaugh-Skaife, Collins, Kinney, and LaFond (2009) documents a significant increase of the cost of equity capital following Section 404 disclosures, arguing that Ogneva et al.'s findings suffer from look-ahead bias in the classification of internal control quality. ${ }^{37}$

\section{Conclusions based on studies of internal control procedures}

The determinants and consequences of internal control deficiencies disclosed under SOX Section 302 exhibit predictable patterns that suggest that such deficiencies measure the propensity for misstatements. The use of this variable to proxy for variation in EQ, however, is subject to a concern that disclosures of material weaknesses are correlated with manager and auditor incentives to discover and disclose internal control weaknesses (Ashbaugh-Skaife et al., 2007; Hogan and Wilkins, 2008).

The mixed findings on the consequences of internal control disclosures based on Section 404 reports cast doubt on whether the Section 404 disclosures are a source of information about financial reporting quality to investors. There are several explanations for the difference in the consequences of Section 302 and Section 404 reports. First, the threshold for Section 404 material weaknesses may be lower than that for Section 302. Second, the Section 404 sample currently is limited to accelerated filers that have a richer information environment. Third, there is ambiguity regarding

\footnotetext{
${ }^{37}$ A related study by Chang, Chen, Liao, and Mishra (2006) finds that firms that have CEOs and CFOs certify their financial statements under SOX experience a decline in bid-ask spreads.
} 
whether disclosure of material weaknesses is mandatory under Section 302, and as a result, less severe material weaknesses are not disclosed (Doyle et al., 2007b). Fourth, the Section 404 disclosures are made in the annual report, while the Section 302 disclosures can be made on dates without confounding announcements in the event window.

There is a wide range of different types of internal control weaknesses (e.g., weaknesses resulting in restatements versus not, weaknesses resulting in accounting errors versus earnings management, weaknesses driven by various determinants such as organizational changes). Thus firms with internal control weakness disclosures are also a sample that researchers could use to examine the complete path from a determinant to "earnings quality" to a consequence.

\section{Cross country studies}

This section discusses the papers in our database that examine determinants and consequences of cross-country variation in earnings quality. Section 4.1 discusses studies on determinants of country-level earnings informativeness to equity markets, using proxies such as ERCs. Section 4.2 discusses studies that examine determinants of country-level earnings management as a specific element of earnings quality. Section 4.3 discusses studies on consequences of country-level earnings quality.

\subsection{Earnings informativeness proxies for earnings quality}

Four papers in our database examine variations in country-level value-relevance measures. Alford, Jones, Leftwich, and Zmijewski (1993) document cross-country variation in long-window ERCs and earnings-based hedge portfolio returns for 17 countries. They do not test hypotheses about predictable differences in ERCs across countries. Rather, they provide the reader with a 
summary of important institutional cross-country differences (e.g., interim reporting frequency) to help interpret the results ex post. Ali and Hwang (2000) compute the two measures of earnings informativeness (ERC and earnings-based hedge portfolio returns) from Alford et al. (1993), plus two additional measure - value relevance of accruals and combined value relevance of earnings and book value of equity - across partitions of 16 countries that they predict to exhibit variation in earnings informativeness ex ante. They investigate six country-level institutional factors, but the results they emphasize are that earnings informativeness is lower in countries where financial systems are bank-oriented rather than market-oriented and where the accounting rules are less likely to be tilted toward preferences of equity markets because of the standard-setting process. Hung (2000) uses earnings-based hedge portfolio returns to measure country-level earnings informativeness. She finds across 21 countries that more extensive use of accrual accounting rather than cash accounting is associated with lower earnings informativeness only in countries with weak shareholder protection. ${ }^{38}$ DeFond, Hung, and Trezevant (2007), for 26 countries, document a positive association between average country-level earnings quality, measured based on a score developed in Leuz et al. (2003), and abnormal return variance during a two day annual earnings announcement window. They interpret this finding as evidence that a high Leuz et al. quality score implies greater earnings credibility and hence improves earnings informativeness. They also find that abnormal return variance around earnings announcements is higher in countries with better enforced insider trading laws, strong investor protection, and less frequent interim reporting.

Researchers commonly examine the variation in earnings quality between code law countries (i.e., those with a "stakeholder" corporate governance model) and common law countries (i.e., those

\footnotetext{
${ }^{38}$ Hung (2000) develops her own country-specific accrual accounting intensity index based on the accounting treatment of: (1) Goodwill, (2) Equity method investments, (3) Deprecation, (4) Purchased intangibles, (5) Internally developed intangibles, (6) Research and development costs, (7) Interest capitalization, (8) Lease capitalization, (9) Percentage of completion allowances, (10) Pensions, and (11) Post retirement benefits.
} 
with "shareholder" corporate governance model) countries. Ball, Kothari, and Robin (2000) find that earnings are less timely in recognizing economic losses in code law countries than in common law countries, consistent with their prediction that institutions and practices in code law countries have developed over time such that the demand for decision-useful information is lower. ${ }^{39}$ Ball, Robin, and Wu (2003) examine a sample of firms in East Asian countries. They assert that the accounting standards in these countries are of high quality (i.e., as they are more similar to U.K. or U.S. GAAP or IAS than they are to standards in code law countries), but that these countries have institutions with incentive structures more similar to those that evolve under the code law. They show that earnings quality (measured by timely loss recognition) is lower in these countries and thus conclude that the institutional and governance environment of code-law countries diminishes managers' and auditors' incentives to provide high quality accounting information. Guenther and Young (2000) similarly suggest that earnings quality is demand driven and institutional factors such as legal system and tax conformity affect earnings quality. They operationalize earnings quality as the association between cross-sectional average return on assets in a country and its real economic growth measured by the percentage change in a country's real GDP. They document that this association is high in the U.K., U.S. and Japan, and low in France and Germany.

\subsection{Earnings management as an element of earnings quality}

A common hypothesis in cross-country studies is that variation in investor protection affects the aggregate level of observed earnings management in a country. Leuz, Nanda, and Wysocki (2003), who measure earnings management by accruals-based measures, smoothness, and small loss avoidance, find less earnings management for countries with developed stock markets, dispersed

\footnotetext{
${ }^{39}$ Ball et al. (2000) also find that U.K. earnings are less timely than U.S. earnings in incorporating economic losses. Pope and Walker (1999), however, suggest that this result is sensitive to the consideration of extraordinary items. They find that earnings after extraordinary items in the U.K. are more timely than U.S. earnings.
} 
ownership, strong investor rights, and strong legal enforcement. The Leuz et al. (2003) artificial smoothness measures are commonly used in cross-country studies as a proxy for earnings management. The first proxy, measured at the country-level, is the median of the firm-level standard deviation of operating earnings divided by the firm-level standard deviation of cash flow from operations. The second proxy is the contemporaneous correlation between changes in accounting accruals and changes in operating cash flows. Both measures emphasize that smoothness represents earnings management when it is measured relative to inherent or fundamental smoothness of the firm's operations. Operating cash flow smoothness is used to control for inherent smoothness.

Lang, Raedy, and Wilson (2006) compare the extent of earnings management between a sample of non-U.S. firms that are cross-listed in the U.S. and a sample of U.S. firms. They document that the cross-listed non-U.S. firms exhibit more evidence of smoothness, a greater tendency to report small profits, and less timely recognition of losses, and lower ERCs than U.S. firms and that this difference is greater for firms from countries with poor investor protection. ${ }^{40}$ Lang, Raedy, and Wilson (2006) do not use the Leuz et al. (2003) measure of artificial smoothness; they develop their own measure of artificial smoothness that similarly attempts to control for smoothness of the fundamental earnings process. They measure smoothness as the volatility of earnings scaled by total assets, where "volatility" is the variance of the residuals from a regression of annual scaled changes in net income on control variables for fundamental firm characteristics. Their analysis also uses a matched sample design with matching based on past sales growth and industry, which is an effort to control for fundamental variability.

Three later studies extend Leuz et al. by providing evidence on how the interactions between different institutional factors influence the extent of earnings management. Haw et al. (2004) document that earnings management (measured by the unsigned magnitude of discretionary

\footnotetext{
${ }^{40}$ They use ERCs as one of their earnings management proxies.
} 
accruals) that stems from the conflicts between controlling shareholders and minority shareholders is lower in countries with high protection of minority shareholders' rights and strong legal enforcement. Francis and Wang (2008) find that earnings quality (measured by the magnitude of discretionary accruals, the likelihood of reporting a loss, and timely loss recognition) is positively related to country-level investor protection, but only for firms with Big-four auditors. They suggest that investor protection affects earnings quality through the incentives of Big-four auditors (i.e., litigation risk and reputation risk). Finally, Burgstahler, Hail, and Leuz (2006) document interactions between the effects of institutions on earnings management and the effects provided by public equity markets interact. Using a sample of private and public firms from 13 European Union countries, they find that private companies manage earnings more, consistent with less pressure for earnings quality. Stronger legal institutions curb earnings management. The Burgstahler et al. (2006) earnings management measures are similar to those used in Leuz et al. (2003).

\subsection{Consequences of country-level earnings quality}

The three papers in our database that examine consequences of earnings quality at the country level focus on the earnings management element of earnings quality. Bhattacharya, Daouk, and Welker (2003) find that high country-level earnings quality measured by earnings aggressiveness (i.e., accruals), loss avoidance, and earnings smoothness (measured following Leuz et al., 2003), are associated with higher country-level of cost of equity capital and lower trading volume. Their hypothesis assumes that these features of earnings are associated with greater opacity. Pincus, Rajgopal, and Venkatachalam (2007) find that the accrual anomaly, while a global phenomenon, is concentrated in four countries, Australia, Canada, the United Kingdom, and the U.S., all of which are common law countries. The accrual anomaly is positively associated with the 
Hung (2001) index of accrual accounting intensity and negatively associated with share ownership concentration. Somewhat weaker evidence suggests that the occurrence of the accrual anomaly is negatively related to investor rights. Pincus et al. (2007) interpret the results, taken together, as suggestive that earnings management is associated with the accrual anomaly. Biddle and Hilary (2006) document that smoothness using the Leuz et al. (2003) measure is associated with lower investment efficiency as measured by investment cash flow sensitivity metrics (see also Verdi, 2006).

\subsection{Summary}

The cross-country studies allow inferences about the impact of certain control mechanisms that are not possible using a sample of U.S. firms because of a lack of variation in the control mechanism within the U.S. This branch of studies generally concludes that earnings quality (including earnings management) is influenced by investor protection, bank versus market-oriented economy, code versus common law tradition, accounting standards, and managers' and auditors' incentives. There is not much conflicting evidence. The cross-country variation is generally asserted to proxy for very broad theoretical constructs such as differences in the demand for information or the ability of accounting rules to reflect fundamental value. The cross-country studies are not designed to provide inferences about specific internal control mechanisms.

The cross-country studies commonly use return-based earnings quality measures such as ERCs and timely loss recognition. There are many differences across countries that can affect these returns-based metrics other than the institutional factors envisioned as determinants by the researchers. The studies clearly recognize the potential for alternative explanations for the results, and most studies either use empirical methods to control for un-modeled sources of cross-country variation or model expected sources of variation such as industry concentration. However, even 
observable variables such as natural resource endowments and the level of economic development are not frequently modeled, and less consideration is given to unobservable cultural differences such as trust in governance mechanisms (Zingales, Sapienza, and Guiso, 2008). Somewhat surprisingly, little effort is devoted to controlling for variation in the return component of the returns-based proxies for earnings quality, despite evidence of variation in the relation between economic and market development (Frost, Gordon, and Hayes, 2006).

\section{The determinants of earnings quality}

In this section, we juxtapose the studies according to the determinant of earnings quality that is examined (see Table 1). There are six categories of determinants: 1) Firm characteristics, 2) Financial reporting practices, 3) Governance and controls, 4) Auditors, 5) Equity market incentives, and 6) External factors.

\subsection{Firm characteristics as determinants of earnings quality}

Several studies use multiple proxies for firm fundamentals, including simply industry membership, and provide broad evidence that firm operating characteristics are associated with the various proxies for earnings quality. Hagerman and Zmijewski (1979) provide preliminary evidence on the association between size, risk, capital intensity, and industry concentration and a firm's choice of accounting principles. LIFO adoption, in particular, is a common choice to examine (e.g., Jung, 1989; Lindahl, 1989). Lev (1983) relates (theoretically and empirically) multiple proxies for the economic fundamentals of a firm's operating environment to properties of its earnings (i.e., persistence and volatility). Dechow (1994) relates multiple characteristics of a firm's operating environment to the ability of accruals to capture underlying firm performance, where this ability is 
measured by stock returns. Four firm characteristics deserve a separate discussion: 1) Performance and losses; 2) Growth and investment; 3) Debt; and 4) Size.

\subsubsection{Firm performance}

The most commonly studied firm characteristic that affects EQ proxies is performance. The studies hypothesize that weak financial performance provides incentives for earnings management. ${ }^{41}$ Petroni (1992) documents downwardly biased discretionary reserves for claim losses for financially weak P\&C insurers. DeFond and Park (1997) document income smoothing in which firms manage earnings upward (downward) when unmanaged performance is poor (good) and when expected performance is strong (weak). ${ }^{42}$ Balsam, Haw, and Lilien (1995) suggest that firms use discretion to time the adoption of income increasing accounting methods when the firm's change in ROA is lowest. Keating and Zimmerman (1999) suggest that poorly performing firms use the discretion allowed in accounting standard adoption to their advantage. Financially weak firms also disclose more internal control weaknesses (Doyle, Ge, and McVay, 2007a) and are more likely to correct previously reported earnings, which is interpreted as ex post evidence of earnings management (Kinney and McDaniel, 1989).

Francis, Hanna, and Vincent (1996) find no evidence that write-offs, after controlling for the likelihood that assets are impaired, are associated with poor performance. The only study in our database that finds negative evidence is done by DeAngelo, DeAngelo, and Skinner (1994). For a sample of firms with persistent losses, they find that the accruals reflect the underlying economics

\footnotetext{
${ }^{41} \mathrm{Lee}, \mathrm{Li}$, and Yue (2006) create a stylized model in which firms with higher performance overstate earnings more. The model predictions result from assumptions about the cost of earnings management and about how earnings performance and earnings growth affect the proportion of true economic earnings in total reported earnings. Their empirical evidence is mixed.

${ }^{42}$ Elgers, Pfeiffer, and Porter (2003), however, suggest that the results in DeFond and Park (1997) are sensitive to the method used to "back out" abnormal accruals.
} 
and do not appear to be made to boost earnings. They acknowledge, however, that their sample is a unique sample of troubled firms, not just firms with weak performance.

\subsubsection{Firm growth and investment}

There is some debate as discussed in Section 3 over whether growth, the unobservable construct, or accruals as a measure of growth, affects earnings persistence. The bottom line is that high growth firms have less sustainable earnings (Nissim and Penman, 2000). This finding is not surprising. Earnings summarize performance of the firm's earnings process during the reporting period. If the fundamental process changes (i.e., grows), so will earnings, and properties of earnings like persistence and smoothness will be adversely affected. Studies like Penman and Zhang (2002) provide more contextual evidence about how the accounting system affects the degree to which growth matters. In addition to the impact of growth on the fundamental element of earnings properties, growth also is associated with greater measurement error and more manipulation opportunities (Richardson et al., 2005).

We are not aware of papers that specifically analyze the role of growth as a determinant of timely loss recognition or benchmarking. Researchers have, however, examined growth as a determinant of the external indicators of quality. AAER firms have high market to book ratios and high accruals during manipulation years (see Dechow et al., 2009). Doyle et al., (2007a) and Ashbaugh-Skaife et al. (2007) find that young growth firms disclose more internal control weaknesses. Lee et al. (2006), however, do not find evidence supporting the association between restated amounts and growth. 


\subsubsection{Firm debt $t^{43}$}

Watts and Zimmerman (1986) suggest the debt covenant hypothesis: Firms closer to violating debt covenants will make income-increasing accounting choices to avoid covenant violations. Early research used debt-equity ratios or other indirect proxies for the existence of debt covenants (e.g., Bowen, Noreen, and Lacey, 1981; Zmijewski and Hagerman, 1981; Daley and Vigeland, 1983; Johnson and Ramanan, 1988). ${ }^{44}$ These papers provide consistent cross-sectional evidence that more highly-levered firms choose income-increasing accounting methods. ${ }^{45}$ In addition, Balsam, Haw, and Lilien (1995) suggest that firms time the adoption of income-increasing accounting methods when leverage is highest. LaBelle (1990) finds that greater leverage and lower interest coverage are associated with accounting method changes in Canada. Specifically in the oil and gas industry, Johnson and Ramanan (1988) and Malmquist (1990) identify operating characteristics associated with the choice of successful efforts vs. full cost accounting, and find that leverage-related variables are incrementally important determinants of the choice.

Three papers examine choices other than accounting methods. Bartov (1993) finds that firms time asset sales to use the gains to reduce earnings volatility and to avoid debt covenant violation. The smoothing and debt covenant explanations for the real earnings management are incremental to each other. Kinney and McDaniel (1989) find that more highly levered firms are more likely to correct previously reported earnings, which implies that they had misreported, and Efendi et al. (2007) find that firms with lower interest coverage ratios (higher ratio of interest to income) are more likely to restate. In addition, Dechow et al. (1996) find higher leverage ratios for manipulation

\footnotetext{
${ }^{43}$ We include debt as a firm characteristic, although debt may also be viewed in its role as a monitor, much like the monitors discussed in Section 3.3.

${ }^{44}$ Daley and Vigeland (1983) also find that the firms that choose income increasing voluntary accounting methods have higher ratios of dividends to retained earnings, which is another proxy for the extent to which debt covenants are likely to be binding.

${ }^{45}$ See Christie (1990) for a rigorous statistical meta-analysis of existing studies of theories of accounting method choice. He finds that size and leverage are consistently related to accounting choice.
} 
firms identified in the AAERs than control firms, but Beneish (1999) does not find this relation for his sample of manipulation firms.

The aforementioned papers interpret the correlation between leverage and earnings management as evidence that debt covenants provide incentives for firms to manage earnings, but they do not examine debt covenants specifically. ${ }^{46}$ Subsequent research tested the debt covenant hypothesis using data on specific debt covenants. Sweeney (1994) provides evidence that firms make income-increasing accounting choices as they move closer to violating debt covenants. DeFond and Jiambalvo (1994) find that working capital accruals and a measure of abnormal accruals are both higher in the year prior to the year that a firm reports a covenant violation in its annual report. In the year of violation, the accruals are high after controlling for management changes and audit qualifications. Using a comprehensive sample of detailed debt covenants, Dichev and Skinner (2002) show that an unusually large (small) number of loan quarters have financial measures at or just above (below) covenant thresholds, consistent with the debt covenant hypothesis. In contrast, DeAngelo et al. (1994), discussed previously, find relatively little difference between accruals for firms with and without binding covenants.

While the conclusion is that firms closer to covenants, measured directly or indirectly, are more likely to manage earnings, the implications of the conclusion for our assessment of earnings quality are ambiguous. On the one hand, the fact that earnings are managed opportunistically generally implies that the earnings are less reliable. On the other hand, the mechanisms used to manage earnings under the debt covenant hypothesis are typically accounting method choices that

\footnotetext{
${ }^{46}$ Zimmer (1986) shows that accounting choice is related to leverage even in the absence of debt covenants using a sample of Australian firms. Specifically, he finds that higher leverage is associated with interest capitalization (incomeincreasing), but the significance is eliminated when he controls for whether firms use project-specific financing. He interprets this as evidence that leverage does not capture covenants but rather that it is correlated with type of financing used by companies.
} 
are fairly transparent. ${ }^{47}$ If the earnings management is transparent to decision-makers, either because the accounting choices are obvious (e.g., accounting method changes) or because the decisionmakers rationally infer that income-increasing actions are taken to avoid covenant violation, then the earnings quality - its decision usefulness - is not impaired from the perspective of the decisionmaker who detects it. Evidence in Aboody, Barth, and Kasznik (1999) suggests that equity markets may rationally infer earnings management using cues about the firm's debt market incentives. They show that the relation between UK asset revaluations and equity market responses is weaker for highly levered firms, which is interpreted as evidence that investors' perceptions about whether the revaluation is managed increases with leverage.

Leverage also is predicted to be associated with returns-based proxies for earnings quality, such as $E R C$ s, when equity is viewed as a call option on the value of the firm (Dhaliwal, Lee, and Fargher, 1991; Core and Schrand, 1999). Plummer and Tse (1999) also distinguish the information needs of equityholders and debtholders as a function of default risk. They find that $E R C$ s (contemporaneous returns and unexpected earnings) decrease as default risk increases for equity returns, but the opposite result holds for bond returns.

\subsubsection{Firm size}

Early papers investigated the association between firm size and accounting choice motivated by the political visibility hypothesis that predicts that large firms will make income-decreasing accounting method choices in response to greater political/regulatory scrutiny (Jensen and Meckling, 1976; Watts and Zimmerman, 1986). The evidence is mixed. Hagerman and Zmijewski (1979) find that size is positively correlated with the choice of two income-deflating methods (depreciation and investment tax credit accounting), but not with two others (inventory and amortization for pension

\footnotetext{
${ }^{47}$ The evidence in Bartov (1993) on real earnings management is an exception.
} 
past service costs). Zmijewski and Hagerman (1981) document that larger firms are more likely to choose a set of accounting policies that in the aggregate are income-decreasing, suggesting that while size does not explain individual choice very well, it explains the firm's overall strategy. Bowen, Noreen, and Lacey (1981) find support for the political visibility hypothesis in the oil industry (i.e., large firms avoid using the interest costs capitalization method), but contradictory results in other industries. Moreover, Zimmer (1986) finds that larger firms capitalize interest in Australia, which is inconsistent with the political cost argument. Moses (1987) finds that firm size and market share (marginally) are associated with accounting method changes specifically to smooth (as opposed to decrease) earnings.

Overall, in some specific settings, size is likely to be an important indicator of the type of visibility that increases expected political costs. However, in other settings, the political costs may be most severe for firms in a targeted industry (Han and Wang, 1998) or for young firms (Beneish, 1999). While there is fairly compelling evidence that political pressure can create incentives for earnings management (Section 5.6), and size is often used as a proxy for pressure, the leap to an association between firm size and any dimension of EQ would be inappropriate. Firm size could proxy for factors other than political visibility such as information environment, capital market pressure, or financial resources. For example, several studies hypothesize fixed costs associated with maintaining adequate internal control procedures, and hence predict a positive relation between firm size and internal control quality. ${ }^{48}$ These studies show that small firms are more likely to have internal control deficiencies and are more likely to correct previously reported earnings (Kinney and McDaniel, 1989; Ge and McVay, 2005; Doyle, et al., 2007a; Ashbaugh-Skaife et al., 2007).

\footnotetext{
${ }^{48}$ Ball and Foster (1982) also make this point. One argument they make for not using size as a proxy for political costs is that the cost of compliance may be fixed, such that small firms that bear the greatest cost.
} 


\subsubsection{Summary of firm characteristics as a determinant of earnings quality}

Our review yields the following insights. First, fundamental firm characteristics are associated with accounting method choice. Any studies that predict accounting choices as an indication of earnings quality must control for these fundamental differences before inferring opportunism. Second, the evidence that weak performance provides incentives for earnings management is fairly well-established. The extent to which opportunities constrain the behavior, however, is a less actively researched topic (see DeAngelo et al., 1994). Third, while the evidence suggests a relation between size and earnings management, it is impossible to generalize any sort of implications for a relation between size and earnings quality on any dimension, given that firm size could proxy for various underlying constructs (e.g., political visibility, information environment etc.).

Finally, equity investors appear to unwind firm's incentives arising from debt contracts to manage earnings (Aboody et al., 1999). The evidence, however, on investors' ability to unwind incentives and to incorporate an expectation of rational earnings management into their pricing is limited, even for debt-related incentives, which are among the strongest documented incentives for earnings management and potentially the most transparent to investors. Other than Aboody et al. (1999) and Shivakumar (2000), we do not have studies in our database that condition equity market reactions to earnings on investors' ability to unwind earnings management that represents a valuemaximizing activity that is the outcome of efficient contracting. 


\subsection{Financial reporting practices as determinants of earnings quality}

\subsubsection{Accounting methods}

We use the term "methods" broadly to include principles (e.g., full cost vs. successful efforts), estimates that are associated with accounting principles (e.g., straight-line vs. accelerated depreciation), or estimates (e.g., pension accounting assumptions).

Two early papers examined the relation between methods and earnings smoothness. Barefield and Comiskey (1971) find that straight-line depreciation relative to accelerated depreciation creates a smoother earnings stream. Beidleman (1973) concludes that firms' pension and retirement expense and R\&D expense choices normalize (smooth) earnings, however their choices related to remitted earnings from unconsolidated subsidiaries, SG\&A expenses, and income effects from plant retirements do not. The studies acknowledge that accounting methods are endogenous, but the empirical analyses do not address the issue. Gonedes (1969) examined the association between method choice ${ }^{49}$ and the cost of equity capital as a measure of the ".... degree of risk (uncertainty) perceived by decision-makers...", which he proposed as a proxy for the informativeness of earnings.

Two later papers generate simulated data to compare the mechanical earnings-related properties across accounting methods. Dharan (1987) generates earnings streams using the installment method for revenue recognition and using the sales method, which includes the hypothetical manager's estimate (with error) of future cash collections. He finds that the sales method generally produces lower earnings volatility and cash flow forecast errors. The relative benefits of the accrual model are larger when sales are easier to predict, and the benefits decline as the standard deviation of the residuals from a deterministic model of sales increase. Healy, Myers, and Howe (2002) find that application of the (pseudo) successful efforts method to R\&D

\footnotetext{
${ }^{49}$ The three "method" choices examined were amortization of the investment credit, interperiod tax allocation, and the presentation of funds flow statements in annual reports.
} 
expenditures in the pharmaceutical industry provides earnings streams that are more closely associated with fundamental values than immediate expensing or full capitalization. Moses (1987) attempts a direct assessment of the impact of methods on earnings quality proxies in a large sample. He suggests that firms change accounting methods to achieve smoother earnings. His analysis includes all methods changes; they are primarily associated with inventory and pension accounting. Income-increasing changes are more likely than income-deceasing changes, and the propensity for changing is positively associated with firm size, existence of a bonus plan, and incentives for meeting earnings targets.

Five studies examine choices of specific accounting methods. Loudder and Behn (1995) and Altamuro, Beatty and Weber (2005) suggest that R\&D capitalization and pre-SAB 101 revenue recognition practices, both of which are generally income increasing, result in more informative earnings as measured by ERCs. Lev and Sougiannis (1996) use a clever research approach to understand the implications of method choice for earnings quality. They use real firm data to "simulate" earnings outcomes if R\&D were (pseudo) capitalized and show that the capitalized amounts are associated with information used by equity markets to value high-R\&D firms (i.e., value-relevance). Aboody, Barth, and Kasznik (1999) find that asset revaluations in the UK are positively related to future operating income and cash flows and investors respond positively to revaluations. Sivakumar and Waymire (2003) exploit a change in fixed asset accounting rules in the early 1900s and find evidence of increased asymmetric timeliness using the Basu metric (conservatism), but no evidence of smoothing, where smoothing techniques could incorporate artificial accounting accruals or real cost management. 


\subsubsection{Other financial reporting practices}

McVay (2006) suggests that firms use discretion over income statement classification within a period to shift expenses into categories that would be perceived as less persistent. Several papers indicate that firms time income recognition across periods within a fiscal year. Kerstein and Rai (2007) and Jacob and Jorgensen (2007) document that the kink in earnings is strongest for fiscal years for which the incentives for earnings management are greatest relative to annual periods ending at the first three fiscal quarters. Brown and Pinello (2007) suggest that firms use more earnings management to avoid negative earnings surprises at interim quarters than at fiscal years because the financial auditing process increases opportunities for earnings management in interim periods.

\subsubsection{Principles based vs. rules based methods and earnings quality}

A potential advantage of principles-based standards is that removing alternative accounting treatments for a transaction in favor of single principle that reflects underlying performance would result in a more informative earnings number because it reduces earnings management. Managers cannot opportunistically apply an inappropriate method or estimate but claim that they were following GAAP as a defense. A potential disadvantage is that principles-based standards constrain a manager's ability to provide relevant information $?^{50}$

Two studies conclude that principles-based standards likely will not diminish opportunistic earnings management. Cuccia, Hackenbrack, and Nelson (1995) conduct a field experiment that asked "managers" to make tax reporting decisions. Nelson, Elliott, and Tarpley (2002) conduct a survey of auditors that not only assessed the likelihood that a manager would manage earnings but also the likelihood that an auditor would adjust for discretion. However, Barth, Landsman, and Lang

\footnotetext{
${ }^{50}$ See Barth, Landsman, and Lang (2008) for a thorough discussion of the debate.
} 
(2008) hypothesize that International Accounting Standards (IAS) increases earnings quality in part because the standards are principles-based, and they find evidence that use of (IAS) is associated with less earnings management, more timely loss recognition, and greater value relevance. ${ }^{51}$ They are careful to acknowledge that these ex post characteristics of earnings also are a function of differences in institutions, which affect the demand for information, enforcement, and fundamental firm characteristics of the IAS adopters. While they attempt to control for these differences, the results are still subject to their caveat.

\subsubsection{Summary}

There is relatively sparse evidence on the ability of accounting methods to capture firm fundamentals, either across different methods or across different fundamentals. We were at first surprised by the small number of papers in this category, but research design issues seem to be the explanation. If firms follow different methods, it is because they have chosen to, which creates an endogeneity problem. When accounting methods are mandatory (i.e., exogenous), there is no crosssectional variation to examine. An alternative is to study firms in different mandatory reporting regimes (i.e., different countries or different time periods), which creates an omitted correlated variables problem. After the mid-1970s, the limited set of papers we found use either simulations or examine specific methods, which improves internal validity but at the expense of generalizability. In summary, the results on the implications of accounting methods for earnings quality are method specific.

\footnotetext{
${ }^{51}$ The degree of earnings management is measured based on earnings variability, earnings variability relative to cash flow variability (Leuz, Nanda, and Wysocki, 2003), the correlation between accruals and cash flows, and meeting earnings targets. Timely loss recognition is measured by the frequency of large losses, and value relevance is measured as the contemporaneous association between stock prices and earnings and equity book value.
} 
The notion that accounting method choice is opportunistically used for earnings management purposes, thus reducing the overall quality of earnings, does not get much support. It is not the case that cash flow methods dominate accrual-based methods that involve estimation (Dharan, 1987) or that more "aggressive" income recognition methods are viewed as opportunistic (Loudder and Behn, 1995; Altamuro et al., 2005). Moreover, investors appear to efficiently adjust their valuation decisions to reflect information that is not reported (Lev and Sougiannis, 1996). Investors also appear to adjust their valuations when they anticipate earnings management (Aboody et al., 1999).

\subsection{Governance and controls as determinants of earnings quality}

Using the terminology of Jensen and Meckling (1976), internal controls include monitoring mechanisms, optimally chosen by the principal in the principal-agent relationship, as well as bonding mechanisms, optimally chosen by the agent at some cost. The mechanisms we discuss in this section include: 1) The Board of directors (BOD); 2) Internal control procedures, ${ }^{52} 3$ ) Managerial share ownership; 4) Managerial compensation; and 5) Managerial change. The studies associated with the BOD and internal control procedures view internal controls as monitors of the financial reporting system that constrain a manager's opportunity or ability to manage earnings, while the studies of managerial share ownership and managerial compensation are predicted to affect earnings quality because they provide incentives for earnings management. ${ }^{53}$ In both cases, internal controls affect earnings management, and discretionary accruals and accounting misstatements are popular measures of earnings quality.

\footnotetext{
${ }^{52}$ We emphasize the distinction between "internal controls" as the term is used by Jensen and Meckling (1976), which includes what researchers commonly refer to as corporate governance mechanisms, from internal control "procedures." We will use the term internal control procedures for the tasks performed to monitor the financial reporting system.

${ }^{53}$ See Ng and Steockenius (1979), Lambert (1984), Verrecchia (1986), Dye (1988) and Liang (2004).
} 


\subsubsection{The Board of directors and earnings quality}

Several papers document that more independent boards, measured by a greater proportion of outsiders for example, and higher audit committee quality, measured by independence and meeting frequency for example, are associated with less earnings management, measured by discretionary accruals, the likelihood of the firm avoiding an earnings decline and negative earnings surprises, accounting manipulations, and internal control quality (e.g., Beasley, 1996; Klein, 2002; Vafeas, 2005; Farber, 2005; Abbott, Parker, and Peters, 2004). Krishnan (2005) documents a positive association between audit committee quality and quality of internal control procedures. García Lara, García Osma, and Penalva (2009) find a positive association between commonly used governance proxies for effective monitoring and asymmetric timeliness.

Larcker et al. (2007) start with 39 governance variables and use principal component analysis to extract governance factors. They find mixed and weak evidence of associations between the fourteen governance factors and earnings quality measured by discretionary accruals and restatements. Larcker and Richardson (2004) find that strong governance mitigates the negative relation between audit fees and accruals.

The studies consistently suggest a positive association between audit committee quality and earnings management (with the exception of Larcker et al., 2007). This result is not surprising because the audit committee's primary responsibility is to oversee the financial reporting process. Thus inferences from studies that predict an association between audit committee quality and accruals quality have the greatest internal validity ceteris paribus. The theory that underlies tests of an association between BOD quality and earnings management, however, is weaker. Directors are usually involved with decisions at a high level such as setting overall strategy (Adams, Hermalin, and Weisbach, 2008). Hence, while it may be reasonable to argue a correlation between BOD 
quality and the quality of M\&A decisions, the argument that cross-sectional variation in many BOD characteristics can explain cross-sectional variation in earnings management is less compelling. Tests based on an overall governance score as a proxy for internal controls that might constrain earnings management must assume that variation in the score is correlated with the quality of mechanisms that specifically affect earnings management opportunities or incentives. Tests that assume that the monitoring role of governance affects dimensions of earnings quality other than earnings management, such as conservatism, face even greater challenges (e.g., Garcia Lara et al., 2009).

Many internal control mechanisms are substitutes or complements. For example, Krishnan (2005) emphasizes the complementarity of two internal control mechanisms (i.e., audit committees and internal control procedures). Larcker et al. (2007) more thoroughly address the problem and argue that this causes econometric problems (e.g., inconsistent coefficient estimates) when using only a limited set of corporate governance measures.

\subsubsection{Internal control procedures}

Using internal control disclosures under SOX, Doyle et al. (2007b) find that firms with material weaknesses in internal control procedures over financial reporting have lower accruals quality (measured based on Dechow and Dichev, 2002), higher discretionary accruals, lower earnings persistence, and a higher likelihood of restatements than other firms. Ashbaugh-Skaife et al. (2008) further find that firms that have remediated their internal control weaknesses tend to have improved accruals quality. ${ }^{54}$ The predicted association between internal controls and accruals and

\footnotetext{
${ }^{54}$ Both Doyle et al. and Ashbaugh-Skaife et al. attempt to control for the self-selection bias associated with a manager's choice of internal controls. The selection bias associated with using internal control deficiency reports under SOX as a proxy for poor quality is a separate issue and is discussed in Section 2.4.3.
} 
restatements follows directly from the prediction that internal controls lower intentional and unintentional errors.

\subsubsection{Managerial ownership}

There are two competing theories about the incentives that managerial ownership provides for accounting choices: an entrenchment effect (i.e., controlling shareholders extrapolate private benefits at the expense of minority shareholders) and an incentive alignment effect (i.e., controlling shareholders' benefits are closely tied to firm value). These two effects predict different directions for the association between ownership concentration and earnings quality. The evidence on which effect dominates is mixed.

Two early studies find that management controlled firms are more likely to choose an accounting method (e.g., the depreciation method) that increases reported earnings or smoothes earnings than owner controlled firms (Smith, 1976; Dhaliwal, Salamon, and Smith, 1982), which supports the entrenchment effect. Warfield, Wild, and Wild (1995) find that managerial ownership is negatively related to the magnitude of discretionary accruals and is positively related to informativeness of earnings. Wang (2006) documents identical results for founding family ownership. Similarly, Gul, Chen, and Tsui (2003) document that managerial ownership has a mitigating effect on the positive association between audit fees and discretionary accruals. These results support the incentive alignment effect. In contrast, Larcker et al. (2007) find that insider power, primarily measured by managerial ownership, is positively associated with discretionary accruals and restatements. LaFond and Roychowdhury (2008) find a negative relation between managerial ownership and asymmetric timeliness, which they characterize as supporting a demand for conservatism to mitigate the potential entrenchment effect. 
In countries with high ownership concentration, however, the primary agency problem is between the controlling shareholders and minority shareholders. Fan and Wong (2002) document that firms in East Asia with concentrated ownership have lower ERCs. Kim and Yi (2006) find that the magnitude of discretionary accruals increases with the difference between controlling shareholders' voting rights and cash flow rights for Korean firms. Both Fan and Wong (2002) and Kim and Yi (2006) conclude that their findings are consistent with the entrenchment effect. ${ }^{55}$

\subsubsection{Managerial compensation}

Bonus plans and earnings-based compensation: Christie (1990) provides a meta-analysis of early research that examined whether managers choose accounting methods to maximize earnings-based compensation (e.g., Hagerman and Zmijewski, 1979; Bowen, Noreen, and Lacey, 1981) and concludes that earnings-based compensation, typically measured with a dichotomous variable, is associated with income-increasing accounting method/estimation choices. Skinner (1993) provides evidence that the association between earnings-based compensation and accounting choice holds after controlling for the firm's investment opportunity set.

Healy (1985) finds that working capital accruals are lower when the upper and lower bounds of bonus plans are binding and are higher when the bounds are not binding. Several papers challenge this early finding. Holthausen, Larcker, and Sloan (1995), using a confidential database of executive short term bonuses for which upper and lower bounds are known, find evidence that earnings do appear to be reduced by discretionary accruals based on a modified version of the Jones

\footnotetext{
55 The findings for the Asian firms are different from the findings based on U.S. data. There could be two explanations for the differences between Wang's results and those in Fan and Wong (2002). First, founding family firms could be different from other firms with concentrated ownership because of the incentive to protect the family's reputation. Second, Wang's findings are based on data from the U.S., where legal protection for minority shareholders is stronger than in other countries (e.g., Korea).
} 
(1991) model when bonuses are at their maximum. However, they do not find evidence of downward earnings management when earnings are below the minimum necessary to receive a bonus. Gaver, Gaver, and Austin (1995) find a negative correlation between discretionary accruals and non-discretionary earnings for 102 firms that are known to have bonus plans for the 1980-1990 time period. They suggest that this finding is more consistent with smoothing than with the big bath behavior at the lower bound. Dechow, Sloan, and Sweeney (1995) note that Healy's finding also is consistent with a negative correlation between cash flows and accruals and a positive correlation between earnings and accruals given his proxies for the upper and lower bounds.

Using business-unit-level data on earnings and managerial bonuses, Guidry, Leone, and Rock (1999) find results consistent with Healy's bonus-maximization hypothesis. They use several proxies for discretionary accruals, including a measure related to inventory, total accruals (Healy, 1985), and discretionary accruals generated from a modified version of the Jones (1991) model (Dechow et al., 1995).

Equity-based compensation including executive stock options (ESOs): Bergstresser and Philippon (2006) find that firms in which the CEO's total compensation consists mainly of the value of stock options report large discretionary accruals and that these CEOs tend to exercise more stock options and sell more shares in high-accrual years. Burns and Kedia (2006) document a positive association between the likelihood of restatements and the sensitivity of the CEO's option portfolio to stock price. Efendi et al. (2007) find that firms that restate financial statements at the end of the 1990's market bubble are more likely to have a CEO with a significant holding of in-the-money stock options. ${ }^{56}$ Johnson et al. (2009) document stronger compensation incentives from unrestricted stock

\footnotetext{
${ }^{56}$ Several studies suggest that managers attempt to deflate the firm's stock price, and hence the ESO's strike price, prior to a grant via the timing of disclosures around grant dates. Aboody and Kasznik (2000) examine firms' voluntary disclosures and find that under a fixed granting schedule, bad news tends to precede grant dates and good news tends to follow. They also find that stock returns are systematically lower prior to grant dates and increase afterwards (Chauvin
} 
for the AAER firm executives than for those of control firms. Erickson et al. (2006) and Armstrong et al. (2009), however, find no evidence of an association between equity-based incentive compensation and accounting manipulations.

Balsam et al. (2003) find that discretionary accruals are lower prior to option grant dates, and the effect is stronger in settings in which the grant date is not predictable (Baker et al., 2003). Coles et al. (2006) examine discretionary accruals in quarters between the date of cancellation and subsequent reissue of options. Discretionary accruals are relatively income-decreasing leading up to the reissue. Likewise, McAnally et al. (2008) finds that firms intentionally miss earnings targets prior to known option grant dates, which reduces stock price (Skinner and Sloan, 2000), but that firms do not miss earning targets repeatedly in advance of grants.

Insider trading: Beneish (1999) and Summers and Sweeney (1998) find that managers are more likely to sell their shares and redeem SARs during periods of overstated earnings, where these periods are identified ex post by AAERs. Beneish (1999) acknowledges that these are cases of extreme earnings management and that his results might not be generalizable to periods of less extreme earnings management that nonetheless affects earnings quality. Darrough and Rangan (2005) find that insider selling is positively related to discretionary current accruals and negatively related to changes in $R \& D$ spending in the year of an IPO. They interpret both results as consistent with opportunistic earnings management.

\subsubsection{Managerial change}

Moore (1973), Pourciau (1993), and Geiger and North (2006) find evidence that incoming managers are more likely to exercise discretion in managing earnings (measured by abnormal

and Shenoy, 2001; Yermack, 1997). A related line of research examines backdating, in which grant dates are retroactively assigned to historically low share prices (Heron and Lie, 2006, Narayanan et al., 2006). 
accruals) downward in the year of the change. Pourciau (1993) also shows that earnings tend to be managed upward in the year following management change. Incoming managers can blame departing managers for asset impairments. In addition, they can lower the earnings benchmark against which future results are evaluated or create hidden reserves to manage future earnings.

Dechow and Sloan (1991) document that departing CEOs are more likely to cut $R \& D$ expenditures when they are closer to retirement. The shorter career horizon creates stronger incentives to focus on short-term operating performance at the expense of long-term operating performance. Pourciau (1993), however, does not find evidence that managers use accruals that increase earnings during their last year with the firm.

DeAngelo (1988) finds evidence that managers use accounting discretion (i.e., abnormal accruals) to report favorable accounting earnings during a proxy contest for board seats after having been targeted by dissidents for poor earnings performance. She also finds evidence of big-bath earnings management behavior when dissidents are elected following proxy contests. In follow-up research, Collins and DeAngelo (1990) find that the market is more responsive to earnings during the proxy contest, which is opposite to the expected result if investors anticipate that managers are using accounting discretion to boost earnings.

The question of managerial turnover and more generally the impact of individual characteristics of a manager on earnings management is important but the evidence is limited (see Francis, Huang, Rajgopal and Zang, 2008; Schrand and Zechman, 2009; Ge, Matsumoto and Zhang, 2009). Studies of the implications of manager change face two hurdles. First, it is difficult to control for factors such as performance that could cause management turnover/selection and simultaneously affect EQ proxies. Second, in studies of departures, it is difficult to identify whether and when managers expect to depart. This difficulty might explain the difference in results in 
Dechow and Sloan (1991), who study retirees with expected departure dates, and Pourciau (1993), who studies non-routine executive turnover.

\subsubsection{Summary of governance and controls as determinants of earnings quality}

The evidence that internal control procedures are associated with less earnings management and that managerial turnover is a disciplining mechanism associated with earnings management, as a specific dimension of earnings quality, is generally consistent. The evidence on how other governance mechanisms and controls (i.e., BOD characteristics, managerial ownership, and managerial compensation) affect earnings management is weak or mixed.

A notable deficiency of this literature is that our database contains no studies that attempt to understand whether managers internalize the earnings quality implications of investment and financing decisions. Governance mechanisms and controls (other than internal control procedures) may not have a direct effect on earnings management, but these mechanisms likely do affect other managerial decisions, which in turn can affect dimensions of earnings quality. For example, characteristics of the BOD will affect investment decisions, and investment can affect earnings persistence and sustainability (Penman and Zhang, 2002). Likewise, an extensive literature documents an association between equity-based compensation and investment decisions, but our database does not contain any studies that attempt to predict that equity-based compensation will have consequences for EQ proxies other than earnings management. This omission is surprising given that variation in compensation contract form is commonly predicted to affect variation in investment risk-taking (e.g., Shevlin and Rajgopal, 2002), which is associated with earnings sustainability and persistence, two prominent measures of earnings quality. 
Despite the long-standing recognition that optimal contracts, and more generally internal controls as defined by Jensen and Meckling (1976), may lead to accounting choices that benefit the agent at the expense of the firm (i.e., opportunistic earnings management) or to efficient accounting choices that maximize the value of the firm, the debate is still open. ${ }^{57}$ Christie and Zimmerman (1994) and Bowen et al. (2008) examine which of these two alternative explanations is dominant in explaining observed discretionary accounting choices. Both papers conclude that contracting efficiency is the main explanation. In addition, Bowen et al. (2008) find that accounting discretion associated with poor controls is positively related to future operating performance (i.e., operating cash flows and return on assets), which they interpret as evidence that earnings management is beneficial to shareholders.

Their findings raise the question of whether and when equityholders recognize that discretionary accounting choices are ex post efficient vs. opportunistic. Christie and Zimmerman (1994) assume that the takeover market would discipline opportunism and use this to identify a sample of firms that are likely to be opportunistic. While it is reasonable to assume that participants in the takeover market can unwind earnings management, it is an empirical question whether equity investors, or other parties such as analysts, are able to unwind earnings management. The stock option grant papers provide evidence that equity investors infer that earnings may be managed around grant dates and incorporate an expectation of rational earnings management into their pricing. However, research that explores the extent to which equity investors infer rational earnings

\footnotetext{
${ }^{57}$ Dye and Verrecchia (1995), Fischer and Verrecchia (2000), and Stocken and Verrecchia (2004) use varied modeling techniques to yield predictions about accounting method choice and conditions that affect efficiency. The predictions about accounting choices, including disclosure, depend on the parameterization of the model and the assumptions about the contracting environment, information asymmetry, and the costs to the manager of various firm decisions. Managers sometimes choose accounting methods to convey information and sometimes choose methods that intentionally increase the noise in financial reports. Discretion sometimes improves efficiency but sometimes decreases it. The choice of a more noisy financial reporting system can be associated with increased efficiency, which may seem to be an unintuitive result.
} 
management related to incentives provided by control mechanisms, and perhaps react favorably to it, is limited.

\subsection{Auditors as determinants of earnings quality}

The impact of auditors on EQ derives from their role in mitigating intentional and unintentional misstatements. The ability of an auditor to mitigate misstatements is a function of both the auditor's ability to detect a material misstatement and to adjust for or report it (DeAngelo, 1981). Researchers predict that an auditor's ability to detect errors is a function of auditor effort and effectiveness. Researchers predict that an auditor's incentives to report or correct errors depends on factors such as litigation risk, reputation costs, and auditor independence (e.g., Caramanis and Lennox, 2008).

The two most commonly studied features of auditors are audit firm size and fee structures. Both features can be correlated with an auditor's ability to detect errors and an auditor's incentives to report, which makes it difficult to disentangle the reason for the auditor's impact on quality.

\subsubsection{Studies of auditor size}

Firms with Big-X auditors ${ }^{58}$ have significantly lower discretionary accruals than firms with non-Big-X auditors (Becker, DeFond, Jiambalvo, and Subramanyam, 1998; Francis, Maydew, and Sparks, 1999; Kim, Chung, and Firth, 2003). Petroni and Beasley (1996) do not find that the accuracy and bias of the loss reserve account in property-casualty insurers in the insurance industry varies based on audit firm size, but Gaver and Paterson (2001) find that weak insurers do not understate their reserve account when they have both Big-six auditors and Big-six actuaries. While these studies consistently suggest that effective auditing limits earnings management, Dechow et al.

\footnotetext{
${ }^{58}$ Big-eight, Big-six, or Big-five, depending on the timing of the study.
} 
(1996) suggest that having "Big" auditors does not prevent extreme accounting manipulations. One explanation for the difference in results is that the dichotomous partition of audit firms based on audit firm size is too crude to capture auditor effectiveness in a small sample.

Audit firm size also is correlated with EQ proxies other than accruals. In a cross-country analysis, Francis and Wang (2008) document that the positive association between country-level investor protection and EQ, measured by abnormal accruals, the likelihood of reporting a loss, and asymmetric timeliness, is higher only for firms with Big-four auditors. Teoh and Wong (1993) find that firms with Big-eight auditors have significantly higher ERCs. Hackenbrack and Hogan (2002) find that firms that switch auditors for service-related reasons have increasing $E R C$ s after the auditor change. However, firms that switch auditors for non-service-related reasons, related primarily to fees and fee disputes, have decreasing $E R C$ s.

DeFond and Subramanyam (1998) attempt to explain why the ex post incidence of litigation against auditors is lower for Big-six auditors (see also, Palmrose, 1988). One explanation is that big auditors force more conservative accounting, which leads to a lower litigation rate. In a sample of firms that switch auditors, they show that Big-six predecessor auditors are more conservative in their accounting choices (i.e., income decreasing discretionary accruals), and they provide weak evidence that non-Big 6 successor auditors are less conservative.

\subsubsection{Studies of auditor fees}

Srinidhi and Gul (2007) document a positive association between the magnitude of fees for audit services and accruals quality measured based on Dechow and Dichev (2002). Larcker and Richardson (2004) document a positive association between total fees (i.e., the sum of audit and 
nonaudit fees) and discretionary accruals. ${ }^{59} \mathrm{~A}$ branch of the literature focuses on nonaudit fees. Greater nonaudit services could compromise auditor independence, reducing the auditor's incentives to report/adjust misstatements. However, greater nonaudit services could increase audit quality by increasing an auditor's ability to detect errors assuming information transfer across service lines. Frankel, Johnson, and Nelson (2002) find that firms with higher nonaudit fees tend to have higher discretionary accruals and smaller earnings surprises. Three subsequent empirical studies confirm the findings in Frankel et al., employing alternative measures of earnings quality (i.e., accruals quality, ERCs, restatements) or a different sample (Srinidhi and Gul, 2007; Ferguson, Seow, and Young, 2004; Francis and Ke, 2006). Consistent with these empirical observations, an experimental study by Joe and Vandervelde (2007) finds that auditors identify fewer fraud risk factors in an audit task when they also perform a nonaudit task than when the nonaudit task is performed but by another firm.

Several papers challenge or add context to the results on nonaudit fees as a determinant of EQ. Chung and Kallapur (2003) make adjustments for several hypothesized methodological issues in Frankel et al. and find no association between nonaudit fees and discretionary accruals. Larcker and Richardson (2004) show that the positive association between measures of nonaudit fees and discretionary accruals holds for only about $8.5 \%$ of the sample and that these firms tends to have weak corporate governance. They find a negative association between nonaudit fees and discretionary accruals when using alternative measures for nonaudit fees. Two other studies use alternative measures of earnings quality, performance-adjusted discretionary accruals and restatements, and also find conflicting results (Ashbaugh, LaFond, and Mayhew, 2003; Ruddock, Taylor, and Taylor, 2006).

\footnotetext{
${ }^{59} \mathrm{Gul}$, Chen, and Tsui (2003) find a positive association between audit fees and discretionary accruals. However, they do not attribute their results to auditors' economic bonding with clients. They suggest that high discretionary accruals increase auditors' assessment of risk level, and auditors accordingly charge higher fees.
} 


\subsubsection{Studies of other auditor characteristics}

Auditor effort: Direct studies of the effects of auditor effort are generally not possible because effort is unobservable, but experimental settings and surveys provide some evidence on auditor effort. Phillips (1999) suggests that auditors increase their effort when the risk of misstatements is high; accordingly, the presence of auditing can deter financial reporting irregularities (e.g., Schneider and Wilner, 1990). Hirst (1994) finds that auditing judgments reflect earnings management incentives from management buyout and bonus plans, which suggests that an auditor's ability to detect errors varies with his effort to understand incentives. Nelson, Elliot, and Tarpley (2002) survey 253 auditors from one of the Big-five audit firms who identify 515 experiences of attempted earnings management. The surveyed auditors suggest that they $d o$ adjust for attempted earnings management, especially when attempted earnings management increases current-year earnings. Using a unique archival dataset, Caramanis and Lennox (2008) document a significant negative relation between audit hours worked, as a proxy for auditor effort, and discretionary accruals for a sample of audits from Greece. ${ }^{60}$

Industry expertise: Krishnan (2003) finds that the magnitude of discretionary accruals is lower for clients of auditors with industry expertise.

Litigation risk: In an experiment, Barron, Pratt, and Stice (2001) find that auditors are more likely to adjust errors that overstate earnings than errors that understate earnings, and they are more likely to correct errors when litigation against the auditor of a competitor to the client firm for a similar misstatement resulted in a loss to the auditor. They conclude that auditors are more likely to correct

\footnotetext{
${ }^{60}$ However, an "in-basket" task experiment that asked managers to make discretionary accrual decisions and that varied the manager's perceptions of internal and external auditor aggressiveness based on fabricated correspondence included in the experimental materials found no support for the hypothesis that internal and external auditors act as a deterrent to aggressive financial reporting (Uecker, Brief, and Kinney, 1981).
} 
errors when litigation risk is high. Using archival data, Heninger (2001) finds that shareholder lawsuits against auditors increase with discretionary accruals.

Auditor tenure: Johnson, Khurana, and Reynolds (2002) find no evidence that long auditor tenure is associated with low earnings quality, measured by the magnitude of discretionary accruals and the persistence of accruals. Chen et al. (2008) show that audit partner tenure is negatively associated with the magnitude of discretionary accruals in a sample of Taiwanese companies.

Revolving-door auditors: Menon and Williams (2004) report that hiring former auditing partners as officers, which they suggest might compromise auditor independence, is associated with two proxies for lower EQ: higher discretionary accruals and a higher likelihood of meeting analyst forecasts. However, using a longer sample period, Geiger, Lennox, and North (2008) find no evidence that such appointments are associated with lower financial reporting quality, as measured by discretionary accruals and the likelihood that the firm is the subject of an SEC enforcement action.

\subsubsection{Summary}

We began this section by discussing the theoretical foundation for the prediction that auditor effort/effectiveness can mitigate accounting misstatements. Auditor effort/effectiveness, however, is unobservable. Evidence from experiments and surveys suggest that greater effectiveness, specifically related to recognizing audit risk and adjusting the audit process, ${ }^{61}$ decreases observed earnings management. The most direct empirical proxies for effort/effectiveness such as hours spent auditing and auditor industry expertise, also are negatively associated with earnings management. However, one must use caution when interpreting the evidence that uses indirect proxies for auditor effort/effectiveness such as fees and audit firm size. To mitigate misstatements, auditors must both

\footnotetext{
${ }^{61}$ Uecker, Brief, and Kinney (1981), however, conclude that the perceived aggressiveness of the auditor (both internal and external) does not deter earnings management behavior by management based on a field experiment that employed business managers.
} 
detect and report material misstatements. ${ }^{62}$ Fees and size can measure both the auditor's ability to detect errors and his incentives to report the misstatement.

Larger audit firms are negatively associated with discretionary "low quality" accruals. This outcome appears to result from both greater expertise (effectiveness) and stronger incentives to constrain misreporting (DeAngelo, 1981). The auditor size results do not identify whether greater detection ability or greater reporting incentives affect misreporting. The studies on auditor fees and tenure provide some evidence to identify the effects of detection ability versus reporting incentives. Higher audit fees are predicted to be positively correlated with auditor expertise, and hence with detection ability, but they also are predicted to be negatively associated auditor independence and hence with decreased reporting incentives (DeAngelo, 1981). The preponderance of the evidence suggests that higher audit fees and longer auditor tenure are associated with higher accrual quality (or at least not associated with lower quality). This evidence would seemingly suggest that the detection ability effect dominates the independence concerns on average. Studies that attempt to further parse out the independence concerns support this conclusion given that the evidence on revolving door practice and non-audit fees certainly isn't conclusive that independence is a significant concern.

The auditors' role in affecting earnings quality is limited to a conclusion that auditors specifically constrain income-increasing discretionary accruals. This inference is valid given the auditor's role in the financial reporting process. Tests that use proxies for EQ other than indicators of earnings management, however, such as ERCs or statistical properties of earnings, are more likely

\footnotetext{
${ }^{62}$ The empirical prediction that auditor characteristics would be associated with an actual number in the income statement (e.g., discretionary accruals) is based on the stronger assumption that auditors not only report the error but that they adjust for it. Evidence in Whittred (1980) calls into question this stronger assumption. Whittred (1980) finds that reporting delays, which could be due to longer auditor-client negotiations and more effort in auditing, are associated with qualified reports. Thus, the auditor has exerted greater effort and detected the error, but the outcome is that earnings quality as reported in the income statement is lower for these firms. The auditor reports the lower quality via the opinion decision.
} 
to suffer from omitted correlated variables problems. A significant portion of the cross-sectional variation in ERCs or variables related to properties of earnings (e.g., timely loss recognition and the likelihood of reporting a loss used in Francis and Wang, 2008) comes from the ability of the accounting system to capture the firm's fundamental earnings process and not from the controllable and auditable dimension of quality. Hence, while the empirical evidence in studies that use ERCs or properties of earnings as proxies for EQ are consistent with the predicted positive relation between auditor effort and earnings quality, the studies must deal with substantial concerns about alternative explanations for results, including auditor self-selection and omitted correlated variables.

A notable underrepresented element of the literature is studies that recognize the important roles of entities other than auditors, such as actuaries, that can interact with the auditor to affect the earnings quality outcome (Gaver and Paterson, 2001). Likewise, there are entities other than auditors that have a similar role in the financial reporting process, and thus may affect earnings quality, although research in this area is limited. Morsfield and Tan (2006) document that IPO firms backed by venture capitalists exhibit lower discretionary accruals than other IPO firms in the IPOyear. Jo, Kim, and Park (2007) document that SEOs that have underwriters with higher reputations are associated with lower discretionary accruals than other SEOs. Studies also suggest that institutional investors affect EQ (Bushee, 1998), but the motivation is different. Institutions are predicted to affect EQ because of their anticipated information demands, not because they are directly involved in the financial reporting process.

\subsection{Capital market incentives as determinants of earnings quality}

The papers in this section discuss how capital market incentives influence firms' accounting choices and hence are potential determinants of earnings quality. 


\subsubsection{Incentives when firms raise capital}

The premise of this literature is that the cost/benefit trade-offs of accounting choices change during periods when a firm raises capital. Greater litigation risk, for example, may increase the costs of opportunistic accounting choices. Greater utility associated with the availability or price of capital may increase the benefits of opportunistic accounting choices. Hence, the firm's accounting choices, and thus its earnings quality, may differ when a firm is raising capital.

A firm's initial public offering (IPO) is a commonly examined setting. Friedlan (1994) and Teoh, Wong, and Rao (1998) find that firms have income increasing discretionary accruals prior to setting the offer price in an IPO. Aharony, Lin, and Loeb (1993) find little evidence that accruals are abnormally high prior to a firm's IPO. To the extent there is evidence suggesting earnings management, they find it more prevalent among smaller and more levered firms and those that use lower quality underwriters and brokers. Teoh, Wong, and Rao (1998), however, find unusually high abnormal accruals in the IPO issue-year and lower allowances for doubtful receivables. Similar to Aharony et al. (1993), Morsfield and Tan (2006) find that monitoring is a mitigating factor; IPO-year abnormal accruals are lower for IPO firms with venture capitalists than for other IPO firms.

We also observe evidence outside the IPO setting that firms' accruals choices are affected by capital market incentives. Haw, Qi, $\mathrm{Wu}$, and $\mathrm{Wu}$ (2005) find that Chinese firms that meet or just miss the $10 \%$ ROE requirements to qualify to make a stock rights offering in China between 1996 and 1998 have higher accruals. Erickson and Wang (1999) find evidence of income increasing earnings management via accruals prior to stock-for-stock merger agreements. In a management buyout (MBO), when the incentive is to understate performance to justify lower offer prices to existing shareholders, DeAngelo (1986) finds no evidence of income-decreasing discretionary accruals in the MBO year for 64 deals prior to 1982 using the year-over-year change in working 
capital accruals as a proxy. Perry and Williams (1994), however, estimate discretionary accruals using the Jones model and find lower discretionary accruals prior to the buyout relative to an industry and size matched control sample for 175 MBOs from 1981-1988. Results using outcomebased measures of earnings management such as $A A E R$ s and restatements also suggest that capital raising activities are associated with earnings management (Dechow, Sloan and Sweeney, 1996; Efendi, Srivastava, and Swanson, 2007).

Two studies infer capital market incentives for accounting choices. Bowen, Davis, and Rajgopal (2002) find that internet firms with greater cash burn rates, which they use as a proxy for external financing needs, are more likely to report advertising barter arrangements on the gross basis on the income statement, which is preferable for managers who believe they are being evaluated based on revenues. Lang, Raedy, and Yetman (2003) infer capital market incentives from cross-listing status and document differences in multiple proxies for EQ across cross-listed firms and a matched sample of firms from the same country. ${ }^{63}$ Cross-listed firms appear to engage in less earnings management (measured by earnings smoothing, accruals, and frequency of small positive earnings), report more conservative earnings (measured by timeliness of loss recognition), and have higher $E R C \mathrm{~s}$. The differences are caused by both changes around cross-listing and differences in accounting quality before listing. Ndubizu (2007) similarly finds that foreign firms appear to boost accruals at the time of cross-listing their stock in the U.S., however, he finds no differences between firms that raise capital at the time of cross-listing and a control group of cross-listing firms that do not. Finally, Dietrich, Harris, and Muller (2000) find that firms make accounting method choices regarding fair value estimates of investment properties to boost earnings and time asset sales to help smooth earnings before raising debt.

\footnotetext{
${ }^{63}$ The quality metrics are measured for both samples based on accounting data reported in local markets using locally generally accepted accounting principles (GAAP).
} 
Reviewing these studies together yields the following conclusions:

1) Evidence consistently suggests that incentives to influence equity market valuations affect firms' accounting choices, in particular their accrual choices. The hypothesis that equity markets would provide incentives for these accounting choices assumes that equity markets cannot detect the earnings management, although the papers do not test this. The papers provide evidence only on whether managers believe that the specific mechanism they examine is detectable.

2) The papers generally focus on event-driven incentives for accounting choices. These accounting choices, however, can have long-term consequences, such as a diminished reputation for transparency that adverse selection models predict should have a negative impact on the firm's cost of capital. ${ }^{64}$ The studies generally do not emphasize the trade-off between the short-term benefits of the accounting choice at the time of the event (e.g., the IPO) and the potential long-term reputation loss due to these one-off earnings management decisions.

In fact, the finding that IPO cross-listed firms and non-IPO cross-listed firms have similar levels of accruals management (Ndubizu, 2007) suggests that the expected benefits of investor recognition (or visibility), rather than capital raising activities, provides incentives for accounting choices. Similarly, Bowen et al. (2002) find a positive association between levels of activity on Motley Fool and use of the gross basis of reporting for advertising barter arrangements, which suggests that firms use accounting choice to influence visibility. Like reputation discussed in the previous paragraph, investor recognition is a long-term objective that may influence a firms' accounting choices. While the importance of investor recognition is recognized in other areas of accounting research (e.g., studies of investor relations and analysts), little research directly examines

\footnotetext{
${ }^{64}$ Christie and Zimmerman (1994) find that takeover targets are more likely to be using income increasing accounting choices than an industry matched sample. The choices they examine have only a small effect on income but have a substantial impact on retained earnings over long periods. They argue that these choices reflect "economic Darwinism." Firms that use suboptimal accounting choices, or that select the accounting rules for opportunistic reasons rather than signaling reasons, are more likely to be taken over.
} 
how the incentives provided by the potential benefits of investor visibility affect accounting choices and earnings quality.

3) Only one paper in our database examines whether raising capital in debt markets provides incentives for accounting choice. More work within public debt markets and on the trade-offs between debt and equity market incentives would be useful.

\subsubsection{Incentives for accounting choice provided by earnings-based targets ${ }^{65}$}

Phillips, Pincus, and Rego (2003) provide evidence that firms manage deferred tax expense to avoid losses and to avoid earnings declines. Rowchowdhury (2006) provides evidence of real earnings management to meet various earnings-based targets. Das and Zhang (2003) suggest that firms use working capital accruals to be able to round up EPS to meet analysts' forecasts, report positive earnings, or to sustain recent performance. Kasznik (1999) finds that firms that provide management forecasts are more likely to manipulate discretionary accruals to meet their forecasts when they are concerned with litigation risk or fear a loss of reputation accuracy. Barton and Simko (2002) suggest that incentives to meet targets are an important determinant of earnings management, but that opportunities constrain the firm's choice. They find that constrained firms with already overstated net asset values are less likely to report small negative earnings surprises or large positive earnings surprises and infer that the constrained firms could not manipulate earnings.

Earnings targets undoubtedly provide incentives for earnings management. The contribution of these studies is that they provide evidence on specific tools that firms use to manage earnings. However, the studies do not provide evidence on how firms choose among earnings management

\footnotetext{
${ }^{65}$ Section 4.1.4 also reviews evidence related to benchmarks/targets. In that section, we review studies that use meeting a target as a proxy for earnings quality. Those studies test the determinants of reporting earnings that meet a target or the consequences of doing so. The papers in this section, in contrast, treat meeting a target as the independent variable and examine the incentives that targets provide for earnings management.
} 
tools. Barton and Simko (2002) pursue the idea that a firm's choice with respect to a particular tool might be constrained, but they do not pursue the alternatives when the firm is constrained.

A well-recognized problem with studies that use analyst forecasts as a benchmark is that the analyst is an economic agent with his own incentives. Beating an analyst forecast depends not only on the firm's accounting choices, which may affect earnings quality, but also on the analyst's forecasting actions. The studies interpret a relation between "meeting or beating" the forecast and earnings management as evidence that the firm managed earnings, while the alternative explanation is that the analyst managed the forecast (Richardson, Teoh, and Wysocki, 2004). To the extent the analyst's actions are influenced by earnings quality considerations (unmanaged), the net impact on earnings quality arising from these incentives is indeterminate

\subsection{External factors as determinants of earnings quality}

External factors include political processes, tax and non-tax regulation, ${ }^{66}$ and macroeconomic conditions.

\subsubsection{The political process}

Eight papers in our database predict that political processes motivate managers to engage in income-decreasing earnings management, commonly measured by discretionary accruals, during periods of political pressure because profits generate regulatory or political attention/scrutiny that can lead to costly intervention or because profits are a direct input to a political/regulatory decision. The settings examined include: 1) U.S. International Trade Commission import relief investigations

\footnotetext{
${ }^{66}$ Regulators and regulation may be viewed as external monitors like auditors and boards, discussed in Sections 3.3 and 3.4. Consistent with the Kose and Kedia (2006) framework for internal controls, however, regulation is discussed as a distinct determinant of earnings quality because it is a force imposed on the firm rather than a monitoring choice made by the firm.
} 
(Jones, 1991); 2) Department of Justice/Federal Trade Commission antitrust investigations (Cahan, 1992); 3) Political pressure on HMOs (Mensah, Considine, and Oakes, 1994); 4) Congressional hearings on the U.S. cable television industry (Key, 1997); 5) Oil companies during the 1990 Gulf crisis (Han and Wang, 1998); 6) New Zealand's Price Justification Scheme and the Stabilisation of Prices Regulation in the 1970s (Navissi, 1999); 7) Gold price inflation, proposed taxes, and gold firms in Australia (Monem, 2003); and 8) Environmental Protection Agency pressures on potentially responsible parties (PRP) under the Superfund Act (Johnston and Rock, 2005).

The studies investigate a wide variety of settings, but they consistently document that expected political costs affect accounting choices (Watts and Zimmerman, 1986). An assumption common to these studies is that the decision-maker uses the reported earnings number in his decision and does not undo the effects of the accounting choice. ${ }^{67}$ Thus, it is not surprising that these papers investigate discretionary accruals rather than other potentially more transparent accounting choices such as accounting method changes.

\subsubsection{Capital regulations}

Four papers focus exclusively on the relation between incentives to meet capital requirements and earnings management behavior. They use either levels or changes specifications to test for the relation: 1) Petroni (1992) finds that $\mathrm{P} \& \mathrm{C}$ insurers experiencing financial difficulty underestimate policy loss reserves, consistent with incentives provided by insurance industry net worth requirements; 2) Kim and Kross (1998) and Ahmed, Takeda, and Thomas (1999) find that the magnitude of loan loss provisions for banks with low capital ratios significantly decreased after new capital standards became effective in 1989; 3) Schrand and Wong (2003) find that well-capitalized

\footnotetext{
${ }^{67}$ The firm may only need to fool a politician's constituents, which provides the politician with enough justification to support his position, even if the politician is able to unravel the underlying facts.
} 
banks use the valuation allowance against deferred tax assets to create hidden reserves that they can later use to smooth earnings.

An additional five papers study the impact of capital requirements relative to other incentives: 1) Moyer (1990) finds that bank's use adjustments to the loan loss provision, loan charge-offs, and securities gains and losses to avoid violating capital adequacy requirements but she finds no support for the political sensitivity hypothesis (i.e., attempt to reduce income when revenue is high); 2) Beatty, Chamberlain and Magliolo (1995) use a simultaneous system of five equations to examine whether bank managers optimize over a variety of incentives including capital requirements, tax, and earnings goals, and they investigate multiple accruals accounts; 3) Mensah, Considine, and Oakes (1994) suggest that financially weak HMOs understate "incurred but not reported expenses" (IBNRs), consistent with incentives to avoid violation of net worth requirements, but they find no support for the hypothesis that political visibility (measured by size) increases the regulatory pressure; 4) Chen and Daley (1996), for a sample of Canadian banks from 1977 to 1987, find strong support for capital maintenance incentives, weaker support for tax incentives, and no support for equity valuation incentives; and 5) Gaver and Paterson (1999) find that changes in insurers' choices on the realization of capital gains and stock transactions reflect changing incentives in risk-based capital requirements in 1994, while loss reserve estimates do not. Rather, loss reserve decisions are consistent with tax incentives throughout the period of changing capital regulation.

In a related vein, Muller (1999) finds that the decision by British firms to capitalize a brand rather than to write it off immediately at the time of an acquisition is influenced by whether the choice would result in shareholder approval for future acquisitions under London Stock Exchange requirements, which are capital-based. 


\subsubsection{Tax regulations}

Several studies exploit the LIFO conformity rule in the U.S. tax system to test whether incentives to minimize tax costs (i.e., present value of tax payments) affect accounting method choice, which in turn affects EQ. For example, Lee and Hsieh (1985), Hunt (1985), and Dopuch and Pincus (1988) document both tax (e.g., the magnitude of tax savings) and nontax explanations (e.g., contracting costs) for the choice of inventory accounting methods. Keating and Zimmerman (1999) exploit a natural experiment due to a 1981 tax law change that mitigated the impact of tax considerations on financial reporting depreciation choices and find an increase in the frequency of income-increasing depreciation estimate choices and a decrease in the frequency of incomeincreasing depreciation method changes after the 1981 tax law change. Guenther, Maydew, and Nutter (1997) exploit a change in book-tax conformity associated with the Tax Reform Act of 1986 (TRA) and find that firms that are required to switch from the cash method to the accrual method have higher (lower) accruals than firms that already use the accrual method prior to (following) the rule change.

Five papers in our database examine the effects of rate changes associated with the TRA and suggest that the rate change had a one-time impact on accruals choices around the period of the change. Scholes, Wilson, and Wolfson (1992), Guenther (1994), and Maydew (1997) conclude that

firms shift income from the pre-TRA period to the lower tax-rate regime period by deferring revenue and accelerating expenses. The evidence on income shifting in the opposite direction to avoid the U.S. corporate alternative minimum tax (AMT), however, is inconsistent (Boynton, Dobbins, and Plesko, 1992; Choi, Gramlich, and Thomas, 2001).

Two additional studies suggest that changes in tax incentives associated with the TRA led to a shift in accounting choices that will affect EQ on an on-going basis. The TRA increased the 
marginal tax rate for companies with long-term manufacturing contracts, and Calegari (2000) documents that companies with long-term manufacturing contracts increase their leverage and decrease discretionary accruals with high book-tax conformity following the TRA. Klassen, Lang, and Wolfson (1993) provide evidence that suggests that the U.S. tax rate reduction in 1987 results in geographic income shifting to the U.S. for multinational companies. ${ }^{68}$

\subsubsection{The Sarbanes Oxley Act of 2002}

Studies of SOX assert that it increased the expected costs of earnings management (especially accounting fraud) and thus managers are likely to engage in less earnings management after the implementation of SOX. Cohen, Dey, and Lys (2008) document that earnings management activities using accruals declined following SOX but that real earnings management activities increased after SOX. Koh, Matsumoto, and Rajgopal (2008) provide evidence that managers switch from using discretionary accruals to expectation management in order to meet analyst forecasts.

\subsubsection{Other}

Three papers in our database study other external factors that provide incentives for earnings management, but that do not fit into the categories defined above. Hall and Stammerjohan (1997) find that firms in the oil industry that are facing potentially large litigation damage awards choose income-decreasing non-working capital accruals relative to a control sample. Bowen, DuCharme, and Shores (1995) find that firms with greater incentives provided by ongoing implicit claims with third parties including customers, suppliers, employees, and short-term creditors make more income increasing inventory and depreciation accounting choices. As an example of their proxies for the

\footnotetext{
${ }^{68}$ See Shackelford and Shevlin (2001) for a comprehensive review of income shifting by multinationals, particularly following the TRA.
} 
importance of implicit claims, they propose that implicit customer claims are positively associated with product uniqueness, and they measure variation in uniqueness by R\&D expense. Rosner (2003) finds that firms that subsequently declare bankruptcy have greater income-increasing abnormal accruals compared to a matched sample and suggests that the firms engaged in earnings management in an effort to avoid bankruptcy.

\subsubsection{Summary}

Capital regulations, specifically in the banking and insurance industries, provide strong incentives to manage earnings, and loss provisions are most commonly used to meet these regulations. Other incentives are of second-order importance when capital requirements are likely to be binding. ${ }^{69}$

The studies document that firms manage discretionary accruals during periods of heightened pressure (either external or internal) or in response to specific regulatory changes. Thus, the results suggest that earnings quality is time-varying. External factors such as changing pressures from antitrust regulation during merger discussions will create firm-specific time-varying EQ patterns. However, the majority of the external factors discussed are clustered in calendar time (e.g., the TRA or bank capital requirement changes) and the resulting effects on EQ will be clustered in calendar time as well. External factors that affect accounting method choice, in contrast, will lead to crosssectional variation in EQ, but not time-variation (Calegari, 2000; Klassen, Lang, and Wolfson, 1993).

\footnotetext{
${ }^{69}$ This conclusion on net worth requirements, however, may not generalize to other settings. The financial services industry has greater power to detect specific earnings management responses to regulations given the direct link between the capital requirements and the loss provision accounts and the significance and variation of the loss provision accounts across banks/insurance carriers.
} 
Equity market incentives receive little support as a determinant of accounting choices when measured relative to incentives provided by external factors. However, the tests of equity market incentives are likely to be of low power relative to tests of incentives provided by regulatory capital requirements to manage specific accounts such as the loan loss provision.

The earnings management activities associated with these external factors may potentially mislead other financial statement users. We did not catalogue any studies on how/whether firms communicate to equity markets during periods of regulatory scrutiny to offset the negative message they falsely send to regulators/politicians, or the extent to which firms may forgo accessing capital during these periods. We also did not catalogue any studies that assess equity market reactions to earnings during these periods when investors might rationally infer the earnings management. ${ }^{70}$

Several papers provide evidence that firms use multiple tools in response to a single incentive. These results emphasize a point we have made previously: accruals management, ceteris paribus, may impair earnings quality, but it represents only one choice within the firm's portfolio of accounting and real choices. Hunt, Moyer, and Shevlin (2000) examine both multiple tools and multiple incentives.

Finally, there is (surprisingly) limited research on macroeconomic conditions as a determinant of EQ. Although we had initially defined a category to collect these papers, our journal search found only one paper that focuses primarily on macroeconomic factors as a determinant of earnings quality (Liu and Ryan, 2006) and one paper that gives them significant albeit secondary

\footnotetext{
${ }^{70}$ Two studies, however, provide related discussions/evidence. Ronen and Aharoni (1989) develop a model that shows that higher tax rates are associated with choices of income-increasing accounting methods, excepting accounting methods subject to book tax conformity. A key assumption of the model is that equity market participants will see through the earnings management and value the firm's equity correctly. Beatty and Harris (1999) compare security gains and losses in public banks to those in private banks, both of which are subject to capital requirements, to determine how earnings management differs under the assumption that public banks have greater incentives to engage in earnings management than private banks due to equity market incentives. However, this paper does not test how and when banks trade-off the equity market incentives against other earnings management incentives that firms face.
} 
attention (Aboody et al. , 1999). ${ }^{71}$ Both studies predict that macroeconomic factors are correlated with increased incentives for earnings management. We did not find any studies that hypothesize macroeconomic conditions as a determinant of earnings quality for other reasons, for example, because of variation in the ability of accruals to capture performance fundamentals when the "fundamentals" are different.

\section{The consequences of earnings quality}

\subsection{Capital market consequences of earnings quality}

The hypothesized capital market consequences of earnings quality include: short-window stock price returns around the earnings announcement date, contemporaneous long-window returns, and future stock price performance after the release of earnings-related information (Section 6.1.1); market-multiples (Section 6.1.2); cost of equity capital (Section 6.1.3); and cost of debt capital (Section 6.1.4). ${ }^{72}$

\subsubsection{Return responses to earnings quality}

Contemporaneous short-window returns: In the short-window returns tests, information is assumed to be of higher quality if it has a higher association with returns. Inferring variation in EQ from the association between unexpected earnings and returns has been a prevalent research methodology since the publication of Kormendi and Lipe (1987) and Easton and Zmijewski (1989). The key findings are:

\footnotetext{
${ }^{71}$ Wilson (1987) finds that his results are driven by two observations (1981 and 1982) and conjectures that the cause might be a "macroeconomic phenomenon," given that both were years of significant economic downturn. Bernard and Stober (1989), however, find no evidence for this conjecture.

${ }^{72}$ Many of the studies that examine market consequences use multiple measures and are cited more than once.
} 
1) The market responds more favorably when earnings are composed of cash flows than accruals (Wilson, 1987). Bernard and Stober (1989), however, find that the results in Wilson (1987) are driven by two quarters.

2) Investors discount discretionary accruals if they are made aware of them or if they can infer that they are more likely to represent earnings management (DeFond and Park, 2001; Balsam, Bartov, and Marquardt, 2002; Baber, Chen, and Kang, 2006; Gleason and Mills, 2008; Coles, Hertzel, and Kalpathy, 2006). Louis and Robinson (2005) similarly find that when managers combine discretionary accruals with another credible signal (i.e., a stock split), investors do not discount them.

3) Negative special items (write-offs or write-downs) are generally associated with a small negative stock price reaction of around one percent (Elliott and Shaw, 1988). When a firm has a history of special items, the response coefficient associated with earnings before special items receive a lower weight (Elliot and Hanna, 1996). Variation in reactions to inventory write-offs and restructuring charges suggest that they convey information about expected future performance (Francis, Hanna, and Vincent, 1996).

4) Investors respond more strongly to pro-forma earnings than to GAAP earnings on average (Bhattacharya, Black, Christensen, and Larson, 2003). The coefficient is only significant for firms with relatively less informative GAAP earnings, as measured by historical ERCs (Lougee and Marquardt, 2004).

5) Indicators of general financial reporting quality concerns are associated with negative stock price reactions. There is a strong negative stock market reaction to announcements of restatements and/or AAERs (Feroz et al., 1991; Dechow et al., 1996; and Palmrose, Richardson, and Scholz, 2004). The evidence is consistent, but the implications for EQ are ambiguous (see Section 3.3). The revelation 
of internal control procedure deficiencies as required under SOX Section 302 generate small negative stock responses of around 2 percent (Hammersley, Myers, and Shakespeare, 2008; Beneish, Billings, and Hodder, 2008). Announcements about audit fees that may indicate to investors that earnings are of low quality are associated with negative short window returns (Frankel, Johnson, and Nelson, 2002; Hackenbrack and Hogan, 2002).

6) Earnings with qualified audit opinions are associated with either negative price reactions (Dopuch, Holthausen, and Leftwich 1986; Choi and Jeter 1992; Chen, Su, and Zhao, 2000) or no reaction (Chow and Rice, 1982; Dodd et al., 1984).

Contemporaneous long-window returns (association studies): Many early studies examine whether earnings measured under different methods result in different market consequences. A series of early papers conclude that investors interpret financial statement information conditional on the accounting method used (Mlynarczyk, 1969; Archibald, 1972; Ball, 1972; Gonedes, 1975 and 1978; Harrison, 1977; Sunder, 1975). Other studies, however, challenge these results or present new analyses that suggest that analysts and other subjects tend to be functionally fixated on earnings (Dyckman, 1964; Kaplan and Roll, 1972; Cassidy, 1976; Harrison, 1977). These studies make cross-sectional predictions about which methods reflect underlying economics to infer investor rationality. More recently, Loudder and Behn (1995) use a similar methodology and conclude that investors understand R\&D accounting based on predicted patterns in long window ERCs. Altamuro, Beatty, and Weber (2005) however, assume that markets rationally interpret revenue recognition practices and interpret patterns in long-window ERCs as evidence that pre-SAB 101 earnings are more useful for firms that were required to switch than earnings measured based on SAB 101. 
Audit quality is positively associated with contemporaneous long-window returns, where audit quality is measured either by greater independence (Francis and Ke, 2006) or Big-8 status (Teoh and Wong, 1993).

Future returns: Several studies examine the association between EQ proxies measured in one period and future-period stock returns; predictable future returns suggest mispricing. Large-sample studies suggest mispricing of various accrual metrics and components of accruals: total accruals (Sloan, 1996); discretionary accruals (Xie, 2001); accruals and growth in long-term net operating assets as separate components of Sloan's total accrual measure (Fairfield, Whisenant, and Yohn, 2003); and special items and accruals (Dechow and Ge, 2006). Dechow, Richardson, and Sloan (2008) show that investors correctly price various cash components of earnings except for the change in the cash balance. Cheng and Thomas (2006) find that abnormal accruals are associated with future stock returns after controlling for cash flows, which they interpret as evidence that the accrual anomaly is not subsumed by the value-glamour anomaly.

For specific accruals, Lev and Sougiannis (1996) show that firms with high R\&D reserves are underpriced, and Penman and Zhang (2002) find that conservative accounting as it relates to LIFO reserves and R\&D and advertising expenditures and changes in investment are associated with future returns. Beaver and McNichols (2001), however, find that development accruals for P\&C insurers are not associated with future stock returns.

The mispricing is greater for less reliable accruals, where reliability is determined by the researchers (Richardson et al., 2005). It is mitigated when investors are given balance sheet information at the earnings release date that can help them back out discretionary accruals (Louis, Robinson, and Sbaraglia, 2008; Levi, 2007); and when firms have large positive book-tax 
differences, which investors rationally interpret as a "red flag" for decreasing persistence (Hanlon, 2005).

The mispricing even exists at the time of an IPO or SEO (Rangan, 1998; Teoh et al., 1998; DuCharme, Malatesta, and Sefcik, 2004). These results contradict the notion that investors anticipate earnings management in cases when it is likely. More consistent with investor anticipation, Shivakumar (2000) finds evidence of abnormal accruals prior to SEOs but not mispricing. DuCharme et al. (2004) find that the likelihood of litigation is positively associated with abnormal accruals around equity offerings, which begs the question whether issuers anticipate the litigation risk.

\subsubsection{Market valuation}

Discretionary loss reserves are associated with lower market valuations in the $\mathrm{P} \& \mathrm{C}$ insurance industry (Petroni, Ryan, and Wahlen, 2000; Beaver and McNichols, 1998) and in the banking industry (Beaver and Engel, 1996). Firms that consistently meet or beat prior period earnings have higher price-earnings ratios or market-multiples than matched samples (Barth, Elliott, and Finn, 1999; Myers, Myers, and Skinner, 2007) even if there is evidence of earnings management to achieve the results (Myers, Myers, and Skinner, 2007). Kasznik and McNichols (2002) document that firms that meet analyst expectations do not get rewarded with higher relative valuations unless they meet them consistently. When firms eventually miss a target, they are likely to immediately lose the extra valuation (e.g., Skinner and Sloan, 2000; Myers, Myers, and Skinner, 2007). 


\subsubsection{Earnings quality and cost of equity capital}

The proxies used for cost of capital include: 1) A firm's implied or ex ante cost of equity capital, which is the discount rate that equates current market value with the sum of the present value of expected future cash flows in an equity valuation model; 2) bid-ask spreads; and 3) beta. ${ }^{73} \mathrm{We}$ conclude this section with a discussion of the emerging literature on accrual quality as a priced risk factor.

Implied cost of equity capital: Francis et al. (2004), discussed extensively in Section 3, find that accrual quality, earnings persistence, smoothness, value relevance, and timeliness are associated with cost of equity capital in the predicted direction, while predictability and conservatism are not. ${ }^{74}$ Accrual quality has the largest cost of equity capital effects. Bhattacharya, Daouk, and Welker (2003) find evidence of an association between country-level earnings quality measures including earnings aggressiveness (i.e., accruals), loss avoidance, and earnings smoothing, and country-level measures of total cost of capital.

Hribar and Jenkins (2004) suggest that restatements are associated with increases in the implied cost of equity capital. There is mixed evidence on whether revelations of internal control deficiencies affect a firm's cost of equity capital (Beneish et al., 2008; Ogneva et al., 2007;

Ashbaugh-Skaife et al., 2009). Auditor independence is associated with a lower implied cost of equity capital for the audit client (Khurana and Raman, 2006).

\footnotetext{
${ }^{73}$ See Frankel and Lee (1998), Botosan and Plumlee (2002), Kasznik (2004), Brav et al. (2004), Easton and Monahan (2005), and Botosan and Plumlee (2005) for specifications and discussions of implied cost of equity capital metrics. See Callahan, Lee, and Yohn (1997) and Mohanram and Rajgopal (2009) for discussions of spreads (and PIN) as measures of the adverse selection component of the cost of capital. See Section 3.1 for an extensive discussion of Francis et al. (2005), which provides evidence on accrual quality as a priced risk factor.

${ }^{74}$ However, McInnis (2009) does not find evidence of higher average stock returns for firms with high earnings smoothness. He suggests that the association between earnings smoothness and cost of equity capital documented in prior research is driven by optimism in analysts' long-term earnings forecasts.
} 
Bid-ask spread: Evidence on the association between earnings quality and bid ask spreads is mixed and appears to depend heavily on the EQ proxy. Dechow et al. (1996) find an increase in residual bid ask spread for AAER firms. Chang et al. (2006) find that SOX requirements concerning CEO/CFO certifications are associated with lower spreads. Palmrose et al. (2004), however, do not find evidence of a significant change in spreads subsequent to restatements.

There is a negative association between earnings predictability and bid-ask spreads (AffleckGraves et al., 2002), but a U-shaped relation between smoothness and spreads (Jayaraman, 2008). The smoothness measure is the difference between earnings volatility and cash flow volatility, so the result suggests that when earnings are too smooth relative to cash flows, or much more volatile, then market prices appear to reflect greater asymmetry.

Beta: Loss reserve revisions of $\mathrm{P} \& \mathrm{C}$ insurers as a measure of discretionary accruals (Petroni, Ryan, and Wahlen, 2000) and internal control deficiencies (Ashbaugh-Skaife et al., 2009) are positively associated with beta.

Accrual quality as a priced risk factor: Francis et al. (2005) (FLOS) rank their measure of accrual quality (discussed in Section 3.1.1) into quintiles and show variation across the quintiles in the cost of debt (interest to average debt), industry adjusted EP ratios, and betas from CAPM type regressions. They also calculate the difference in returns each month between the top two quintiles and the bottom two quintiles and determine whether the AQ factor is priced (has a significant coefficient):

$$
R_{j, m}-R_{f, m}=\alpha_{j}+\beta_{j}\left(R_{M, m}-R_{f, m}\right)+s_{j} S M B_{m}+h_{j} H M L_{m}+e_{j} A Q \text { factor }_{m}+\varepsilon_{j m}
$$

FLOS find a significant coefficient on $\mathrm{e}_{\mathrm{j}}$. When the AQ factor is decomposed into the innate and discretionary component, they find that the result is driven mainly by the innate component although 
the discretionary component is still significant. FLOS's interpretation is that accrual quality plays an economically meaningful role in determining the cost of equity capital.

The results and the theoretical underpinnings for the analysis have generated considerable controversy. FLOS motivate the prediction that information uncertainty risk is priced using a model by Easley and O'Hara (2004), which suggests that information risk is not diversifiable and is priced in the presence of uninformed investors who are not able to adjust their portfolio weights in the same way as informed investors. Lambert, Leuz, and Verrecchia (2007, pp. 396-397), however, argue that when the number of traders becomes large, the information effect is diversified away. A similar conclusion can be drawn from Hughes, Liu, and Liu (2005) who suggest that the cross-sectional effect of asymmetric information on cost of capital may be fully diversified away in a pure exchange economy with a large number of assets.

In addition, Core, Guay, and Verdi (2008, p7) comment on the interpretation of the regression results:

It is crucial to note that the average positive coefficient on the AQ factor in these contemporaneous regressions of stock returns on factor returns does not imply that $A Q$ is a priced risk factor. Rather an average positive regression coefficient means that, on average, firms have a positive contemporaneous exposure to the AQ_factor mimicking strategy. For example, the significant coefficient on the market portfolio does not suggest that the market factor is priced, but only confirms that the average beta in a sample of firms is positive and mechanically close to one. (italics added)

Daniel and Titman (1996) make this same point for the Fama and French market-to-book and size factors. Just because high market-to-book firms covary contemporaneously with each other does not imply that investors price this covariance risk. ${ }^{75}$

In order to show that the AQ_factor is a priced risk factor, researchers must show, for example, that when ranking firms on AQ, firms with low accrual quality earn higher future returns; or that the AQ_factor beta explains the cross-section of expected returns/future returns; or that low accrual quality stock that are highly correlated with the AQ_factor have higher expected returns than

\footnotetext{
${ }^{75}$ Daniel and Titman document that the return premium to high book-to-market is not due to their covariance with HML. This suggests that the market-to-book factor is not a priced risk but a "characteristic" that explains future returns.
} 
low accrual quality stock that are not highly correlated with the factor. This is the point made by Fama and French (1992) who suggested that beta was "dead" as a priced risk factor because market beta does not appear to explain the cross-section of future returns.

Core et al. (2008) perform such tests and suggest that the AQ_factor is not priced. In other words, low quality accrual firms may covary with each other, but investors do not price this covariance risk and so do not demand a higher expected return/cost of capital. Ecker, Francis, Kim, Olsson, and Schipper (2006) examine whether sorting on AQ provides differences in returns. However, Core et al. counter that the equally-weighted portfolio formation along with daily rebalancing is likely to overstate the returns, particularly since AQ appears to be correlated with firm size. Kravet and Shevlin (2009) argue that even well-accepted risk factors such as market, size, and book to market factors are also often insignificant in the second stage regression, as reported in Core et al., suggesting that the insignificance of the AQ factor coefficient does not necessarily rule out AQ factor as a priced risk factor. Kravet and Shevlin follow the FLOS approach and document a significant increase in the pricing of the AQ factor (especially the discretionary component of the AQ factor) after restatement announcements, consistent with restatement leading to increased cost of equity capital. $^{76}$

Aboody, Hughes, and Liu (2005) perform tests to determine whether accrual quality is a priced risk factor. They investigate whether the systematic component of earnings quality (a proxy for information asymmetry) is priced and whether privately informed/insider earn higher profits when trading on stock with a higher exposure to the earnings quality factor. They use four related measures of earnings quality: (i) the absolute value of abnormal accruals from a modified Jones model (Dechow, Sloan, and Sweeney 1996); (ii) the absolute value of abnormal current accruals

\footnotetext{
${ }^{76}$ In addition, Liu and Wysocki (2006) show that AQ loses significance in the earnings-to-price and interest rate regressions when measures of operating volatility are introduced.
} 
(that excludes depreciation); (iii) the absolute value of the residual from a Dechow and Dichev model; (iv) the standard deviation of the residual from (iii) using the time-series of the firm's residual (i.e., as in FLOS). Aboody, Hughes, and Liu (2005) find that a mimicking portfolio strategy that buys firms with high AQ beta earns positive abnormal returns earns positive abnormal returns. Core et al., however, find that this result is sensitive to the time period examined. They find no results when using a longer time horizon. In addition, Aboody et al. conclude that the AQ_factor loading is weak, particularly compared to the returns on their insider trading results.

\subsubsection{Debt market consequences of earnings quality}

Only three consequences papers in our database extend the definition of earnings quality to decision usefulness in debt markets. Francis et al. (2005) find that firms with lower quality accruals have a higher cost of debt measured by: 1) the ratio of interest expense to interest-bearing outstanding debt (i.e., an ex post measure), and 2) S\&P Issuer Credit Ratings (i.e., an ex ante measure). Anderson et al. (2004) find that firms with higher board independence, higher audit committee independence, and larger board size have lower costs of debt measured as the yield spread. They cite prior empirical studies (e.g., Klein, 2002) to justify these indirect proxies for financial reporting quality. Bhojraj and Swaminathan (2007) find that one-year ahead bond returns of firms with high operating accruals are significantly lower than those of firms with low operating accruals, consistent with bond investors mispricing high and low accrual firms in much the same way that equity investors do. 


\subsubsection{Summary}

To summarize, the evidence that there is a lower market reaction when earnings are of lower quality and that the market reacts negatively to evidence of a decline in quality (Section 6.1.1) is fairly consistent across all earnings quality proxies. An open question, however, is whether the negative response reflects a decline in the quality of the firm's fundamental earnings process or a decline in the quality of the information to measure the process. Researchers typically assert the latter explanation.

The evidence in Section 6.1.2 on market valuations suggests that firms that consistently beat benchmarks are rewarded with higher valuations, but firms that manage earnings through discretionary loss reserves are not. There are several explanations for this combination of results: 1) the market rewards some types of earnings management and not others; 2) greater market mispricing of less transparent earnings management; and 3) "rational bubbles" caused by an association between reported growth and investor synchronization risk (see, for example, Abreu and Brunnermeier, 2002). More research on this observed phenomenon is necessary to disentangle these explanations.

The evidence to date generally finds a negative association between earnings quality proxies and the cost of equity capital with the exception of the findings by Core et al. (2008). Research on the relation between earnings quality and the cost of equity capital will surely evolve as the theories that relate information precision about diversifiable and non-diversifiable sources of risk to the cost of capital evolve.

Finally, while the evidence from debt markets is limited, it is nonetheless consistent with evidence about earnings quality proxies in equity markets. Debt markets provide a useful opportunity to validate the findings in equity markets. In addition, variation in the decision- 
usefulness of earnings in debt markets relative to equity markets provides an opportunity 1) to examine accounting choices that are irrelevant to quality characteristics of interest to equity markets, and 2) to assess trade-offs between multiple incentives for producing high-quality earnings.

\subsection{Non-market consequences of earnings quality}

The categories of non-market consequences of EQ are: 1) litigation against the firm, 2) compensation, 3) executive and director turnover, 4) audit opinions, 5) analysts' forecasts, and 6) real activities including disclosure decisions and investment/financing activities. A noteworthy feature of these categories is that many of them are also the "determinants" variables that were discussed in Section 5, which emphasizes the importance of considering causality when interpreting the evidence.

\subsubsection{Consequences of earnings quality for litigation}

Palmrose and Scholz (2004) find that the likelihood of litigation increases with restatements, and Lev, Ryan, and $\mathrm{Wu}(2008)$ find that a restatement that depicts a different pattern of earnings than was previously reported is associated with a greater likelihood of shareholder litigation. Gong, Louis, and Sun (2008) and DuCharme, Malatesta, and Sefcik (2004) exploit high-risk settings stock-for-stock swaps and IPOs and SEOs, respectively - to examine whether abnormal accruals are associated with litigation propensity. They find a positive association between abnormal accruals in the period leading up to the transactions and post-transaction litigation.

Because the restatement studies (Palmrose and Scholz, 2004; Lev et al., 2008) control for the magnitude of the restatement, they conclude that it is the restatement itself that affects litigation propensity. They suggest that a restatement is the type of evidence that increases the likelihood that 
plaintiffs will prevail in shareholder litigation. DuCharme et al. (2004) similarly interpret their finding as evidence that abnormal accruals are correlated with a plaintiff's assessment of the probability that he will prevail.

Gong et al. (2008) and DuCharme et al. (2004) focus on settings in which firms have significant incentives to manage earnings and hence assert that the abnormal accruals are likely to represent material misstatements outside the boundaries of GAAP. There is no direct evidence that abnormal accruals within the boundaries of GAAP increase the likelihood of litigation.

\subsubsection{Consequences of earnings quality for compensation}

Several studies provide evidence on variation in the weights placed on different components or properties of earnings, that is, their respective pay-for-performance sensitivities. Balsam (1998) finds that operating cash flow and non-discretionary and discretionary accruals are positively and significantly related to CEO cash compensation after controlling for returns; the highest association is with operating cash flow. The weight on positive discretionary accruals is significantly greater when the accruals are used to reduce or eliminate a loss.

Baber, Kang, and Kumar (1998) find a stronger absolute pay-for-performance relation between cash compensation changes and unexpected earnings for more persistent earnings, while Nwaeze, Yang, and Yin (2006) document that the weight placed on earnings relative to operating cash flow is lower for firms with lower earnings persistence, higher earnings variability, and higher total accruals.

Gaver, Gaver, and Austin (1995) find that transitory gains are included in earnings for compensation purposes while transitory losses are excluded. Dechow, Huson, and Sloan (1994) find that compensation appears to be adjusted for nonrecurring charges (e.g., restructuring charges). 
Dechow, Myers and Shakespeare (2008), however, find that compensation is as sensitive to highly discretionary securitization gains as it is to other components of earnings.

Bushman, Chen, Engel, and Smith (2004) conclude that firms use more equity-based compensation when earnings are less informative. Their main proxy for earnings informativeness is timeliness. Cheng and Farber (2008) find that the proportion of option-based pay in a CEO's package declines following a restatement.

The compensation results suggest that expected earnings quality is associated with ex ante compensation contract composition, in levels, and changes in earnings quality are associated with ex post recontracting. Boards also seem to incorporate the implications of discretionary accounting choices on pay-for-performance such as bonuses when the accounting choice is transparent and likely contractible. For example, Balsam (1998) interprets his evidence as follows: “...it appears compensation committees distinguish between the components of income and reward managers when their accounting choices achieve the firms' goals."

\subsubsection{Consequences of earnings quality for executive and director turnover}

Desai, Hogan, and Wilkins (2006) find that at least one executive is terminated in $60 \%$ of the sample firms that had restatements during 1997 or 1998, compared to a rate of $35 \%$ in a matched sample. Only $15 \%$ of these executives are rehired in comparable positions. Beneish (1999) found no evidence of abnormal turnover for CEOs or executives of the misstatement firms, although he did not identify whether the executives were implicated in the fraud. Karpoff et al. (2008a) find that $93 \%$ of individuals identified as having responsibility for a misstatement leave their jobs by the end of the enforcement period. Srinivasan (2005) reports a $48 \%$ turnover rate for directors following an income decreasing restatement. A matched sample has a turnover rate of $33 \%$. Technical and 
income increasing restatement firms have director turnover rates of $18 \%$ and $28 \%$, respectively, and pre-restatement turnover is $14-16 \%$ in all three samples. ${ }^{77}$ Menon and Williams (2008) find evidence of abnormally high turnover for CEOs and CFOs following auditor resignations. Engel, Hayes, and Wang (2003) find a stronger sensitivity of turnover decisions to accounting information when earnings is more informative, where informativeness is measured by asymmetric timeliness.

Taken together, the evidence suggests significant negative labor market consequences for individuals involved in accounting misstatements. However, these public announcements of misstatements have direct implications for the firm's credibility, which may be an additional factor in the turnover decision. Moreover, these studies may not provide evidence that is useful for understanding whether a Board would view earnings management within the boundary of GAAP as impairing earnings quality. Engel et al. (2003) is the only study that provides evidence on the turnover consequences of earnings informativeness rather than extreme, and detected, earnings management.

\subsubsection{Consequences of earnings quality for audit opinions}

Francis and Krishnan (1999) find that high-accrual firms are more likely to get modified audit opinions, particularly from Big-six auditors and when the accruals are income-increasing. Bradshaw, Richardson, and Sloan (2001), however, find no evidence that abnormally high working capital accruals are associated with adverse audit opinions or auditor turnover. ${ }^{78}$ Butler, Leone, and Willenborg (2004) find that the relation between accruals (total accruals or abnormal total accruals)

\footnotetext{
${ }^{77}$ While the results directionally suggest higher director turnover following restatements relative to a matched sample, the significance of the difference is not reported. Moreover, the increase in turnover for the matched sample from 14$16 \%$ in the hypothetical pre-restatement period to $33 \%$ in the post-restatement period is unexplained and raises questions about the impact of calendar time data clustering on the results.

${ }^{78}$ One explanation for the mixed results is that Francis and Krishnan (1999) examine reports in 1987 - 1988, which precedes the issuance of SAS 58 and 59, whereas Bradshaw et al. examine reports in 1988-1998.
} 
and audit opinions is primarily driven by a relation between large negative accruals and going concern opinions.

The mixed results appear to be related to the definition of accruals. Bradshaw et al. (2001) state: "... a third interpretation of our auditor results is that earnings quality issues of the type that we investigate are beyond the scope of the audit. In other words, auditors may understand that inflated accruals imply a greater likelihood of future earnings declines and GAAP violations, but are not required to communicate this information to investors through their audit opinions."

\subsubsection{Consequences of earnings quality for analysts' forecasts}

Brown (1983) examines the impact of five accounting method choices on earnings predictability, measured by analyst forecast errors. He finds that lease capitalization (SFAS 13) improves predictability and changes in actuarial assumptions for pensions impair predictability. He finds no evidence that changes in foreign currency accounting (SFAS 8), interest capitalization (SFAS 34), or LIFO adoption affect predictability. Ashbaugh and Pincus (2001) document greater forecast errors when a firm's home country GAAP differs more significantly from IAS and that analyst forecast errors decreased after adoption of IAS. Bhattacharya, Black, Christensen, and Larson (2003) show that analyst forecast revisions are more highly associated with unexpected pro forma earnings than with unexpected GAAP operating earnings. Kim and Schroeder (1990) document predictable patterns in analysts' forecasts related to discretionary accruals that managers use to maximize bonus compensation, which suggests that analysts anticipate managers' accounting choices.

The following studies, however, suggest that analysts' forecasts do not always incorporate information related to earnings quality. Elliott and Philbrick (1990) document that analysts' forecast 
revisions do not fully account for the current year's earnings effect of a variety of changes in accounting method, although the association between forecast errors and the earnings effect is generally insignificant. Bradshaw, et al. (2001) show that analyst forecast errors are large for firms with abnormally high working capital accruals, after having verified that their accruals metric is in fact associated with subsequent earnings declines. Finally, Abarbanell and Lehavy (2003) show that analysts' stock recommendations are associated with abnormal accruals, which suggests that analysts fundamentally understand the lower earnings quality, but that analysts do not incorporate this predictable earnings management into their forecasts.

In summary, if we assume that analysts are unbiased and qualified predictors of future earnings, we can use variation in their forecasts to infer attributes of earnings that improve its predictability. ${ }^{79}$ Brown (1983), Elliott and Philbrick (1990), Ashbaugh and Pincus (2001), and Bhattacharya, et al. (2003) provide evidence on specific accounts/methods/estimates that improve predictability. The analyses are joint tests of analyst "efficiency" and earnings quality.

The fundamental assumption that analysts are unbiased and expert forecasters, however, is questionable. Abarbanell and Lehavy (2003) suggest that analysts understand the implications of accruals for earnings predictability, but that forecasts are biased. Kim and Schroeder (1990) and Coles et al. (2006) suggest that when analysts can rationally anticipate accruals management, they appropriately incorporate the implications of accruals into their forecasts. Large sample studies, however, do not reveal this pattern (Bradshaw, et al., 2001). ${ }^{80}$ Overall, the extent to which earnings

\footnotetext{
${ }^{79}$ Using analyst forecasts and an assumption of analyst efficiency to infer earnings quality rather than market prices and an assumption of market efficiency has the advantage that the forecast relates only to earnings. Market prices reflect information other than earnings. Hence, tests that infer earnings quality using market prices and assuming market efficiency confound interpretation of the impact of earnings quality alone on decision usefulness. A disadvantage, however, is that analysts' incentives to issue accurate and unbiased forecasts may differ (Francis, Chen, Philbrick, and Willis, 2004). Equity market investors, however, presumably have incentives to make unbiased forecasts of firm value and to incorporate these into their trading decisions.

${ }^{80}$ Two papers provide related evidence. Burgstahler and Eames (2003) investigate the "kink" in the distribution of earnings around analyst forecasts and show that on average analysts anticipate earnings management that will avoid
} 
management affects predictability depends on the analysts' ability to detect the earnings

management.

\subsubsection{Consequences of earnings quality for real activities (including voluntary disclosure)}

Lougee and Marquardt (2004) document that firms with low earnings informativeness, measured by $E R C$ s, are more likely to voluntarily disclose pro forma earnings. Chen, DeFond, and Park (2002) document that firms with low or uncertain earnings informativeness have a greater propensity to voluntarily disclose balance sheet information in earnings announcements. Chen et al. use multiple ex ante indicators to identify firms with low earnings informativeness (e.g., industry, loss firms, analyst forecast errors, capital market incentives, and firm age). Lennox and Park (2002) find that when earnings are more informative (i.e., high $E R C s$ ), firms issue management forecasts as a particular form of voluntary disclosure. They predict this finding assuming that managers forecast when they are reasonably confident about their accuracy due to reputation concerns. The Lennox and Park finding is directionally opposite to the negative correlation between informativeness and disclosure in Lougee and Marquardt (2004) and Chen et al. (2002).

These studies show that disclosure decisions are endogenously determined by earnings quality. Assuming that equity market participants set prices based on all available information, not just earnings, these findings raise questions about the validity of inferences from tests that measure the association between earnings quality proxies and market-consequences without considering the endogenously-determined availability of non-earnings information. This concern is complicated by

small losses. Analysis of forecast errors further refines their conclusions about the exact types of earnings management analysts can anticipate. Hirst and Hopkins (1998), in an experimental setting, find that buy-side analysts do not adjust valuations for earnings management, specifically cherry-picking sales of AFS securities. When the gains are aggregated with net income, analysts treat do not treat the managed gains differently from unmanaged earnings at control firms. As they manipulate the transparency of the reporting about the gains, the analysts are more likely to discount the managed earnings in their valuations. Thus, analysts' ability to understand earnings management is technique and setting specific. 
the fact that some disclosures are inversely related to commonly used proxies for earnings quality (Lougee and Marquardt, 2004; Chen, DeFond, and Park, 2002), while others are positively related (Lennox and Park, 2002).

We found three papers that predict a real consequence of EQ other than disclosure. Biddle and Hilary (2006) suggest that high accounting quality (i.e., conservatism, loss avoidance, and earnings smoothing) would reduce information asymmetry between managers and outside suppliers of capital and therefore would improve investment efficiency (see also Verdi, 2006). They document that accounting quality is negatively associated with investment-cash flow sensitivity. McNichols and Stubben (2008) show that firms overinvest during misstatement periods. They suggest that overinvestment likely arises from believing in misreported growth trends. Finally, Karpoff, Lee, and Martin (2008) infer from losses in market valuation following AAERs that firms incur substantial reputational penalties for the misstatement, presumably including the negative effects on the firm's future cash flows due to lower sales and higher contracting and financing costs.

\subsubsection{Conclusions from reviewing the literature on non-equity market consequences}

Comparing the results across these categories emphasizes the importance of considering the context when determining the appropriate proxy for decision-usefulness. An investor's decision to litigate depends on whether an earnings misstatement is severe or transparent enough to increase the probability of prevailing as a plaintiff. The auditor's reporting decision, in contrast, depends on whether an earnings misstatement is severe or transparent enough to decrease the probability of prevailing as a defendant. A Board's compensation contract design problem depends on the ex ante informativeness of available signals of the agent's performance, while its variable cash compensation and recontracting decisions depend on the ex post informativeness of the available signals. 


\section{Conclusion}

Our approach in this review is to define earnings quality broadly to be decision usefulness in any decision by any decision maker. As such, the number of relevant articles numbers over 300, and by necessity our discussion is broad.

An alternative approach might have been to limit the scope of the review to studies of decision-usefulness only in an equity valuation context, in accordance with the original use of the term in financial statement analysis. Under that approach, we would have argued that using the term earnings quality outside of the equity valuation context is inappropriate, and we would have criticized the studies that do so and simply ignored them in our review. We would have demanded that researchers and others not use the term earnings quality outside the context of equity valuation models. But we believe that ship has sailed and such a recommendation would therefore serve no purpose. Rather we attempt to understand earnings quality more broadly in its current use.

We emphasize two significant conclusions based on our survey of the earnings quality literature as a whole. First, because all of the proxies for earnings quality that involve earnings (i.e., properties such as persistence, timely loss recognition, smoothness, and small profits, as well as the ERCs) have at their core the reported accrual-based earnings number, these proxies are affected by both the firm's fundamental earnings process and by the measurement of that process. The current research does not adequately recognize the distinction between the fundamental earnings process and the measurement of the process, which limits the conclusions we, as a profession, can make to statements about "earnings quality" rather than about the contribution of accounting measurement to the quality of reported earnings.

Second, although all of the proxies based on reported earnings are affected by both the unobservable process and the measurement, the proxies are not equally affected by these two factors. 
Therefore, the proxies are not measures of the same underlying construct, but rather they measure different elements of decision usefulness. We hope the breadth of the discussion of each proxy has shed light on the context-specific dimensions of quality captured by each proxy and on the sometimes subtle distinctions between them.

We introduced Figures 1 and 2 in the introduction to illustrate the earnings quality proxies that have been used to test the theoretical determinants and consequences of earnings quality. Our objective in providing Figures 1 and 2 is not to suggest that researchers fill in the mosaic. A significant point of this review is that the earnings quality proxies measure different facets of quality, and an implication of this statement is that not all of the cells in the figures represent sensible hypotheses. It may be worth investigating certain cells, not because the theory predicts a relation, but because not finding a relation would provide useful counterfactual evidence.

The figures do, however, highlight some potential opportunities for future research. For example, SOX internal control deficiency firms provide a relatively new opportunity to examine the consequences of financial statement reliability. The implications of benchmarking for compensation and analysts' decisions also are interesting areas for future research. We emphasize, however, that careful research design and a clearer understanding of the strengths and weaknesses of these proxies in the setting examined is important for establishing a meaningful result. Throughout the review, we noted situations where we think the inferences are weak because we question the hypothesized relation between a particular determinant and EQ or between EQ and a particular consequence. Most of the problem stems not from a weak theory but from treating the earnings quality proxies as substitutes for each other and not precisely matching the theory to the construct. 


\section{References}

Abarbanell, J., and Bushee, B., 1997. Fundamental analysis, future earnings, and stock prices. Journal of Accounting Research 35, 1-24.

Abarbanell, J., Lehavy, R., 2003. Can stock recommendations predict earnings management and analysts' earnings forecast errors?. Journal of Accounting Research 41, 1-31.

Abbott, L., Parker, S., Peters, G., 2004. Audit committee characteristics and restatements. Auditing 23, 69-87.

Aboody, D., Barth, M., Kasznik, R., 1999. Revaluations of fixed assets and future firm performance: Evidence from the UK. Journal of Accounting and Economics 26, 149-178.

Aboody, D., Hughes, J., Liu, J., 2005. Earnings quality, insider trading, and cost of capital. Journal of Accounting Research 43, 651-673.

Abreu, D., Brunnermeier, M., 2002. Synchronization risk and delayed arbitrage. Journal of Financial Economics 66, 341-60.

Adams, R., Hermalin, B., Weisbach, M., 2008. The role of boards of directors in corporate governance: A conceptual framework and survey. Working paper, University of Queensland, Ohio State University, and University of California, Berkeley.

Affleck-Graves, J., Callahan, C., Chipalkatti, N., 2002. Earnings predictability, information asymmetry, and market liquidity. Journal of Accounting Research 40, 561-583.

Agrawal, A., Chadha, S., 2005. Corporate governance and accounting scandals. Journal of Law and Economics 48, 371-406.

Aharoni, A., Ronen, J., 1989. The choice among accounting alternatives and management compensation: Effects of corporate tax. The Accounting Review 64, 69-86.

Aharony, J., Lin, C., Loeb, M., 1993. Initial public offerings, accounting choices, and earnings management. Contemporary Accounting Research 10, 61-81.

Ahmed, A., Takeda, C., Thomas, S., 1999. Bank loan loss provisions: A reexamination of capital management, earnings management and signaling effects. Journal of Accounting and Economics 28, 1-25.

Albrecht, W., Lookabill, L., McKeown, J., 1977. The time-series properties of annual earnings. Journal of Accounting Research 15, 226-244.

Alford, A., Jones, J., Leftwich, R., Zmijewski, M., 1993. The relative informativeness of accounting disclosures in different countries. Journal of Accounting Research 31, 183-223.

Ali, A., Hwang, L., 2000. Country-specific factors related to financial reporting and the value relevance of accounting data. Journal of Accounting Research 38, 1-21.

Altamuro, J., Beatty, A., 2009. How does internal control regulation affect financial reporting? Working paper, Ohio State University.

Altamuro, J., Beatty, A., Weber, J., 2005. The effects of accelerated revenue recognition on earnings management and earnings informativeness: Evidence from SEC Staff Accounting Bulletin No. 101. The Accounting Review 80, 373-401.

American Institute of Certified Public Accountants (AICPA). 1988a. Statement on Auditing Standards No. 58. Reports on audited financial statements. New York: AICPA.

American Institute of Certified Public Accountants (AICPA). 1988b. Statement on Auditing Standards No. 59. The auditor's consideration of an entity's ability to continue as a going concern. New York: AICPA.

American Institute of Certified Public Accountants (AICPA). 2002. Statement on Auditing Standards No. 99. Consideration of Fraud in a Financial Statement Audit. New York: AICPA. 
Amir, E., Harris, T., Venuti, E., 1993. A comparison of the value-relevance of U.S. versus non-U.S. GAAP accounting measures using form 20-F reconciliations. Journal of Accounting Research 31, 230-264.

Amir, E., Lev, B., 1996. Value-relevance of nonfinancial information: The wireless communications industry. Journal of Accounting and Economics 22, 3-30.

Anderson, R., Mansi, S., Reeb, D., 2004. Board characteristics, accounting report integrity, and the cost of debt. Journal of Accounting and Economics 37, 315-342.

Archibald, T., 1972. Stock-market reaction to the depreciation switch-back. The Accounting Review 47, 22-30.

Archibald, T., Beaver, W., Becker, S., Sorter, G., 1964. Corporate personality as reflected in accounting decisions: Some preliminary findings. Journal of Accounting Research 2, 183-196.

Armstrong C., Jagolinzer, A., Larcker, D., 2009. Chief executive officer equity incentives and accounting irregularities. Working paper, University of Pennsylvania and Stanford University.

Ashbaugh, H., LaFond, R., Mayhew, B., 2003. Do nonaudit services compromise auditor independence? Further evidence. The Accounting Review 78, 611-639.

Ashbaugh, H., Pincus, M., 2001. Domestic accounting standards, international accounting standards, and the predictability of earnings. Journal of Accounting Research 39, 417-434.

Ashbaugh-Skaife, H.,Collins, D., Kinney, W., 2007. The discovery and reporting of internal control deficiencies prior to sox-mandated audits. Journal of Accounting and Economics 44, 166-192.

Ashbaugh-Skaife, H., Collins, D., Kinney, W., LaFond, R., 2008. The effect of sox internal control deficiencies and their remediation on accrual quality. The Accounting Review 83, 217-250.

Ashbaugh-Skaife, H., Collins, D., Kinney, W., LaFond, R., 2009. The effect of SOX internal control deficiencies on firm risk and cost of equity. Journal of Accounting Research 47, 1-43.

Atiase, R., Bamber, L., Tse, S., 1989. Timeliness of financial reporting, the firm size effect, and stock price reactions to annual earnings announcements. Contemporary Accounting Research 5, 526-552.

Austin, J., Gaver, J., Gaver, K., 1995. Additional evidence on bonus plans and income management. Journal of Accounting and Economics 19, 3-28.

Ayers, B., Jiang, J., Yeung, P., 2006. Discretionary accruals and earnings management: An analysis of pseudo earnings targets. The Accounting Review 81, 617-652.

Baber, W., Chen, S., Kang, S., 2006. Stock price reaction to evidence of earnings management: Implications for supplementary financial disclosure. Review of Accounting Studies 11, 5-19.

Baber, W., Kang, S., Kumar, K., 1998. Accounting earnings and executive compensation: The role of earnings persistence. Journal of Accounting and Economics 25, 169-193.

Baginski, S., Branson, B., Lorek, K., Willinger, G., 1999. The relationship between economic characteristics and alternative annual earnings persistence measures. The Accounting Review 74, 105-120.

Baker, T., Collins, D., Reitenga, A., 2003. Stock option compensation and earnings management incentives. Journal of Accounting, Auditing, and Finance 18, 557-582.

Ball, R., 1972. Changes in accounting techniques and stock prices. Journal of Accounting Research $10,1-38$.

Ball, R., Brown, P., 1967. Some preliminary findings on the association between the earnings of a firm, its industry, and the economy. Journal of Accounting Research 5, 55-80.

Ball, R., Brown, P., 1968. An empirical evaluation of accounting income numbers. Journal of Accounting Research 6, 159-178. 
Ball, R., Foster, G., 1982. Corporate financial reporting: A methodological review of empirical research. Journal of Accounting Research 20, 161-234.

Ball, R., Kothari, S., Robin, A., 2000. The effect of international institutional factors on properties of accounting earnings. Journal of Accounting and Economics 29, 1-51.

Ball, R., Robin, A., Sadka, G., 2008. Is financial reporting shaped by equity markets or by debt markets? An international study of timeliness and conservatism. Review of Accounting Studies 13, 168-205.

Ball, R., Robin, A., Wu, J., 2003. Incentives versus standards: Properties of accounting income in four East Asian countries. Journal of Accounting and Economics 36, 235-270.

Ball, R., Shivakumar, L., 2005. Earnings quality in UK private firms: Comparative loss recognition timeliness. Journal of Accounting and Economics 39, 83-128.

Balsam, S., 1998. Discretionary accounting choices and CEO compensation. Contemporary Accounting Research 15, 229-252.

Balsam, S., Bartov, E., Marquardt, C., 2002. Accruals management, investor sophistication, and equity valuation: Evidence from 10-Q filings. Journal of Accounting Research 40, 987-1012.

Balsam, S., Chen, H., Sankaraguruswamy, S., 2003. Earnings management prior to stock option grants. Working paper, Temple University, Arizona State University, and National University of Singapore.

Balsam, S., Haw, I., Lilien, S., 1995. Mandated accounting changes and managerial discretion. Journal of Accounting and Economics 20, 3-29.

Barefield, R., Comiskey, E., 1971. Depreciation policy and the behavior of corporate profits. Journal of Accounting Research 9, 351-358.

Barnea, A., Ronen, J., Sadan, S., 1976. Classificatory smoothing of income with extraordinary items. The Accounting Review 51, 110-122.

Barron, O., Pratt, J., Stice, J., 2001. Misstatement direction, litigation risk, and planned audit investment. Journal of Accounting Research 39, 449-462.

Barth, M., Cram, D., Nelson, K., 2001. Accruals and the prediction of future cash flow. The Accounting Review 76, 27-58.

Barth, M., Elliott, J., Finn, M., 1999. Market rewards associated with patterns of increasing earnings. Journal of Accounting Research 37, 387-413.

Barth, M., Landsman, W., Lang, M., 2008. International accounting standards and accounting quality. Journal of Accounting Research 46, 467-498.

Barton, J., 2001. Does the use of financial derivatives affect earnings management decisions?. The Accounting Review 76, 1-26.

Barton, J., Simko, P., 2002. The balance sheet as an earnings management constraint. The Accounting Review 77, 1-27.

Barton, J., Waymire, G., 2004. Investor protection under unregulated financial reporting. Journal of Accounting and Economics 38, 65-116.

Bartov, E., 1993. The timing of asset sales and earnings manipulation. The Accounting Review 68, 840-855.

Bartov, E., Givoly, D., Hayn, C., 2002. The rewards to meeting or beating earnings expectations. Journal of Accounting and Economics 33, 173-204.

Bartov, E., Lindahl, F., Ricks, W., 1998. Stock price behavior around announcements of write-offs. Review of Accounting Studies 3, 327-346.

Basu, S., 1997. The conservatism principle and the asymmetric timeliness of earnings. Journal of Accounting and Economics 24, 3-37. 
Beasley, M., 1996. An empirical analysis of the relation between the board of director composition and financial statement fraud. The Accounting Review 71, 443-465.

Beasley, M., Petroni, K., 1996. Errors in accounting estimates and their relation to audit firm type. Journal of Accounting Research 34, 151-171.

Beatty, A., Chamberlain, S., Magliolo, J., 1995. Managing financial reports of commercial banks: The influence of taxes, regulatory capital, and earnings. Journal of Accounting Research 33, 231261. Beatty, A., Harris, D., 1999. The effects of taxes, agency costs and information asymmetry on earnings management: A comparison of public and private firms. Review of Accounting Studies 4, 299-326.

Beatty, A., Ke, B., Petroni, K., 2002. Earnings management to avoid earnings declines across publicly and privately held banks. The Accounting Review 77, 547-570.

Beaver, W., 1968. The information content of annual earnings announcements. Journal of Accounting Research 6, 67-92.Beaver, W., 1970. The time series behavior of earnings. Journal of Accounting Research 8, 62-99.

Beaver, W., Engel, E., 1996. Discretionary behavior with respect to allowances for loan losses and the behavior of security prices. Journal of Accounting and Economics 22, 177-206.

Beaver, W., McNichols, M., 1998. The characteristics and valuation of loss reserves of property casualty insurers. Review of Accounting Studies 3, 73-95.

Beaver, W., McNichols, M., 2001. Do stock prices of property casualty insurers fully reflect information about earnings, accruals, cash flows, and development?. Review of Accounting Studies 6, 197-220.

Beaver, W., McNichols, M., Nelson, K., 2003. Management of the loss reserve accrual and the distribution of earnings in the property-casualty insurance industry. Journal of Accounting and Economics 35, 347-376.

Beaver, W., McNichols, M., Nelson, K., 2007. An alternative interpretation of the discontinuity in earnings distributions. Review of Accounting Studies 12, 525-556.

Beaver, W., McNichols, M., Rhie, J., 2005. Have financial statements become less informative? Evidence from the ability of financial ratios to predict bankruptcy. Review of Accounting Studies 10, 93-122.

Becker, C., DeFond, M., Jiambalvo, J., Subramanyam, K., 1998. The effect of audit quality on earnings management. Contemporary Accounting Research 15, 1-24.

Bedard, J., 2006. Sarbanes Oxley internal control requirements and earnings quality. Working paper, Laval University.

Beidleman, C., 1973. Income smoothing: The role of management. The Accounting Review 48, 653667.

Beneish, M., 1999. Incentives and penalties related to earnings overstatements that violate GAAP. The Accounting Review 74, 425-457.

Beneish, M., Billings, M., Hodder, L., 2008. Internal control weaknesses and information uncertainty. The Accounting Review 83, 665-703.

Bens, D., Nagar, V., Skinner, D., Wong, M., 2003. Employee stock options, EPS dilution, and stock repurchases. Journal of Accounting and Economics 36, 51-90.

Bergstresser, D., Philippon, T., 2006. CEO incentives and earnings management. Journal of Financial Economics 80, 511-529.

Bernard, V., Stober, T., 1989. The nature and amount of information in cash flows and accruals. The Accounting Review 64, 624-652. 
Bhattacharya, N., Black, E., Christensen, T., Larson, C., 2003. Assessing the relative informativeness and permanence of pro forma earnings and GAAP operating earnings. Journal of Accounting and Economics 36, 285-319.

Bhattacharya, U., Daouk, H., Welker, M., 2003. The world price of earnings opacity. The Accounting Review 78, 641-678.

Bhojraj, S., Swaminathan, B., 2007. How does the corporate bond market value capital investments and accruals?. Review of Accounting Studies 14, 31-62.

Biddle, G., 1980. Accounting methods and management decisions: The case of inventory costing and inventory policy. Journal of Accounting Research 18, 235-280.

Biddle, G., Hilary, G., 2006. Accounting quality and firm-level capital investment. The Accounting Review 81, 963-982.

Bonner, S., Palmrose, Z., Young, S., 1998. Fraud type and auditor litigation: An analysis of SEC accounting and auditing enforcement releases. The Accounting Review 73, 503-532.

Bowen, R., Burgstahler, D., Daley, L., 1986. Evidence on the relationships between earnings and various measures of cash flow. The Accounting Review 61, 713-725.

Bowen, R., Davis, A., Rajgopal, S., 2002. Determinants of revenue-reporting practices for internet firms. Contemporary Accounting Research 19, 523-562.

Bowen, R., DuCharme, L., Shores, D., 1995. Stakeholders' implicit claims and accounting method choice. Journal of Accounting and Economics 20, 255-295.

Bowen, R., Lacey, J., Noreen, E., 1981. Determinants of the corporate decision to capitalize interest. Journal of Accounting and Economics 3, 151-179.

Bowen, R., Rajgopal, S., Venkatachalam, M., 2008. Accounting discretion, corporate governance, and firm performance. Contemporary Accounting Research 25, 310-405.

Boynton, C., Dobbins, P., Plesko, G., 1992. Earnings management and the corporate alternative minimum tax. Journal of Accounting Research 30, 131-153.

Bradshaw, M., Richardson, S., Sloan, R., 2001. Do analysts and auditors use information in accruals?. Journal of Accounting Research 39, 45-74.

Bradshaw, M., Sloan, R., 2002. GAAP versus the street: An empirical assessment of two alternative definitions of earnings. Journal of Accounting Research 40, 41-66.

Brief, A., Kinney, W., Uecker, W., 1981. Perception of the internal and external auditor as a deterrent to corporate irregularities. The Accounting Review 56, 465-478.

Brown, L., 1983. Accounting changes and the accuracy of analyst's earnings forecasts. Journal of Accounting Research 21, 432-443.

Brown, L., Pinello, A., 2007. To what extent does the financial reporting process curb earnings surprise games?. Journal of Accounting Research 45, 947-981.

Brown, S., Lo, K., Lys, T., 1999. Use of $\mathrm{r} 2$ in accounting research: Measuring changes in value relevance over the last four decades. Journal of Accounting and Economics 28, 83-115.

Bryan, S., 1997. Incremental information content of required disclosures contained in management discussion and analysis. The Accounting Review 72, 285-301.

Burgstahler, D., Dichev, I., 1997. Earnings management to avoid earnings decreases and losses. Journal of Accounting and Economics 24, 99-126.

Burgstahler, D., Eames, M., 2003. Earnings management to avoid losses and earnings decrease: Are analysts fooled?. Contemporary Accounting Research 20, 253-294.

Burgstahler, D., Hail, L., Leuz, C., 2006. The importance of reporting incentives: Earnings management in European private and public firms. The Accounting Review 81, 983-1016. 
Burgstahler, D., Kinney, W., Martin, R., 2002. Earnings surprise materiality as measured by stock returns. Journal of Accounting Research 40, 1297-1329.

Burns, N., Kedia, S., 2006. The impact of performance-based compensation on misreporting. Journal of Financial Economics 79, 35-67.

Bushee, B., 1998. The influence of institutional investors in myopic R\&D investment behavior. The Accounting Review 73, 305-333.

Bushman, R., Chen, Q., Engel, E., Smith, A., 2004. Financial accounting information, organizational complexity and corporate governance systems. Journal of Accounting and Economics 37, 167201.

Butler, M., Leone, A., Willenborg, M., 2004. An empirical analysis of auditor reporting and its association with abnormal accruals. Journal of Accounting and Economics 37, 139-165.

Cahan, S., 1992. The effect of antitrust investigations on discretionary accruals: A refined test of the political-cost hypothesis. The Accounting Review 67, 77-95.

Calegari, M., 2000. The effect of tax accounting rules on capital structure and discretionary accruals. Journal of Accounting and Economics 30, 1-31. Callahan, C., Lee, C., Yohn, T., 1997. Accounting information and bid-ask spreads. Accounting Horizons 11, 50-60.

Caramanis, C., Lennox, C., 2008. Audit effort and earnings management. Journal of Accounting and Economics 45, 116-138.

Cassidy, D., 1976. Investor evaluation of accounting information: Some additional empirical evidence. Journal of Accounting Research 14, 212-229.

Chambers, R., 1956. Some observations on "Structure of accounting theory". The Accounting Review 31, 584-592.

Chambers, R., 1965. Edwards and Bell on business income. The Accounting Review 40, 731-741.

Chambers, D., 1999. Earnings management and capital market misallocation. Working paper, Kennesaw State University.

Chaney, P., Jeter, D., Lewis, C., 1998. The use of accruals in income smoothing: A permanent earnings hypothesis. Advances in Quantitative Analysis of Finance \& Accounting 6, 103 -135.

Chang, H., Chen, J., Liao, W., Mishra, B., 2006. CEOs'/CFOs' swearing by the numbers: Does it impact share price of the firm?. The Accounting Review 81, 1-27.

Chauvin, K., Shenoy, C., 2001. Stock price decreases prior to executive stock option grants. Journal of Corporate Finance 7, 53-76.

Chen, C., Gul, F., Tsui, J., 2003. Discretionary accounting accruals, managers' incentives, and audit fees. Contemporary Accounting Research 20, 441-464.

Chen, C., Lin, C., Lin, Y., 2008. Audit partner tenure, audit firm tenure, and discretionary accruals: Does long auditor tenure impair earnings quality?. Contemporary Accounting Research 25, 447471.

Chen, C., Su, X., Zhao, R., 2000. An emerging market's reaction to initial modified audit opinions: Evidence from the shanghai stock exchange. Contemporary Accounting Research 17, 429-455.

Chen, P., Daley, L., 1996. Regulatory capital, tax, and earnings management effects on loan loss accruals in the Canadian banking industry. Contemporary Accounting Research 13, 91-128.

Chen, Q., Francis, J., Philbrick, D., Schipper, K., Willis, R., 2004. Security Analyst Independence. CFA Institute.

Chen, Q., Hemmer, T., Zhang Y., 2007. On the relation between conservatism in accounting standards and incentives for earnings management. Journal of Accounting Research 45, 541-565.

Chen, S., DeFond, M., Park, C., 2002. Voluntary disclosure of balance sheet information in quarterly earnings announcements. Journal of Accounting and Economics 33, 229-251. 
Chen, S., Shevlin, T., Tong, Y., 2007. Does the pricing of financial reporting quality change around dividend changes?. Journal of Accounting Research 45, 1-40.

Cheng, C., Thomas, W., 2006. Evidence of the abnormal accrual anomaly incremental to operating cash flows. The Accounting Review 81, 1151-1167.

Cheng, Q., Farber, D., 2008. Earnings restatements, changes in CEO compensation, and firm performance. The Accounting Review 83, 1217-1250.

Cheng, Q., Warfield, T., 2005. Equity incentives and earnings management. The Accounting Review 80, 441-476.

Choi, W., Gramlich, J., Thomas, J., 2001. Potential errors in detecting earnings management: Reexamining studies investigating the AMT of 1986. Contemporary Accounting Research 18, 571-613.

Chow, C., Rice, S., 1982. Qualified audit opinions and share prices: An investigation. Auditing 1, 35-54.

Christensen, P., Feltham, G., Şabac, F., 2005. A contracting perspective on earnings quality. Journal of Accounting and Economics 39, 265-294.

Christie, A., 1990. Aggregation of test statistics: An evaluation of the evidence on contracting and size hypotheses. Journal of Accounting and Economics 12, 15-36.

Christie, A., Zimmerman, J., 1994. Efficient and opportunistic choices of accounting procedures: Corporate control. The Accounting Review 69, 539-566.

Cronbach, L., Meehl, P., 1955. Construct validity in psychological tests. Psychological Bulletin, 52, 281-302.

Chung, H., Kallapur, S., 2003. Client importance, nonaudit services, and abnormal accruals. The Accounting Review 78, 931-955.

Chung, H., Wynn, J., 2008. Managerial legal liability coverage and earnings conservatism. Journal of Accounting and Economics 46, 135-153.

Chung, R., Firth, M., Kim, J., 2003. Auditor conservatism, asymmetric monitoring, and earnings management. Contemporary Accounting Research 20, 323-359.

Cohen, D., Dey, A., Lys, T., 2008. Real and accrual-based earnings management in the pre- and post-Sarbanes-Oxley periods. The Accounting Review 83, 757-787.

Coles, J., Hertzel, M., Kalpathy, S., 2006. Earnings management around employee stock option reissues. Journal of Accounting and Economics 41, 173-200.

Collins, D., DeAngelo, L., 1990. Accounting information and corporate governance: Market and analyst reactions to earnings of firms engaged in proxy contests. Journal of Accounting and Economics 13, 213-247.

Collins, D., Gong, G., Hribar, P., 2003. Investor sophistication and the mispricing of accruals. Review of Accounting Studies 8, 251-276.

Collins, D., Kothari, S., Shanken, J., Sloan, R., 1994. Lack of timeliness and noise as explanations for the low contemporaneous return-earnings association. Journal of Accounting and Economics $18,289-324$.

Collins, D., Li, O., Xie, H., 2007. What drives the increased informativeness of earnings announcements over time?. Review of Accounting Studies 14, 1-30.

Collins, D., Maydew, E., Weiss, I., 1997. Changes in the value-relevance of earnings and book values over the past forty years. Journal of Accounting and Economics 24, 39-67.

Collins, D., Salatka, W., 1993. Noisy accounting earnings signals and earnings response coefficients: The case of foreign currency accounting. Contemporary Accounting Research 10, 119-159. 
Considine, J., Mensah, Y., Oakes, L., 1994. Statutory insolvency regulations and earnings management in the prepaid health-care industry. The Accounting Review 69, 70-95.

Cook, K., Huston, G., Omer, T., 2008. Earnings management through effective tax rates: The effects of tax-planning investment and the Sarbanes-Oxley act of 2002. Contemporary Accounting Research 25, 415-445.

Copeland, R., 1968. Income smoothing. Journal of Accounting Research 6, 101-116.

Cordery, C., Johnson, C., Khurana, I., Lowe, J., Sawyers, R., Wunderle, R., 1992. The information content of audit qualifications. Auditing: A Journal of Practice and Theory 11, 69-82.

Core, J., Guay, W., VanBuskirk, A., 2003. Market valuations in the new economy: An investigation of what has changed. Journal of Accounting and Economics 34, 43-67.

Core, J., Guay, W., Verdi, R., 2008. Is accruals quality a priced risk factor?. Journal of Accounting and Economics 46, 2-22.

Core, J., Schrand, C., 1999. The effect of accounting-based debt covenants on equity valuation. Journal of Accounting and Economics 27, 1-34.

Cuccia, A., Hackenbrack, K., Nelson, M., 1995. The ability of professional standards to mitigate aggressive reporting. The Accounting Review 70, 227-248.

Cushing, B., 1974. A mathematical approach to the analysis and design of internal control systems. The Accounting Review 49, 24-41.

Daines, H., 1929. The changing objectives of accounting. The Accounting Review 4, 94-110.

Daley, L., Vigeland, R., 1983. The effects of debt covenants and political costs on the choice of accounting methods: The case of accounting for R\&D costs. Journal of Accounting and Economics 5, 195-211.

Daniel, K., Titman, S., 1997. Evidence on the characteristics of cross sectional variation in stock returns. Journal of Finance 52, 1-33.

Darrough, M., Rangan, S., 2005. Do insiders manipulate earnings when they sell their shares in an initial public offering?. Journal of Accounting Research 43, 1-33.

Das, S., Zhang, H., 2003. Rounding-up in reported EPS, behavioral thresholds, and earnings management. Journal of Accounting and Economics 35, 31-50.

Dascher, P., Malcom, R., 1970. A note on income smoothing in the chemical industry. Journal of Accounting Research 8, 253-259.

DeAngelo, H., DeAngelo, L., Skinner, D., 1994. Accounting choice in troubled companies. Journal of Accounting and Economics 17, 113-143.

DeAngelo, L., 1981. Auditor independence, 'low balling', and disclosure regulation. Journal of Accounting and Economics 3, 113-127.

DeAngelo, L., 1986. Accounting numbers as market valuation substitutes: A study of management buyouts of public stockholders. The Accounting Review 61, 400-420.

DeAngelo, L., 1988. Discussion of evidence of earnings management from the provision for bad debts. Journal of Accounting Research 26, 32-40.

DeAngelo, L., 1988. Managerial competition, information costs, and corporate governance: The use of accounting performance measures in proxy contests. Journal of Accounting and Economics 10, 3-36.

Dechow, P., 1994. Accounting earnings and cash flows as measures of firm performance: The role of accounting accruals. Journal of Accounting and Economics 18, 3-42.

Dechow, P., Dichev, I., 2002. The quality of accruals and earnings: The role of accrual estimation errors. The Accounting Review 77, 35-59. 
Dechow, P., Ge, W., 2006. The persistence of earnings and cash flows and the role of special items: Implications for the accrual anomaly. Review of Accounting Studies 11, 253-296.

Dechow, P., Ge, W., Larson, C., Sloan, R., 2009. Predicting material accounting misstatements. Working paper, University of California, Berkeley, University of Washington, and Washington University in St. Louis.

Dechow, P., Huson, M., Sloan, R., 1994. The effect of restructuring charges on executives' cash compensation. The Accounting Review 69, 138-156.

Dechow, P., Kothari, S., Watts, R., 1998. The relation between earnings and cash flows. Journal of Accounting and Economics 25, 133-168.

Dechow, P., Myers, L., Shakespeare, C., 2009. Fair value accounting and gains from asset securitizations: A convenient earnings management tool with compensation side-benefits. Working paper, University of Michigan, University of California, Berkeley, and University of Arkansas.

Dechow, P., Richardson, S., Sloan, R., 2008. The persistence and pricing of the cash component of earnings. Journal of Accounting Research 46, 537-566.

Dechow, P., Richardson, S., Tuna, I., 2003. Why are earnings kinky? An examination of the earnings management explanation. Review of Accounting Studies 8, 355-384.

Dechow, P., Schrand, C., 2004. Earnings quality. The Research Foundation of CFA Institute.

Dechow, P., Skinner, D., 2000. Earnings management: Reconciling the views of accounting academics, practitioners, and regulators. Accounting Horizons 14, 232-250.

Dechow, P., Sloan, R., 1991. Executive incentives and the horizon problem: An empirical investigation. Journal of Accounting and Economics 14, 51-89.

Dechow, P., Sloan, R., Sweeney, A., 1995. Detecting earnings management. The Accounting Review 70, 193-225.

Dechow, P., Sloan, R., Sweeney, A., 1996. Causes and consequences of earnings manipulation: An analysis of firms subject to enforcement actions by the SEC. Contemporary Accounting Research 13, 1-36.

DeFond, M., Hung, M., Trezevant, R., 2007. Investor protection and the information content of annual earnings announcements: International evidence. Journal of Accounting and Economics 43, 37-67.

DeFond, M., Jiambalvo, J., 1994. Debt covenant violation and manipulation of accruals. Journal of Accounting and Economics 17, 145-176.

DeFond, M., Park, C., 1997. Smoothing income in anticipation of future earnings. Journal of Accounting and Economics 23, 115-139.

DeFond M., Park, C., 2001. The reversal of abnormal accruals and the market valuation of earnings surprises. The Accounting Review 76, 375-404.

DeFond, M., Subramanyam, K., 1998. Auditor changes and discretionary accruals. Journal of Accounting and Economics 25, 35-67.

Demski, J., 1973. Rational choice of accounting method for a class of partnership. Journal of Accounting Research 11, 176-190.

Demski, J., 1998. Performance measure manipulation. Contemporary Accounting Research 15, 261285.

Desai, H., Hogan, C., Wilkins, M., 2006. The reputational penalty for aggressive accounting: Earnings restatements and management turnover. The Accounting Review 81, 83-112.

Desai, H., Krishnamurthy, S., Venkataraman, K., 2006. Do short sellers target firms with poor earnings quality? Evidence from earnings restatements. Review of Accounting Studies 11, 71-90. 
Desai, H., Rajgopal, S., Venkatachalam, M., 2004. Value-glamour and accrual mispricing: One anomaly or two?. The Accounting Review 79, 355-385.

Dhaliwal, D., Fargher, N., Lee, K., 1991. The association between unexpected earnings and abnormal security returns in the presence of financial leverage. Contemporary Accounting Research 8, 20-41.

Dhaliwal, D., Gleason, C., Mills, L., 2004. Last-chance earnings management: Using the tax expense to meet analysts' forecasts. Contemporary Accounting Research 21, 431-459.

Dhaliwal, D., Salamon, G., Smith, E., 1982. The effect of owner versus management control on the choice of accounting methods. Journal of Accounting and Economics 4, 41-53.

Dharan, B., 1987. The effect of sales and collection disclosures on cash flow forecasting and income smoothing. Contemporary Accounting Research 3, 445-459.

Dharan, B., Lev, B., 1993. The valuation consequence of accounting changes: A multi-year examination. Journal of Accounting, Auditing and Finance 8, 475-494.

Dichev, I., Skinner, D., 2002. Large-sample evidence on the debt covenant hypothesis. Journal of Accounting research 40(4), 1091-1123.

Dichev, I., Tang, V., 2008. Matching and the changing properties of accounting earnings over the last 40 years. The Accounting Review 83, 1425-1460.

Dietrich, J., Harris, M., Muller, K., 2000. The reliability of investment property fair value estimates. Journal of Accounting and Economics 30, 125-158.

Dietrich, J., K. Muller, and E. Riedl. 2007. Asymmetric timeliness tests of accounting conservatism. Review of Accounting Studies 12(1): 95-125.

Dodd, D., Graham, B., 1934. Security Analysis, The McGraw-Hill Book Company, Inc.

Dodd, P., Dopuch, N., Holthausen, R., Leftwich, R., 1984. Qualified audit opinions and stock prices: Information content, announcement dates and concurrent disclosures. Journal of Accounting and Economics 6, 3-38.

Dontoh, A., Radhakrishnan, S., Ronen, J., 2004. The declining value-relevance of accounting information and non-information-based trading: An empirical analysis. Contemporary Accounting Research 21, 795-812.

Dopuch, N., Holthausen, R., Leftwich, R., 1986. Abnormal stock returns associated with media disclosures of 'subject to' qualified audit opinions. Journal of Accounting and Economics 8, 93117.

Dopuch, N., Pincus, M., 1988. Evidence on the choice of inventory accounting methods: LIFO versus FIFO. Journal of Accounting Research 26, 28-59.

Doyle, J., Ge, W., McVay, S., 2007. Accruals quality and internal control over financial reporting. The Accounting Review 82, 1141-1170.

Doyle, J., Ge, W., McVay, S., 2007. Determinants of weaknesses in internal control over financial reporting. Journal of Accounting and Economics 44, 193-223.

Doyle, J., Lundholm, R., Soliman, M., 2003. The predictive value of expenses excluded from pro forma earnings. Review of Accounting Studies 8, 145-174.

Ducharme, L., Malatesta, P., Sefcik, S., 2004. Earnings management, stock issues, and shareholder lawsuits. Journal of Financial Economics 71, 27-49.

Durtschi, C., Easton, P., 2005. Earnings management? The shapes of the frequency distributions of earnings metrics are not evidence ipso facto. Journal of Accounting Research 43, 557-592.

Dutta, S., Reichelstein, S., 2005. Accrual accounting for performance evaluation. Review of Accounting Studies 10, 527-552.

Dyckman, T., 1964. On the Investment Decision. The Accounting Review 39, 285-295. 
Dye, R., 1988. Earnings management in an overlapping generations model. Journal of Accounting Research 26, 195-235.

Dye, R., Verrecchia, R., 1995. Discretion vs. uniformity: Choices among GAAP. The Accounting Review 70, 389-415.

Easley, D., O'Hara, M., 2004. Information and the cost of capital. Journal of Finance 59, 1553-1583.

Easton, P., Monahan, S., Vasvari, F., 2009. Initial evidence on the role of accounting earnings in the bond market. Journal of Accounting Research 47, 721-766.

Easton, P., Zmijewski, M., 1989. Cross-sectional variation in the stock market response to the announcement of accounting earnings. Journal of Accounting and Economics 9, 117-141.

Ecker, F., Francis, J., Kim, I., Olsson, P., Schipper, K., 2006. A returns-based representation of earnings quality. The Accounting Review 81, 749-780.

Efendi, J., Srivastava, A., Swanson, E., 2007. Why do corporate managers misstate financial statements? The role of option compensation and other factors. Journal of Financial Economics 85, 667-708.

Elgers, P., Pfeiffer, R., Porter, S., 2003. Anticipatory income smoothing: A re-examination. Journal of Accounting and Economics 35, 405-422.

Elliot, J., Hanna, J., 1996. Repeated accounting write-offs and the information content of earnings. Journal of Accounting Research 34, 135-155.

Elliott, J., Nelson, M., Tarpley, R., 2002. Evidence from auditors about managers' and auditors' earnings management decisions. The Accounting Review 77, 175-202.

Elliott, J., Nelson, M., Tarpley, R., 2003. How are earnings managed? Examples from auditors. Accounting Horizons 17, 17-35.

Elliott, J., Philbrick, D., 1990. Accounting changes and earnings predictability. The Accounting Review 65, 157-174.

Elliott, J., Shaw, W., 1988. Write-offs as accounting procedures to manage perceptions. Journal of Accounting Research 26, 91-119.

Engel, E., Hayes, R., Wang, X., 2003. CEO turnover and properties of accounting information. Journal of Accounting and Economics 36, 197-226.

Erickson, M., Hanlon, M., Maydew, E., 2006. Is there a link between executive equity incentives and accounting fraud?. Journal of Accounting Research 44, 113-143.

Erickson, M., Wang, S., 1999. Earnings management by acquiring firms in stock for stock mergers. Journal of Accounting and Economics 27, 149-176.

Evans, J., Sridhar, S., 1996. Multiple control systems, accrual accounting, and earnings management. Journal of Accounting Research 34, 45-65.

Ewert, R., Wagenhofer, A., 2009, Earnings quality metrics and what they measure, Working paper, University of Graz.

Fairfield, P., Whisenant, S., Yohn, T., 2003a. Accrued earnings and growth: Implications for future profitability and market mispricing. The Accounting Review 78, 353-371.

Fairfield, P., Whisenant, S., Yohn, T., 2003b. The differential persistence of accruals and cash flows for future operating income versus future profitability. Review of Accounting Studies 8, 221243.

Fama, E., French, K., 1992. The cross-section of expected stock returns. Journal of Finance 47, 427465.

Fan, J., Wong, T., 2002. Corporate ownership structure and the informativeness of accounting earnings in East Asia. Journal of Accounting and Economics 33, 401-425. 
Farber, D., 2005. Restoring trust after fraud: Does corporate governance matter?. The Accounting Review 80, 539-561.

Feng, M., Ge, W., Luo, S., Shevlin, T., 2009. Why do CFOs become involved in material accounting manipulations?. Working paper, University of Washington and University of Pittsburgh.

Ferguson, M., Seow, G., Young, D., 2004. Nonaudit services and earnings management: UK evidence. Contemporary Accounting Research 21, 813-841.

Feroz, E., Park, K., Pastena, V., 1991. The financial and market effects of the SEC's accounting and auditing enforcement releases. Journal of Accounting Research 29, 107-142.

Financial Accounting Standards Board, 1978. Statement of Financial Accounting Concepts No. 1, Objectives of financial reporting by business enterprises, FASB, Norwalk, CT.

Finger, C., 1994. The ability of earnings to predict future earnings and cash flows. Journal of Accounting Research 32, 210-223.

Fischer, P., Stocken, P., 2004. Effect of investor speculation on earnings management. Journal of Accounting Research 42, 843-870.

Fischer, P., Verrecchia, R., 2000. Reporting bias. The Accounting Review 75, 229-245.

Fisher, I., 1907. The Rate of Interest, New York: The Macmillan Co.

Fisher, I., 1930. The Theory of Interest, New York: The Macmillan Co.

Foster, G., 1977. Quarterly accounting data: Time-series properties and predictive ability results. The Accounting Review 52, 1-21.Francis, J., Hanna, J., Vincent, L., 1996. Causes and effects of discretionary asset write-offs. Journal of Accounting Research 34, 117-134.

Francis, J., Huang, A., Rajgopal, S., Zang, A., 2008. CEO reputation and earnings quality. Contemporary Accounting Research 25, 109-147.

Francis, J., Ke, B., 2006. Disclosure of fees paid to auditors and the market valuation of earnings surprises. Review of Accounting Studies 11, 495-523.

Francis, J., Krishnan, J., 1999. Accounting accruals and auditor reporting conservatism. Contemporary Accounting Research 16, 135-165.

Francis, J., LaFond, R., Olsson, P., Schipper, K., 2004. Costs of equity and earnings attributes. The Accounting Review 79, 967-1010.

Francis, J., LaFond, R., Olsson, P., Schipper, K., 2005. The market pricing of accruals quality. Journal of Accounting and Economics 39, 295-327.

Francis, J., Maydew, E., Sparks, H., 1999. The role of big 6 auditors in the credible reporting of accruals. Auditing 18, 17-34.

Francis, J., Nanda, D., Olsson, P., 2008. Voluntary disclosure, earnings quality, and cost of capital. Journal of Accounting Research 46, 53-99.

Francis, J., Olsson, P., Schipper, K., 2006, Earnings quality. Foundation and Trends in Accounting 1, 259-340.

Francis, J., Schipper, K., 1999. Have financial statements lost their relevance?. Journal of Accounting Research 37, 319-352.

Francis, J., Schipper, K., Vincent, L., 2002. Earnings announcements and competing information. Journal of Accounting and Economics 33, 313-342.

Francis, J., Schipper, K., Vincent, L., 2002. Expanded disclosures and the increased usefulness of earnings announcements. The Accounting Review 77, 515-546.

Francis, J., Schipper, K., Vincent, L., 2005. Earnings and dividend informativeness when cash flow rights are separated from voting rights. Journal of Accounting and Economics 39, 329-360.

Francis, J., Wang, D., 2008. The joint effect of investor protection and big 4 audits on earnings quality around the world. Contemporary Accounting Research 25, 157-191. 
Frankel, R., Johnson, M., Nelson, K., 2002. The relation between auditors' fees for nonaudit services and earnings management. The Accounting Review 77, 71-105.

Frankel, R., Lee, C., 1998. Accounting valuation, market expectation, and cross-sectional stock returns. Journal of Accounting and Economics 25, 283-319.

Friedlan, J., 1994. Accounting choices of issuers of initial public offerings. Contemporary Accounting Research 11, 1-31.

García Lara, J., García Osma, B., Penalva, F., 2009. Accounting conservatism and corporate governance. Review of Accounting Studies 14, 161-201.

Gârleanu, N., Pedersen, L., 2004. Adverse selection and the required return. Review of Financial Studies 17, 643-665.

Gaver, J., Paterson, J., 1999. Managing insurance company financial statements to meet regulatory and tax reporting goals. Contemporary Accounting Research 16, 207-241.

Gaver, J., Paterson, J., 2001. The association between external monitoring and earnings management in the property-casualty insurance industry. Journal of Accounting Research 39, 269-282.

Ge, W., 2007. Off-balance-sheet activities, earnings persistence and stock prices: Evidence from operating leases. Working paper, University of Washington.

Ge, W., Matsumoto, D., Zhang, J., 2009. Do CFOs have styles of their own? An empirical investigation of the effect of individual CFOs on financial reporting practices. Working paper, University of Washington.

Ge, W., McVay, S., 2005. The disclosure of material weaknesses in internal control after the Sarbanes-Oxley act. Accounting Horizons 19, 137-158.

Geiger, M., Lennox, C., North, D., 2008. The hiring of accounting and finance officers from audit firms: How did the market react?. Review of Accounting Studies 13, 55-86.

Geiger, M., North, D., 2006. Does hiring a new CFO change things? An investigation of changes in discretionary accruals. The Accounting Review 81, 781-809.

Gelb, D., Zarowin, P., 2002. Corporate disclosure policy and the informativeness of stock prices. Review of Accounting Studies 7, 33-52.

Ghosh, A., Gu, Z., Jain, P., 2005. Sustained earnings and revenue growth, earnings quality, and earnings response coefficients. Review of Accounting Studies 10, 33-57.

Gigler, F., Hemmer, T., 2001. Conservatism, optimal disclosure policy, and the timeliness of financial reports. The Accounting Review 76, 471-493.

Givoly, D., Hayn, C., 2000. The changing time-series properties of earnings, cash flows and accruals: Has financial reporting become more conservative?. Journal of Accounting and Economics 29, 287-320.

Gleason, C., Jenkins, N., Johnson, W., 2008. The contagion effects of accounting restatements. The Accounting Review 83, 83-110.

Gleason, C., Mills, L., 2008. Evidence of differing market responses to beating analysts' targets through tax expense decreases. Review of Accounting Studies 13, 295-318.

Gonedes, N., 1969. The significance of selected accounting procedures: A statistical test. Journal of Accounting Research 7, 90-113.

Gonedes, N., 1975. Risk, information, and the effects of special accounting items on capital market equilibrium. Journal of Accounting Research 13, 220-256.

Gonedes, N., 1978. Corporate signaling, external accounting, and capital market equilibrium: Evidence on dividends, income, and extraordinary items. Journal of Accounting Research 16, 2679. 
Gong, G., Louis, H., Sun, A., 2008. Earnings management, lawsuits, and stock-for-stock acquirers' market performance. Journal of Accounting and Economics 46, 62-77.

Graham, J., Harvey, C., Rajgopal, S., 2005. The economic implications of corporate financial reporting. Journal of Accounting and Economics 40, 3-73.

Greenberg, R., Johnson, G., Ramesh, K., 1986. Earnings versus cash flow as a predictor of future cash flow measures. Journal of Accounting, Auditing, and Finance 1, 266-277.

Griffin, P., 1977. The time-series behavior of quarterly earnings: Preliminary evidence. Journal of Accounting Research 15, 71-83.

Guay, W., Kothari, S., Watts, R., 1996. A market-based evaluation of discretionary accrual models. Journal of Accounting Research 34, 83-105.

Guenther, D., 1994. Earnings management in response to corporate tax rate changes: Evidence from the 1986 tax reform act. The Accounting Review 69, 230-243.

Guenther, D., Maydew, E., Nutter, S., 1997. Financial reporting, tax costs, and book-tax conformity. Journal of Accounting and Economics 23, 225-248.

Guenther, D., Young, D., 2000. The association between financial accounting measures and real economic activity: A multinational study. Journal of Accounting and Economics 29, 53-72.

Guidry, F., Leone, A., Rock, S., 1999. Earnings-based bonus plans and earnings management by business-unit managers. Journal of Accounting and Economics 26, 113-142.

Guiso, L., Sapienza, P., Zingales, L., 2008. Cultural biases in economic exchange? Forthcoming, Quarterly Journal of Economics.

Gul, F., Srinidhi, B., 2007. The differential effects of auditors' nonaudit and audit fees on accrual quality. Contemporary Accounting Research 24, 595-629.

Hackenbrack, K., Hogan, C., 2002. Market response to earnings surprises conditional on reasons for an auditor change. Contemporary Accounting Research 19, 195-223.

Hagerman, R., Zmijewski, M., 1979. Some economic determinants of accounting policy choice. Journal of Accounting and Economics 1, 141-161.

Hagerman, R., Zmijewski, M., 1981. An income strategy approach to the positive theory of accounting standard setting/choice. Journal of Accounting and Economics 3, 129-149.

Hall, S., Stammerjohan, W., 1997. Damage awards and earnings management in the oil industry. The Accounting Review 72, 47-65.

Hammersley, J., Myers, L., Shakespeare, C., 2008. Market reactions to the disclosure of internal control weaknesses and to the characteristics of those weaknesses under section 302 of the Sarbanes Oxley Act of 2002. Review of Accounting Studies 13, 141-165.

Han, J., Wang, S., 1998. Political costs and earnings management of oil companies during the 1990 Persian Gulf crisis. The Accounting Review 73, 103-117.

Hand, J., 1989. Did firms undertake debt-equity swaps for an accounting paper profit or true financial gain?. The Accounting Review 64, 587-623.

Hanlon, M., 2005. The persistence and pricing of earnings, accruals, and cash flows when firms have large book-tax differences. The Accounting Review 80, 137-166.

Harrison, T., 1977. Different market reactions to discretionary and nondiscretionary accounting changes. Journal of Accounting Research 15, 84-107.

Haw, I., Hu, B., Hwang, L., Wu, W., 2004. Ultimate ownership, income management, and legal and extra-legal institutions. Journal of Accounting Research 42, 423-462.

Haw, I., Qi, D., Wu, D., Wu, W., 2005. Market consequences of earnings management in response to security regulations in China. Contemporary Accounting Research 22, 95-140. 
Hayn, C., 1995. The information content of losses. Journal of Accounting and Economics 20, 125153.

Healy, P., 1985. The effect of bonus schemes on accounting decisions. Journal of Accounting and Economics 7, 85-107.

Healy, P., Howe, C., Myers, S., 2002. R\&D accounting and the tradeoff between relevance and objectivity. Journal of Accounting Research 40, 677-710.

Healy, P., Palepu, K., 1990. Effectiveness of accounting-based dividend covenants. Journal of Accounting and Economics 12, 97-123.

Healy, P., Palepu, K., 1993. The effect of firms' financial disclosure strategies on stock prices. Accounting Horizons 7, 1-11.

Healy, P., Wahlen, J., 1999. A review of the earnings management literature and its implications for standard setting, Accounting Horizons 13, 365-383.

Heninger, W., 2001. The association between auditor litigation and abnormal accruals. The Accounting Review 76, 111-126.

Hennes, K., Leone, A., Miller, B., 2008. The importance of distinguishing errors from irregularities in restatement research: The case of restatements and $\mathrm{CEO} / \mathrm{CFO}$ turnover. The Accounting Review 83, 1487-1519.

Heron, R., Lie, E., 2006. Fraction of stock option grants to top executives have been manipulated or backdated?. Working paper, Indiana University and University of Iowa.

Herrmann, D., Inoue, T., Thomas, W., 2003. The sale of assets to manage earnings in Japan. Journal of Accounting Research 41, 89-108.

Hirshleifer, D., Teoh, S., 2003. Limited attention, information disclosure, and financial reporting. Journal of Accounting and Economics 36, 337-386.

Hirst, D., 1994. Auditor sensitivity to earnings management. Contemporary Accounting Research $11,405-422$.

Hirst, D., Hopkins, P., 1998. Comprehensive income reporting and analysts' valuation judgments. Journal of Accounting Research 36, 47-75.

Hogan, C., Wilkins, M., 2008. Evidence on the audit risk model: Do auditors increase audit fees in the presence of internal control deficiencies?. Contemporary Accounting Research 25, 219-242.

Hoitash, R., Krishnan, M., Sankaraguruswamy, S., 2002. Earnings quality and price quality. Working paper, Bentley University, National University of Singapore, and Yeshiva University.

Holthausen, R., Larcker, D., Sloan, R., 1995. Annual bonus schemes and the manipulation of earnings. Journal of Accounting and Economics 19, 29-74.

Holthausen, R., Verrecchia, R., 1988. The effect of sequential information releases on the variance of price changes in an intertemporal multi-asset market. Journal of Accounting Research 26, 82106.

Hribar, P., Jenkins, N., 2004. The effect of accounting restatements on earnings revisions and the estimated cost of capital. Review of Accounting Studies 9, 337-356.

Hribar, P., Jenkins, N., Johnson, W., 2006. Stock repurchases as an earnings management device. Journal of Accounting and Economics 41, 3-27.

Hribar, P., Yang, H., 2007. CEO confidence, management earnings forecasts, and earnings management. Working paper, University of Iowa and Cornell University.

Hsieh, D., Lee, C., 1985. Choice of inventory accounting methods: Comparative analyses of alternative hypotheses. Journal of Accounting Research 23, 468-485.

Hughes, J., Liu, J., Liu, J. 2005. Information, diversification, and cost of capital. Working paper, UCLA. 
Hung, M., 2000. Accounting standards and value relevance of financial statements: An international analysis. Journal of Accounting and Economics 30, 401-420.

Hunt, H., 1985. Potential determinants of corporate inventory accounting decisions. Journal of Accounting Research 23, 448-467.

Hunt, A., Moyer, S., Shevlin, T., Managing interacting accounting measures to meet multiple objectives: A study of LIFO firms. Journal of Accounting and Economics 21(3), 339-374.

Imhoff, E., 2003. Accounting quality, auditing, and corporate governance. Accounting Horizons 17, 117-128.

Imhoff, E., Lobo, G., 1992. The effect of ex ante earnings uncertainty on earnings response coefficients. The Accounting Review 67, 427-439.

Jacob, J., Jorgensen, B., 2007. Earnings management and accounting income aggregation. Journal of Accounting and Economics 43, 369-390.

Jayaraman, S., 2008. Earnings volatility, cash flow volatility, and informed trading. Journal of Accounting Research 46, 809-851.

Jensen, M., Meckling, W., 1976. Theory of the firm: Managerial behavior, agency costs and ownership structure. Journal of Financial Economics 3, 305-360.

Jo, H., Kim, Y., Park, M., 2007. Underwriter choice and earnings management: Evidence from seasoned equity offerings. Review of Accounting Studies 12, 23-59.

Joe, J., Vandervelde, S., 2007. Do auditor-provided nonaudit services improve audit effectiveness?. Contemporary Accounting Research 24, 467-487. Johnson, M., 1999. Business cycles and the relation between security returns and earnings. Review of Accounting Studies 4, 93-117.

Johnson, S., Ryan, H., Tian, Y., 2009. Managerial incentives and corporate fraud: The sources of incentives matter. Review of Finance 13, 115-145.

Johnson, V., Khurana, I., Reynolds, J., 2002. Audit-firm tenure and the quality of financial reports. Contemporary Accounting Research 19, 637-660.

Johnson, W., Ramanan, R., 1988. Discretionary accounting changes from "successful efforts" to "full cost" methods: 1970-76. The Accounting Review 63, 96-110.

Johnston, D., Rock, S., 2005. Earnings management to minimize superfund clean-up and transaction costs. Contemporary Accounting Research 22, 617-642.

Jones, J., 1991. Earnings management during import relief investigations. Journal of Accounting Research 29, 193-228.

Jorion, P., Shi, C., Zhang, S., 2007. Tightening credit standards: The role of accounting quality. Review of Accounting Studies 14, 1-38.

Jung, W., 1989. Strategic choice of inventory accounting methods. Contemporary Accounting Research 6, 1-25.

Kanagaretnam, K., Lobo, G., Yang, D., 2004. Joint tests of signaling and income smoothing through bank loan loss provisions. Contemporary Accounting Research 21, 843-884.

Kaplan, R., Roll, R., 1972. Investor evaluation of accounting information: Some empirical evidence. The Journal of Business 45, 225-257.

Karpoff, J., Lee, D., Martin, G., 2008a. The consequences to managers for financial misrepresentation. Journal of Financial Economics 88, 193-215.

Karpoff, J., Lee, D., Martin, G., 2008b. The cost to firms of cooking the books. Journal of Financial and Quantitative Analysis 43, 581-611.

Kasznik, R., 1999. On the association between voluntary disclosure and earnings management. Journal of Accounting Research 37, 57-81. 
Kasznik, R., 2004. Discussion of "the effect of accounting restatements on earnings revisions and the estimated cost of capital', Review of Accounting Studies 9, 357-367.

Kasznik, R., McNichols, M., 2002. Does meeting earnings expectations matter? Evidence from analyst forecast revisions and share prices. Journal of Accounting Research 40, 727-759.

Keating, A., Zimmerman, J., 1999. Depreciation-policy changes: Tax, earnings management, and investment opportunity incentives. Journal of Accounting and Economics 28, 359-389.

Kedia, S., Kose, J., 2006. Design of corporate governance: Role of ownership structure, takeovers, and bank debt. Working paper, New York University.

Kerstein, J., Rai, A., 2007. Intra-year shifts in the earnings distribution and their implications for earnings management. Journal of Accounting and Economics 44, 399-419.

Key, K., 1997. Political cost incentives for earnings management in the cable television industry. Journal of Accounting and Economics 23, 309-337.

Khan, M., 2008. Are accruals mispriced? Evidence from tests of an intertemporal capital asset pricing model. Journal of Accounting and Economics 45, 55-77.

Khurana, I., Raman, K., 2006. Do investors care about the auditor's economic dependence on the client?. Contemporary Accounting Research 23, 977-1016.

Kim, J., Yi, C., 2006. Ownership structure, business group affiliation, listing status, and earnings management: Evidence from Korea. Contemporary Accounting Research 23, 427-464.

Kim, K., Schroeder, D., 1990. Analysts' use of managerial bonus incentives in forecasting earnings. Journal of Accounting and Economics 13, 3-23.

Kim, M., Kross, W., 1998. The impact of the 1989 change in bank capital standards on loan loss provisions and loan write-offs. Journal of Accounting and Economics 25, 69-99.

Kim, M., Kross, W., 2005. The ability of earnings to predict future operating cash flows has been increasing - not decreasing. Journal of Accounting Research 43, 753-780.

Kinney, M., Wempe, W., 2004. JIT adoption: The effects of LIFO reserves and financial reporting and tax incentives. Contemporary Accounting Research 21, 603-638.

Kinney, W., 1975. A decision-theory approach to the sampling problem in auditing. Journal of Accounting Research 13, 117-132.

Kinney, W., 2000. Research opportunities in internal control quality and quality assurance. Auditing 19, 83-90.

Kinney, W., McDaniel, L., 1989. Characteristics of firms correcting previously reported quarterly earnings. Journal of Accounting and Economics 11, 71-93.

Kinney, W., Palmrose, Z., Scholz, S., 2004. Auditor independence, non-audit services, and restatements: Was the U.S. Government right?. Journal of Accounting Research 42, 561-588.

Kirschenheiter, M., Melumad, N., 2002. Can "big bath" and earnings smoothing co-exist as equilibrium financial reporting strategies?. Journal of Accounting Research 40, 761-796.

Klassen, K., Lang, M., Wolfson, M., 1993. Geographic income shifting by multinational corporations in response to tax rate changes. Journal of Accounting Research 31, 141-173.

Klein, A., 2002. Audit committee, board of director characteristics, and earnings management. Journal of Accounting and Economics 33, 375-400.

Koch, B., 1981. Income smoothing: An experiment. The Accounting Review 56, 574-586.

Koh, K., Matsumoto, D., Rajgopal, S., 2008. Meeting or beating analyst expectations in the postscandals world: Changes in stock market rewards and managerial actions. Contemporary Accounting Research 25, 1067-1098.

Kormendi, R., Lipe, R., 1987. Earnings innovations, earnings persistence, and stock returns. Journal of Business 60, 323-345. 
Kothari, S., Leone, A., Wasley, C., 2005. Performance matched discretionary accrual measures. Journal of Accounting and Economics 39, 163-197.

Kraft, A., Leone, A., Wasley, C., 2006. An analysis of the theories and explanations offered for the mispricing of accruals and accrual components. Journal of Accounting Research 44, 297-339.

Kravet, T., Shevlin, T., 2009. Accounting restatements and information risk. Review of Accounting Studies, forthcoming.

Krishnan, G., 2003. Does big 6 auditor industry expertise constrain earnings management?. Accounting Horizons 17, 1-16.

Krishnan, G., Srinidhi, B., Su, L., 2008. Inventory policy, accruals quality and information risk. Review of Accounting Studies 13, 369-410.

Krishnan, J., 2005. Audit committee quality and internal control: An empirical analysis. The Accounting Review 80, 649-675.

LaBelle, R., 1990. Bond covenants and changes in accounting policy: Canadian evidence. Contemporary Accounting Research 6, 677-698.

LaFond, R., 2005. Is the accrual anomaly a global anomaly?. Working paper, Massachusetts Institute of Technology.

LaFond, R., Roychowdhury, S., 2008. Managerial ownership and accounting conservatism. Journal of Accounting Research 46, 101-135.

Lambert, R., 1984. Income smoothing as rational equilibrium behavior. The Accounting Review 59, 604-618.

Lambert, R., Leuz, C., Verrecchia, R., 2007. Accounting information, disclosure, and the cost of capital. Journal of Accounting Research 45, 385-420.

Landsman, W., Maydew, E., 2002. Has the information content of quarterly earnings announcements declined in the past three decades?. Journal of Accounting Research 40, 797-808.

Lang, M., Raedy, J., Wilson, W., 2006. Earnings management and cross listing: Are reconciled earnings comparable to us earnings?. Journal of Accounting and Economics 42, 255-283.

Lang, M., Raedy, J., Yetman, M., 2003. How representative are firms that are cross-listed in the United States? An analysis of accounting quality. Journal of Accounting Research 41, 363-386.

Larcker, D., Richardson, S., 2004. Fees paid to audit firms, accrual choices, and corporate governance. Journal of Accounting Research 42, 625-658.

Larcker, D., Richardson, S., Tuna, İ., 2007. Corporate governance, accounting outcomes, and organizational performance. The Accounting Review 82, 963-1008.

Lee, C., Li, L., Yue, H., 2006. Performance, growth and earnings management. Review of Accounting Studies 11, 305-334.

Leftwich, R., Watts, R., 1977. The time series of annual accounting earnings. Journal of Accounting Research 15, 253-271.

Lennox, C., Park, C., 2006. The informativeness of earnings and management's issuance of earnings forecasts. Journal of Accounting and Economics 42, 439-458.

Leuz, C., Nanda, D., Wysocki, P., 2003. Earnings management and investor protection: An international comparison. Journal of Financial Economics 69, 505-527.

Leuz, C., Wysocki, P., 2008. Economic consequences of financial reporting and disclosure regulation: A review and suggestions for future research. Working paper, University of Chicago and Massachusetts Institute of Technology.

Lev, B., 1983. Some economic determinants of time-series properties of earnings. Journal of Accounting and Economics 5, 31-48. 
Lev, B., 1989. On the usefulness of earnings and earnings research: Lessons and directions from two decades of empirical research. Journal of Accounting Research 27, 153-192.

Lev, B., Ryan, S., Wu, M., 2008. Rewriting earnings history. Review of Accounting Studies 13, 133.

Lev, B., Sougiannis, T., 1996. The capitalization, amortization, and value-relevance of R\&D. Journal of Accounting and Economics 21, 107-138.

Lev B., Thiagarajan, S., 1993. Fundamental information analysis. Journal of Accounting Research 31, 190-215.

Lev, B., Zarowin, P., 1999. The boundaries of financial reporting and how to extend them. Journal of Accounting Research 37, 353-385.

Levi, S., 2008. Voluntary disclosure of accruals in earnings press releases and the pricing of accruals. Review of Accounting Studies 13, 1-21.

Li, F., 2008. Annual report readability, current earnings, and earnings persistence. Journal of Accounting and Economics 45, 221-247.

Liang, P., 2004. Equilibrium earnings management, incentive contracts, and accounting standards. Contemporary Accounting Research 21, 685-717.

Lindahl, F., 1989. Dynamic analysis of inventory accounting choice. Journal of Accounting Research 27, 201-226.

Littleton, A., 1956. Choice among alternatives. The Accounting Review 31, 363-370.

Littleton, A., Paton, W., 1940. An Introduction to Corporate Accounting Standards, Chicago: American Accounting Association.

Liu, C., Ryan, S., 2006. Income smoothing over the business cycle: Changes in banks' coordinated management of provisions for loan losses and loan charge-offs from the pre-1990 bust to the 1990s boom. The Accounting Review 81, 421-441.

Liu, J., Thomas, J., 2000. Stock returns and accounting earnings. Journal of Accounting Research 38, 71-101.

Liu, M., Wysocki, P., 2006. Operating risk, information risk, and cost of capital. Working paper, Pennsylvania State University and Massachusetts Institute of Technology.

Lo, K., 2008. Earnings management and earnings quality. Journal of Accounting and Economics 45, 350-357.

Loudder, M., Behn, B., 1995. Alternative income determination rules and earnings usefulness: the case of R\&D costs. Contemporary Accounting Research 12, 185-205.

Lougee, B., Marquardt, C., 2004. Earnings informativeness and strategic disclosure: An empirical examination of "pro forma" earnings. The Accounting Review 79, 769-795.

Louis, H., Robinson, D., 2005. Do managers credibly use accruals to signal private information? Evidence from the pricing of discretionary accruals around stock splits. Journal of Accounting and Economics 39, 361-380.

Louis, H., Robinson, D., Sbaraglia, A., 2008. An integrated analysis of the association between accrual disclosure and the abnormal accrual anomaly. Review of Accounting Studies 13, 23-54.

Lundholm, R., O'Keefe, T., 2001. Reconciling value estimates from the discounted cash flow model and the residual income model. Contemporary Accounting Research 18, 311-335.

Magee, R., Sridhar, S., 1996. Financial contracts, opportunism, and disclosure management. Review of Accounting Studies 1, 225-258.

Maines, L., Martin, R., McDaniel, L., 2002. Evaluating financial reporting quality: The effects of financial expertise vs. financial literacy. The Accounting Review 77, 139-167. 
Malmquist, D., 1990. Efficient contracting and the choice of accounting method in the oil and gas industry. Journal of Accounting and Economics 12, 173-205.

Manry, D., Tiras, S., Wheatley, C., 2003. The influence of interim auditor: Reviews on the association of returns with earnings. The Accounting Review 78, 251-274.

Martin, A., 1971. An empirical test of the relevance of accounting information for investment decisions. Journal of Accounting Research 9, 1-31.

Matsumoto, D., 2002. Management's incentives to avoid negative earnings surprises. The Accounting Review 77, 483-514.

Maydew, E., 1997. Tax-induced earnings management by firms with net operating losses. Journal of Accounting Research 35, 83-96.

McAnally, M., Srivastava, A., Weaver, C., 2008. Executive stock options, missed earnings targets, and earnings management. The Accounting Review 83, 185-216.

McInnis, J., 2009. Earnings Smoothness, Average Returns, and Implied Cost of Equity Capital. The Accounting Review, forthcoming.

McNichols, M., 2002. Discussion of "The quality of accruals and earnings: The role of accrual estimation errors". The Accounting Review 77, 61-69.

McNichols, M., Wilson, G., 1988. Evidence of earnings management from the provision for bad debts. Journal of Accounting Research 26, 1-31. McVay, S., 2006. Earnings management using classification shifting: An examination of core earnings and special items. The Accounting Review 81, 501-531.

McVay, S., Nagar, V., Tang, V., 2006. Trading incentives to meet the analyst forecast. Review of Accounting Studies 11, 575-598.

Melumad, N., Nissim, D., 2008, Line-item analysis of earnings quality. Foundation and Trends in Accounting 3, 87-221.

Menon, K., Williams, D., 2004. Former audit partners and abnormal accruals. The Accounting Review 79, 1095-1118.

Menon, K., Williams, D., 2008. Management turnover following auditor resignations. Contemporary Accounting Research 25, 567-604.

Miller, G., 2006. The press as a watchdog for accounting fraud. Journal of Accounting Research 44, 1001-1033.

Miller, G., Skinner, D., 1998. Determinants of the valuation allowance for deferred tax assets under SFAS No. 109. The Accounting Review 73, 213-233.

Mlynarczyk, F., 1969. An empirical study of accounting methods and stock prices. Journal of Accounting Research 7, 63-81.

Moehrle, S., 2002. Do firms use restructuring charge reversals to meet earnings targets?. The Accounting Review 77, 397-413.

Mohanram, P., Rajgopal, S., 2009. Is PIN priced risk? Journal of Accounting and Economics 47, 226-243.

Monem, R., 2003. Earnings management in response to the introduction of the Australian gold tax. Contemporary Accounting Research 20, 747-774.

Moore, M., 1973. Management changes and discretionary accounting decisions. Journal of Accounting Research 11, 100-107.

Morsfield, S., Tan, C., 2006. Do venture capitalists influence the decision to manage earnings in initial public offerings?. The Accounting Review 81, 1119-1150.

Moses, O., 1987. Income smoothing and incentives: Empirical tests using accounting changes. The Accounting Review 62, 358-377. 
Moyer, S., 1990. Capital adequacy ratio regulations and accounting choices in commercial banks. Journal of Accounting and Economics 13, 123-154.

Muller, K., 1999. An examination of the voluntary recognition of acquired brand names in the United Kingdom. Journal of Accounting and Economics 26, 179-191.

Myers, J., Myers, L., Skinner, D., 2007. Earnings momentum and earnings management. Journal of Accounting, Auditing, and Finance 22, 249-84.

Narayanan, M., Schipani, C., Seyhun, H., 2006. Economic impact of backdating of executive stock options. Michigan Law Review 105, 1597-1641.

Navissi, F., 1999. Earnings management under price regulation. Contemporary Accounting Research 16, 281-304.

Ndubizu, G., 2007. Do cross-border listing firms manage earnings or seize a window of opportunity?. The Accounting Review 82, 1009-1030.

$\mathrm{Ng}$, D., Stoeckenius, J., 1979. Auditing: Incentives and truthful reporting. Journal of Accounting Research 17, 1-24.

Niehaus, G., 1989. Ownership structure and inventory method choice. The Accounting Review 64, 269-284.

Nissim, D., Penman, S., 2001. Ratio analysis and equity valuation: from research to practice. Review of Accounting Studies 6, 109-154.

Nwaeze, E., Yang, S., Yin, J., 2006. Accounting information and CEO compensation: The role of cash flow from operations in the presence of earnings. Contemporary Accounting Research 23, 227-265.

O’Glove, T., 1987. Quality of Earnings, New York: The Free Press.

Ogneva, M., Raghunandan, K., Subramanyam, K., 2007. Internal control weakness and cost of equity: Evidence from SOX Section 404 disclosures. The Accounting Review 82, 1255-1297.

Pae, J., Thornton, D., Welker, M.,2005. The link between earnings conservatism and the price-tobook ratio. Contemporary Accounting Research 22, 693-717.

Palmrose, Z., Richardson, V., Scholz, S., 2004. Determinants of market reactions to restatement announcements. Journal of Accounting and Economics 37, 59-89.

Palmrose, Z., Scholz, S., 2004. The circumstances and legal consequences of non-GAAP reporting: Evidence from restatements. Contemporary Accounting Research 21, 139-180.

Penman, S., 1998. A Synthesis of equity valuation techniques and the terminal value calculation for the dividend discount model. Review of Accounting Studies 2, 303-323.

Penman, S., 2003. The quality of financial statements: Perspectives from the recent stock market bubble. Accounting Horizons 17, 77-96.

Penman, S., Sougiannis, T., 1998. A comparison of dividend, cash flow, and earnings approaches to equity valuation. Contemporary Accounting Research 15, 343-383.

Penman, S., Zhang, X., 2002. Accounting conservatism, the quality of earnings, and stock returns. The Accounting Review 77, 237-264.

Perry, S., Williams, T., 1994. Earnings management preceding management buyout offers. Journal of Accounting and Economics 18, 157-179.

Petroni, K., 1992. Optimistic reporting in the property-casualty insurance industry. Journal of Accounting and Economics 15, 485-508.

Petroni, K., Ryan, S., Wahlen, J., 2000. Discretionary and non-discretionary revisions of loss reserves by property-casualty insurers: Differential implications for future profitability, risk and market value. Review of Accounting Studies 5, 95-125. 
Phillips, F., 1999. Auditor attention to and judgments of aggressive financial reporting. Journal of Accounting Research 37, 167-189.

Phillips, J., Pincus, M., Rego, S., 2003. Earnings management: New evidence based on deferred tax expense. The Accounting Review 78, 491-521.

Pincus, M., 1993. Accounting methods and differential stock market response to the announcement of earnings. Journal of Accounting, Auditing and Finance 8, 221-248.

Pincus, M., Rajgopal, S., Venkatachalam, M., 2007. The accrual anomaly: International evidence. The Accounting Review 82, 169-203.

Plumlee, M., Yohn, T., 2009. An analysis of the underlying causes attributed to restatements. Working paper, University of Utah and Indiana University.

Plummer, C., Tse, S., 1999. The effect of limited liability on the informativeness of earnings: Evidence from the stock and bond markets. Contemporary Accounting Research 16, 541-574.

Pope, P., Walker, M., 1999. International differences in the timeliness, conservatism, and classification of earnings. Journal of Accounting Research 37, 53-87.

Pourciau, S., 1993. Earnings management and nonroutine executive changes. Journal of Accounting and Economics 16, 317-336.

Rajgopal, S., Shevlin, T., 2002. Empirical evidence on the relation between stock option compensation and risk taking. Journal of Accounting and Economics 33, 145-171.

Rangan, S., 1998. Earnings management and the performance of seasoned equity offerings. Journal of Financial Economics 50, 101-122.

Richardson, S., 2003. Earnings quality and short sellers. Accounting Horizons 17, 49-61.

Richardson, S., Sloan, R., Soliman, M., Tuna, İ., 2005. Accrual reliability, earnings persistence and stock prices. Journal of Accounting and Economics 39, 437-485.

Richardson, S., Sloan, R., Soliman, M., Tuna, İ., 2006. The implications of accounting distortions and growth for accruals and profitability. The Accounting Review 81, 713-743.

Richardson, S., Teoh, S., Wysocki, P., 2004. The walk-down to beatable analyst forecasts: The role of equity issuance and insider trading incentives. Contemporary Accounting Research 21, 885924.

Richardson, S., Tuna, I., Wysocki, P., 2009. Accounting anomalies, fundamental analysis, and returns to investment strategies. Survey paper, Journal of Accounting and Economics Conference.

Robinson, J., Shane, P., 1990. Acquisition accounting method and bid premia for target firms. The Accounting Review 65, 25-48.

Ronen, J., Sadan, S., 1975. Classificatory smoothing: Alternative income models. Journal of Accounting Research 13, 133-149.

Rosner, R., 2003. Earnings manipulation in failing firms. Contemporary Accounting Research 20, 361-408.

Ruddock, C., Taylor, S., Taylor, S., 2006. Nonaudit services and earnings conservatism: Is auditor independence impaired?. Contemporary Accounting Research 23, 701-746.

Ryan, S., Zarowin, P., 2003. Why has the contemporaneous linear returns-earnings relation declined?. The Accounting Review 78, 523-553.

Ryan, S., 2006. Identifying conditional conservatism. European Accounting Review 15, 511-525.

Schelling, T., 1978. Micromotives and macrobehavior, New York: W.W. Norton \& Co., Inc.

Schipper, K., Vincent, L., 2003. Earnings quality. Accounting Horizons 17, 235-250.

Schneider, A., Wilner, N., 1990. A test of audit deterrent to financial reporting irregularities using the randomized response technique. The Accounting Review 65, 668-681. 
Scholes, M., Wilson, G., Wolfson, M., 1992. Firms' responses to anticipated reductions in tax rates: The Tax Reform Act of 1986. Journal of Accounting Research 30, 161-185.

Schrand, C., Wong, M., 2003. Earnings management using the valuation allowance for deferred tax assets under SFAS No. 109. Contemporary Accounting Research 20, 579-611.

Schrand, C., Zechman, S., 2009. Executive overconfidence and the slippery slope to fraud. Working paper, University of Pennsylvania and University of Chicago.

Shackelford, D., Shevlin, T., 2001. Empirical tax research in accounting. Journal of Accounting and Economics 31, 321-387.

Shivakumar, L., 2000. Do firms mislead investors by overstating earnings before seasoned equity offerings?. Journal of Accounting and Economics 29, 339-371.

Sivakumar, K., Waymire, G., 2003. Enforceable accounting rules and income measurement by early 20th century railroads. Journal of Accounting Research 41, 397-432.

Skinner, D., 1993. The investment opportunity set and accounting procedure choice: Preliminary evidence. Journal of Accounting and Economics 16, 407-445.

Skinner, D., Sloan, R., 2002. Earnings surprises, growth expectations, and stock returns or don't let an earnings torpedo sink your portfolio. Review of Accounting Studies 7, 289-312.

Sloan, R., 1996. Do stock prices fully reflect information in accruals and cash flows about future earnings?. The Accounting Review 71, 289-315.

Smith, E., 1976. The effect of the separation of ownership from control on accounting policy decisions. The Accounting Review 51, 707-723.

Soliman, M., 2008. The use of DuPont analysis by market participants. The Accounting Review 83, 823-853

Srinivasan, S., 2005. Consequences of financial reporting failure for outside directors: Evidence from accounting restatements and audit committee members. Journal of Accounting Research 43, 291-334.

Sterling, R., 1970. The Theory of the Measurement of Enterprise Income, Lawrence: The University Press of Kansas.

Stocken, P., Verrecchia, R., 2004. Financial reporting system choice and disclosure management. The Accounting Review 79, 1181-1203.

Subramanyam, K., 1996. The pricing of discretionary accruals. Journal of Accounting and Economics 22, 249-281.

Summers, S., Sweeney, J., 1998. Fraudulently misstated financial statements and insider trading: An empirical analysis. The Accounting Review 73, 131-146.

Sunder, S., 1975. Stock price and risk related to accounting changes in inventory valuation. The Accounting Review 50, 305-315.

Sweeney, A., 1994. Debt-covenant violations and managers' accounting responses. Journal of Accounting and Economics 17, 281-308.

Teoh, S., Rao, G., Wong, T., 1998. Are accruals during initial public offerings opportunistic?. Review of Accounting Studies 3, 175-208.

Teoh, S., Welch, I., Wong, T., 1998. Earnings management and the underperformance of seasoned equity offerings. Journal of Financial Economics 50, 63-99.

Teoh, S., Wong, T., 1993. Perceived auditor quality and the earnings response coefficient. The Accounting Review 68, 346-366.

Thomas, J., Zhang, H., 2002. Inventory changes and future returns. Review of Accounting Studies 7, 163-187. 
Tucker, J., Zarowin, P., 2006. Does income smoothing improve earnings informativeness?. The Accounting Review 81, 251-270.

Vafeas, N., 2005. Audit committees, boards, and the quality of reported earnings. Contemporary Accounting Research 22, 1093-1122.

Verdi, R., 2006. Financial reporting quality and investment efficiency. Working paper, Massachusetts Institute of Technology.

Verrecchia, R., 1986. Managerial discretion in the choice among financial reporting alternatives. Journal of Accounting and Economics 8, 175-195.

Verrecchia, R., 1990. Information quality and discretionary disclosure. Journal of Accounting and Economics 12, 365-380.

Wang, D., 2006. Founding family ownership and earnings quality. Journal of Accounting Research 44, 619-656.

Warfield, T., Wild, J., Wild, K., 1995. Managerial ownership, accounting choices, and informativeness of earnings. Journal of Accounting and Economics 20, 61-91.

Watts, R., Zimmerman, J., 1986. Positive accounting theory. Prentice-Hall Inc.

White, G., 1970. Discretionary accounting decisions and income normalization. Journal of Accounting Research 8, 260-273.

Whittred, G., 1980. Audit qualification and the timeliness of corporate annual reports. The Accounting Review 55, 563-577.

Willingham, J., Wright, W., 1985. Financial statement errors and internal controls judgments. Auditing: A Journal of Practice and Theory 1, 57-70.

Wilson, G., 1987. The incremental information content of the accrual and funds components of earnings after controlling for earnings. The Accounting Review 62, 293-322.

Xie, H., 2001. The mispricing of abnormal accruals. The Accounting Review 76, 357-373.

Yermack, D., 1997. CEO stock option awards and company news announcements. The Journal of Finance 52, 449-476.

Zhang, X., 2007. Accruals, investment, and the accrual anomaly. The Accounting Review 82, 13331363.

Zimmer, I., 1986. Accounting for interest by real estate developers. Journal of Accounting and Economics 8, 37-51. 


\section{Figure 1. Summary of the investigated determinants of earnings quality}

Figure 1 summarizes the explanatory variables for ("determinants" of) the various earnings quality proxies. The rows represent the most frequently hypothesized determinants of earnings quality and correspond to the organization of the discussion in Sections 5.1 through 5.6. The columns represent our categories of commonly used earnings quality proxies. A shaded box indicates that researchers have investigated whether the determinant explains variation in the earnings quality proxy. The first number in a shaded box indicates the number of papers in our database that examine the association between a determinant and an EQ proxy. The second number in a shaded box (if there is one) indicates the number of papers that provide negative evidence (inconsistent with the theory).

\begin{tabular}{|c|c|c|c|c|c|c|c|c|c|c|c|}
\hline \multirow[b]{3}{*}{ Determinant } & & \multicolumn{10}{|c|}{ Earnings quality proxy } \\
\hline & & \multicolumn{6}{|c|}{ Properties of earnings } & \multirow[b]{2}{*}{ 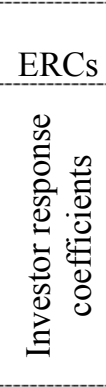 } & \multicolumn{3}{|c|}{$\begin{array}{l}\text { External indicators of } \\
\text { financial reporting quality }\end{array}$} \\
\hline & & 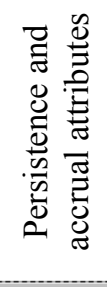 & 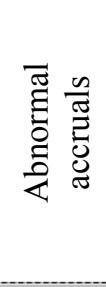 & 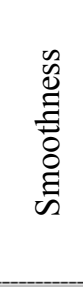 & 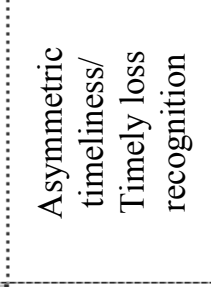 & 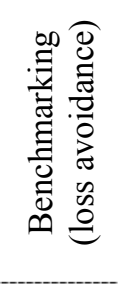 & 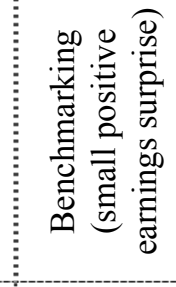 & & $\frac{2}{\sum}$ & 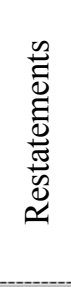 & 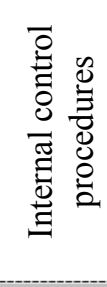 \\
\hline \multirow[t]{6}{*}{$\begin{array}{l}\text { Firm } \\
\text { characteristics }\end{array}$} & Firm performance & 1 & $5 / 2$ & $2 / 1$ & & & & & 1 & 2 & 2 \\
\hline & Firm growth & 6 & 1 & & : & & 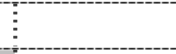 & & 1 & $1 / 1$ & 2 \\
\hline & $\begin{array}{l}\text { Financial statement } \\
\text { components }\end{array}$ & 10 & & & 1 & 3 & & 10 & 2 & 1 & \\
\hline & Firm size & 1 & & 1 & & & & & & 1 & 2 \\
\hline & Firm debt covenant & & $2 / 1$ & & & & & & $3 / 2$ & 2 & \\
\hline & Debt as a call option & & & & & & & 3 & & & \\
\hline \multirow[t]{3}{*}{$\begin{array}{l}\text { Financial reporting } \\
\text { practices }\end{array}$} & Accounting methods & & & 4 & 1 & & & 6 & & & \\
\hline & $\begin{array}{l}\text { Other financial reporting } \\
\text { practices }\end{array}$ & & 1 & & & 2 & 2 & & & & \\
\hline & $\begin{array}{l}\text { Principles based versus } \\
\text { rules based methods }\end{array}$ & & & 1 & 1 & 1 & & 1 & & & \\
\hline
\end{tabular}


Figure 1. Summary of the investigated determinants of earnings quality, continued

\begin{tabular}{|c|c|c|c|c|c|c|c|c|c|c|c|}
\hline \multirow[b]{3}{*}{ Determinant } & & \multicolumn{10}{|c|}{ Earnings quality proxy } \\
\hline & & \multicolumn{6}{|c|}{ Properties of earnings } & \multirow[b]{2}{*}{ 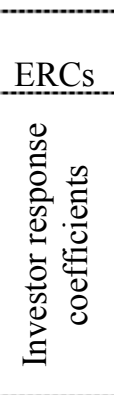 } & \multicolumn{3}{|c|}{$\begin{array}{l}\text { External indicators of } \\
\text { financial reporting quality }\end{array}$} \\
\hline & & 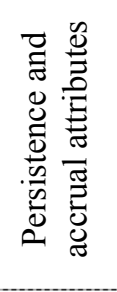 & 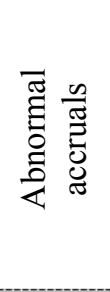 & 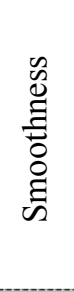 & 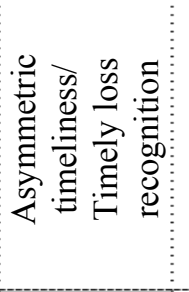 & 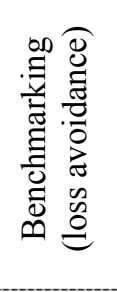 & 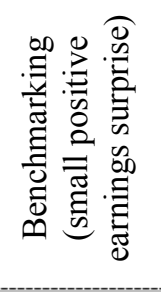 & & $\underset{\frac{2}{4}}{\frac{2}{4}}$ & 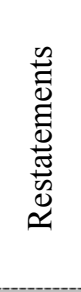 & 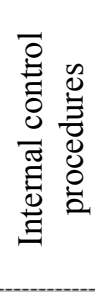 \\
\hline \multirow[t]{6}{*}{$\begin{array}{l}\text { Governance and } \\
\text { controls }\end{array}$} & Board characteristics & & $3 / 1$ & 1 & 1 & & 2 & & 4 & $2 / 1$ & 1 \\
\hline & $\mathrm{I} / \mathrm{C}$ procedures & 1 & 2 & & & & & & & 1 & \\
\hline & Managerial ownership & & $4 / 1$ & 1 & 1 & & & 3 & & $1 / 1$ & \\
\hline & Earnings-based comp. & & $4 / 2$ & & & & & & $2 / 2$ & & \\
\hline & Equity compensation & & 5 & & & & 1 & & $4 / 2$ & $4 / 2$ & \\
\hline & Managerial change & & 2 & & & & & & & & \\
\hline \multirow[t]{4}{*}{ Auditors } & Auditor size & $2 / 1$ & 4 & & & & & 1 & $1 / 1$ & & $1 / 1$ \\
\hline & Auditor fees & & $3 / 1$ & & & & & & & & \\
\hline & Non-audit fees & & $6 / 3$ & & $1 / 1$ & & 1 & 2 & & $2 / 1$ & \\
\hline & Other auditor-related & & $7 / 2$ & & & & $1 / 1$ & & $1 / 1$ & & \\
\hline \multirow[t]{4}{*}{$\begin{array}{l}\text { Capital market } \\
\text { incentives }\end{array}$} & IPO and SEO & 1 & $8 / 1$ & & & & & & 2 & 1 & \\
\hline & Mergers buyout & & $3 / 1$ & & & & & & & & \\
\hline & Cross-listing & & 2 & 1 & 1 & 1 & & 1 & & & \\
\hline & $\begin{array}{l}\text { Incentives to meet } \\
\text { earnings-based targets }\end{array}$ & 3 & $3 / 1$ & & & & & & & & \\
\hline \multirow[t]{4}{*}{ External factors } & Political process & & 8 & & & & & & & & \\
\hline & Capital regulations & 5 & & & & & & & & & \\
\hline & Tax regulations & $7 / 2$ & & & & & & & & & \\
\hline & SOX & & 2 & & & & & & & & \\
\hline Country-level ins & tional factors & 1 & 2 & 2 & 4 & 4 & & 5 & & & \\
\hline
\end{tabular}




\section{Figure 2. Summary of the investigated consequences of earnings quality}

Figure 2 summarizes the outcomes resulting from ("consequences" of) the various earnings quality proxies. The rows represent the most frequently hypothesized consequences of earnings quality and correspond to the organization of the discussion in Sections 6.1 and 6.2. The columns represent our categories of commonly used earnings quality proxies. A shaded box indicates that researchers have investigated whether the earnings quality proxy explains variation in the consequence variable. The first number in a shaded box indicates the number of papers in our database that examine the association between a consequence and an EQ proxy. The second number in a shaded box (if there is one) indicates the number of papers that provide negative evidence (inconsistent with the theory).

\begin{tabular}{|c|c|c|c|c|c|c|c|c|c|c|c|}
\hline & & \multicolumn{10}{|c|}{ Earnings quality proxy } \\
\hline & & \multicolumn{6}{|c|}{ Properties of earnings } & \multirow[b]{2}{*}{ 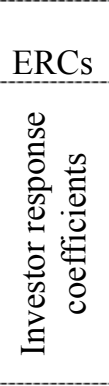 } & \multicolumn{3}{|c|}{$\begin{array}{l}\text { External indicators of } \\
\text { financial reporting quality }\end{array}$} \\
\hline Consequence & & 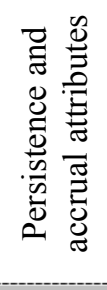 & 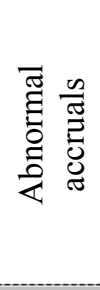 & 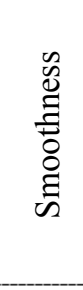 & 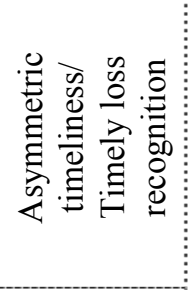 & 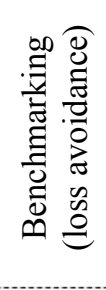 & 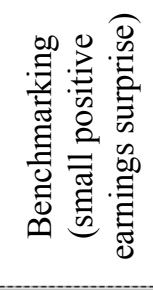 & & $\frac{2}{4}$ & $\begin{array}{l}\stackrel{0}{0} \\
\stackrel{0}{0} \\
\stackrel{\tilde{U}}{0} \\
\stackrel{0}{0}\end{array}$ & 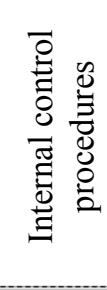 \\
\hline \multirow[t]{6}{*}{ Capital markets } & Short-window returns & 5 & 6 & & & & 1 & & 3 & 2 & 2 \\
\hline & Long-window returns & 3 & 1 & & & & & & & & \\
\hline & Future returns & $10 / 1$ & $6 / 1$ & & & & & & 1 & & \\
\hline & Market multiples & 3 & & & & & 3 & & & & \\
\hline & Cost of equity capital & 3 & $5 / 1$ & $4 / 2$ & 1 & 1 & & 1 & 1 & $3 / 1$ & $3 / 1$ \\
\hline & Debt market & 1 & 1 & & & & & & & & \\
\hline \multirow[t]{6}{*}{$\begin{array}{l}\text { Other than capital } \\
\text { markets }\end{array}$} & Litigation & & 2 & & & & & & 2 & 2 & \\
\hline & Compensation & 2 & 1 & & 1 & & & & & 1 & \\
\hline & Executive turnover & & & & 1 & & 1 & & 2 & 3 & \\
\hline & Audit opinions & $3 / 2$ & $1 / 1$ & & & & & & & & \\
\hline & Analyst decisions & $1 / 1$ & $3 / 1$ & & & & & & & & \\
\hline & Real activities & & 1 & 1 & 1 & 1 & 1 & $2 / 1$ & 1 & 1 & \\
\hline
\end{tabular}


Figure 3: Key links between determinants, earnings quality proxies, and consequences

Figure 3 summarizes the key links between determinants, earnings quality proxies, and consequences. Dark lines represent four or more papers and dotted lines represent two or more papers examining link. Links that are made by only one paper are not included.

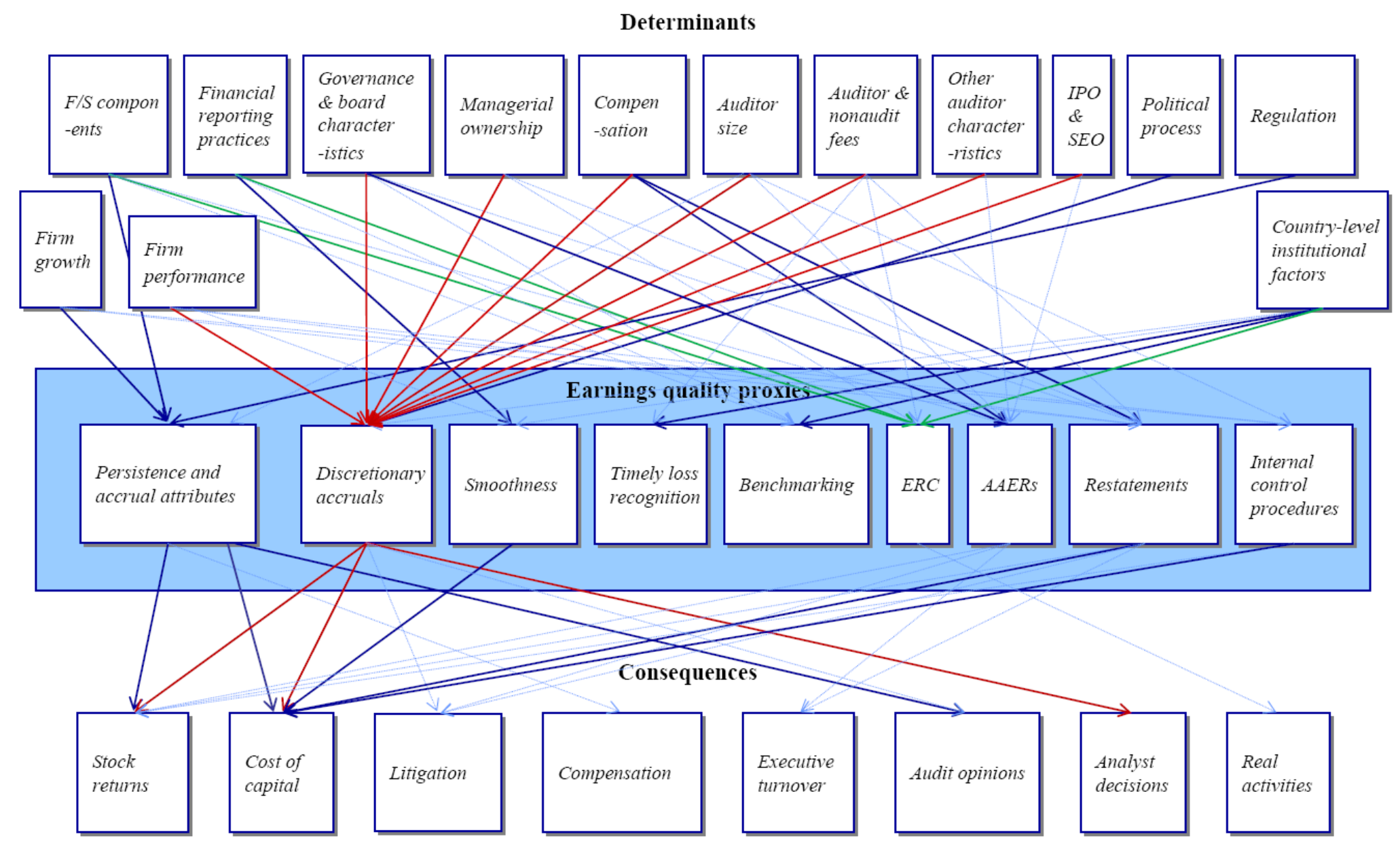




\section{Figure 4: Construct validity across earnings quality proxies}

The links shown in this figure provide a graphical representation of proxies that have been validated using other proxies in papers within our database.

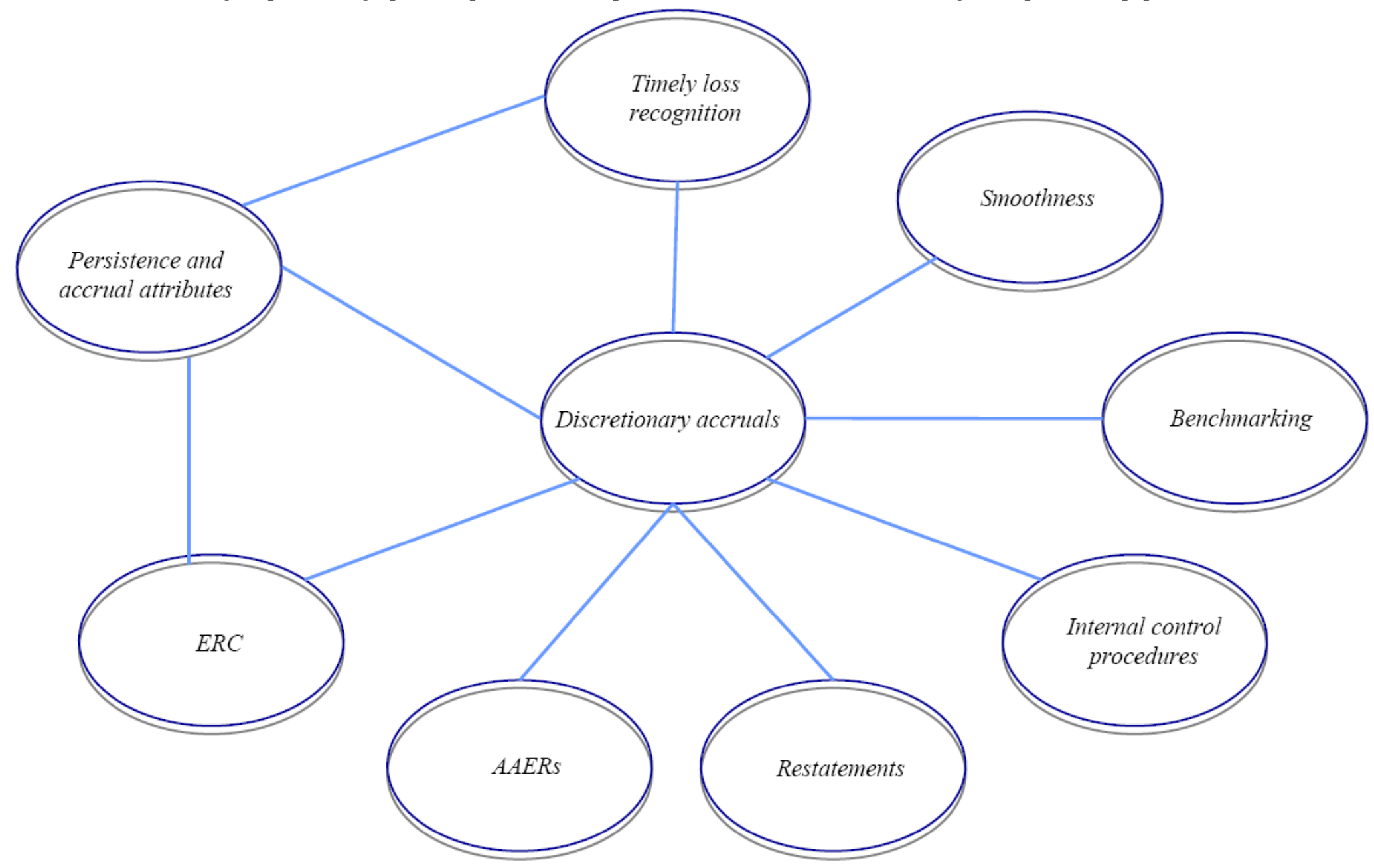




\section{Table 1. Categories of "Earnings quality” proxies, determinants of EQ, and consequences of EQ}

This table outlines the sub-categories of the three categories of earnings quality proxies, the six categories of determinants of earnings quality, and the two categories of consequences of earnings quality. For each, we report the section number in this document in which the item is discussed.

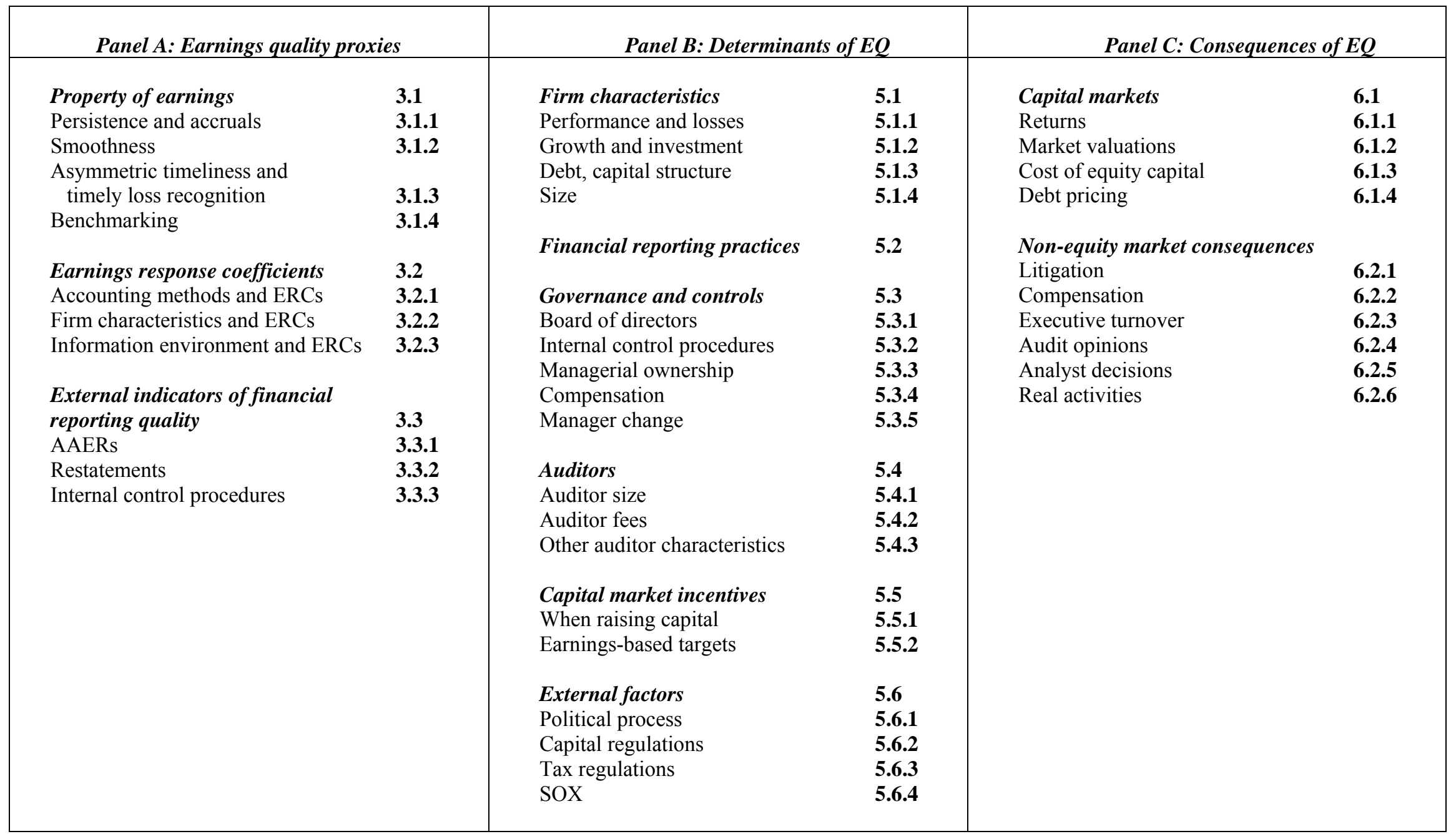




\section{Table 2. Spearman correlations between earnings quality proxies (Sample period: 1987-2007)}

Table 2 reports the spearman correlation coefficients between commonly used specifications of earnings quality proxies, as defined in Exhibit 1 . Persistence is measured as the estimated $\beta$ in the firm-level regression: Earnings $t_{t+1}=\alpha+\beta$ Earnings $_{t}+\varepsilon_{t}$. Total accruals is defined as the difference between earnings and cash flows from operations. $\mid$ Accruals $\mid$ is the absolute value of Total accruals. Estimation errors is defined as the firm-level mean absolute value of the residual from $\triangle W C=\alpha+\beta_{1} C F O_{t-1}+\beta_{2} C F O_{t}+\beta_{3} C F O_{t+1}+\varepsilon_{t} . \sigma($ residual $)$ is the firm-level standard deviation of the residual from the above regression. $\sigma(E A R N) / \sigma(C F O)$ is the firm-level standard deviation of earnings divided by the standard deviation of cash flow from operations. $\operatorname{Corr}(\triangle A C C, \triangle C F O)$ is the firm-level correlation between change in total accruals and change in cash flow from operations. Timely loss recognition is defined as $(\beta 1+\beta 2) / \beta 1$ from the firm-level regression: Earnings $_{t+1}=\alpha_{1}+\alpha_{2} D_{t}+\beta_{1}$ Ret $_{t}+\beta_{2} D_{t} \cdot$ Ret $_{t}+\varepsilon_{t}$ where $\mathrm{D}=1$ if $\operatorname{Ret}<0$. ERC is defined as the estimated $\beta$ from the firm-level regression of annual returns on earnings: $\operatorname{Ret}_{t}=\alpha+\beta$ Earnings $_{t}+\varepsilon_{t}$. The sample consists of 3,733 firms (47,187 firm-years) with eight or more consecutive annual observations. Significance levels are shown in italics. Each earnings attribute is winsorized at 1\% and 99\%. Timely loss recognition is trimmed at the value of -5 and 5 , resulting in 2,487 firms. Total accruals, $\mid$ Accruals $\mid$, Estimation errors, and $\sigma$ (residual) represent the additive inverse of these variables such that all variables are increasing in their hypothesized quality.

\begin{tabular}{|c|c|c|c|c|c|c|c|c|c|}
\hline & & & ials & & $\mathrm{Smc}$ & aness & & & \\
\hline & $\begin{array}{c}\text { Total } \\
\text { accruals }\end{array}$ & $\mid$ Accruals $\mid$ & $\begin{array}{c}\text { Estimation } \\
\text { errors }\end{array}$ & $\sigma($ residual $)$ & $\begin{array}{c}\sigma(\text { Earn }) / \\
\sigma(C F O)\end{array}$ & $\begin{array}{c}\operatorname{Corr}(\triangle A C C, \\
\triangle C F O)\end{array}$ & $\begin{array}{l}\text { Timely loss } \\
\text { recognition }\end{array}$ & Coefficient & $R^{2}$ \\
\hline Persistence & 0.082 & 0.128 & 0.128 & 0.129 & -0.151 & -0.254 & 0.014 & 0.191 & 0.079 \\
\hline & $<.0001$ & $<.0001$ & $<.0001$ & $<.0001$ & $<.0001$ & $<.0001$ & 0.485 & $<.0001$ & $<.0001$ \\
\hline Total accruals & & 0.700 & -0.080 & -0.079 & -0.214 & -0.275 & 0.003 & 0.128 & 0.032 \\
\hline & & $<.0001$ & $<.0001$ & $<.0001$ & $<.0001$ & $<.0001$ & 0.880 & $<.0001$ & 0.052 \\
\hline $\mid$ Accruals $\mid$ & & & 0.308 & 0.303 & -0.241 & -0.264 & -0.007 & 0.174 & 0.030 \\
\hline & & & $<.0001$ & $<.0001$ & $<.0001$ & $<.0001$ & 0.742 & $<.0001$ & 0.069 \\
\hline Estimation errors & & & & 0.993 & -0.299 & -0.250 & 0.026 & 0.214 & 0.048 \\
\hline & & & & $<.0001$ & $<.0001$ & $<.0001$ & 0.202 & $<.0001$ & 0.004 \\
\hline$\sigma($ residual $)$ & & & & & -0.297 & -0.249 & 0.029 & 0.217 & 0.053 \\
\hline & & & & & $<.0001$ & $<.0001$ & 0.149 & $<.0001$ & 0.001 \\
\hline$\sigma(E A R N) /$ & & & & & & 0.709 & -0.059 & -0.339 & -0.152 \\
\hline$\sigma(C F O)$ & & & & & & $<.0001$ & 0.004 & $<.0001$ & $<.0001$ \\
\hline $\operatorname{Corr}(\triangle A C C, \triangle C F O)$ & & & & & & & -0.072 & -0.321 & -0.125 \\
\hline & & & & & & & 0.000 & $<.0001$ & $<.0001$ \\
\hline Timely loss & & & & & & & & 0.200 & 0.172 \\
\hline recognition & & & & & & & & $<.0001$ & $<.0001$ \\
\hline ERC coefficient & & & & & & & & & 0.551 \\
\hline & & & & & & & & & $<.0001$ \\
\hline
\end{tabular}




\section{Exhibit 1: Summary of earnings quality proxies}

This exhibit lists the commonly used proxies for earnings quality and the most common specification(s) of the variable. The exact specification of the proxies can vary by study. For each, we summarize the theory for its use as a measure of quality and an abbreviated summary of the strengths and weaknesses of the proxy. Details are in the review in Section 3.

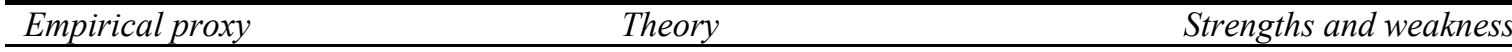

\section{Persistence}

Earnings $_{t+l}=\alpha+\beta$ Earnings $_{t}+\varepsilon_{t}$

$\beta$ measures persistence.

\section{Smoothness}

$\sigma($ Earnings $) / \sigma($ Cash flows $)$

A lower ratio indicates more smoothing of the earnings stream relative to cash flows.
Firms with more persistent earnings generate more accurate DCF-based equity valuations.

Pros: Fits well with a Graham and Dodd view of earnings as a summary metric of expected cash flows useful for equity valuation.

Cons: Difficult to control for persistence of the fundamental earnings process, but this persistence is likely to be a large contributor to persistence of reported earnings. Thus, it is difficult to make statements about the effect of measurement on persistence. Greater persistence may be achieved via opportunistic earnings management.

\section{Timely loss recognition (TLR)}

Earnings $_{t+1}=\alpha_{0}+\alpha_{1} D_{t}+\beta_{0}$ Ret $_{t}$ $+\beta_{1} D_{t}$ Ret $_{t}+\varepsilon_{t}$

where $D=1$ if $\operatorname{Ret}<0$. Higher $\beta_{1}$ is greater TLR.
Managers opportunistically smooth earnings. Therefore, greater smoothness is artificial relative to the fundamental process; or smoothness reduces noisy variation in cash flows as a measure of the process.
Pros: In cross-country tests, measures of artificial smoothness appear to capture meaningful variation in earnings management.

Cons: It is difficult to disentangle smoothness of reported earnings that reflects smoothness of the fundamental earning process from artificial smoothing.

\section{Benchmarks}

* Kinks in earnings distribution

* Changes in earnings distribution

* Kinks in forecast error distribution

* String of positive earnings increases
There is a demand for TLR to combat management's natural optimism. TLR represents high quality earnings.
Pros: Aimed at disentangling the measurement of the process from the process itself

Cons: The net effect of TLR on earnings quality is unknown because TLR results in lower persistence during bad news periods than during good news periods (Basu, 1997). Both persistence and TLR affect the decision usefulness of earnings. TLR is a returns-based metric, see comments on ERCs.
Unusual clustering in earnings distributions indicates earnings management around targets.

Observations at or slightly above targets have low quality earnings.
Pros: The measure is easy to calculate, the concept is intuitively appealing, and survey evidence suggests earnings management around targets. Cons: In addition to statistical validity issues, evidence that kinks represent opportunistic earnings management is mixed, with credible alternative explanations including non-accounting issues (e.g., taxes). It is difficult to distinguish firms that are at kinks by chance versus those that have manipulated their way into the benchmark bins. 
Exhibit 1, continued

\begin{tabular}{|c|c|c|}
\hline Empirical proxy & Theory & Strengths and weakness \\
\hline $\begin{array}{l}\text { Accruals } \\
\text { Accruals }=\text { Earnings }_{t}-C F_{t} \\
\text { Accruals }=\Delta(\text { noncash } \text { working capital }) \\
\text { Accruals }=\Delta \text { (net operating assets }) \\
\text { Specific accrual components }\end{array}$ & $\begin{array}{l}\text { Extreme accruals are low quality } \\
\text { because they represent a less } \\
\text { persistent component of earnings. }\end{array}$ & $\begin{array}{l}\text { Pros: The measure gets directly at the role of an accruals-based accounting } \\
\text { system relative to a cash-flow based system. } \\
\text { Cons: The fundamental earnings process differs for firms with extreme } \\
\text { accruals versus less extreme accruals, which hinders interpretation. }\end{array}$ \\
\hline $\begin{array}{l}\text { Residuals from accrual models } \\
\text { Error term from regressing accruals } \\
\text { on their economic drivers } \\
\text { (See Exhibit 2) }\end{array}$ & $\begin{array}{l}\text { Residuals from accrual models } \\
\text { represent management discretion or } \\
\text { estimation errors, both of which } \\
\text { reduce decision usefulness. }\end{array}$ & $\begin{array}{l}\text { Pros: The measure attempts to isolate the managed or error component of } \\
\text { accruals. The use of these models has become the accepted methodology in } \\
\text { accounting to capture discretion. } \\
\text { Cons: Tests of the determinants/consequences of earnings management are } \\
\text { joint tests of the theory and the abnormal accrual metric as a proxy for } \\
\text { earnings management. Correlated omitted variables associated with } \\
\text { fundamentals, especially performance, are of utmost concern given the } \\
\text { dependence of normal accruals on fundamentals and the endogeneity of the } \\
\text { hypothesized determinants/consequences with the fundamentals. }\end{array}$ \\
\hline $\begin{array}{l}\text { ERCs } \\
\text { Ret }_{t+1}=\alpha+\beta\left(\text { Earnings Surprise }_{t}\right)+\varepsilon_{t} \\
\text { More informative components of } \\
\text { earnings will have a higher } \beta \text {. More } \\
\text { value relevant earnings will have a } \\
\text { higher } \mathrm{R}^{2} \text {. }\end{array}$ & $\begin{array}{l}\text { Investors respond to information } \\
\text { that has value implications. A } \\
\text { higher correlation with value } \\
\text { implies that earnings better reflect } \\
\text { the fundamental earnings process. }\end{array}$ & $\begin{array}{l}\text { Pros: The measure directly links earnings to decision usefulness, which is } \\
\text { quality, albeit specifically in the context of equity valuation decisions. } \\
\text { Cons: Assumes market efficiency. In addition, inferences are impaired by } \\
\text { correlated omitted variables that affect investor reaction (including } \\
\text { endogenously determined availability of other information), measurement } \\
\text { error of unexpected earnings, and cross-sectional variation in return- } \\
\text { generating processes. }\end{array}$ \\
\hline $\begin{array}{l}\text { External indicators of } \\
\text { financial reporting quality } \\
\text { * AAERs identified by SEC } \\
\text { * Restatements } \\
\text { * SOX reports of internal control } \\
\text { deficiencies }\end{array}$ & $\begin{array}{l}\text { Firms had errors (AAERs and } \\
\text { restatement firms) or are likely to } \\
\text { have had errors (internal control } \\
\text { deficiencies) in their financial } \\
\text { reporting systems, which imply low } \\
\text { quality. }\end{array}$ & $\begin{array}{l}\text { Pros: Unambiguously reflect accounting measurement problems (low Type I } \\
\text { error rate). The researcher does not have to use a model to identify low } \\
\text { quality firms. } \\
\text { Cons: For AAERs: small sample sizes, selection issues, and matching } \\
\text { problems due to type II error rate. For restatements and SOX firms: problems } \\
\text { with distinguishing intentional from unintentional errors or ambiguities in } \\
\text { accounting rules that lead to errors. }\end{array}$ \\
\hline
\end{tabular}


Exhibit 2: Summary of widely used models of accruals

This table summarizes commonly used models to estimate normal levels of accruals. Residuals from the model are used as a measure of "abnormal" accruals.

\begin{tabular}{|c|c|c|}
\hline Accrual model & Theory & Notes \\
\hline \multicolumn{3}{|l|}{ Jones (1991) model } \\
\hline$A c c_{t}=\alpha+\beta_{1} \Delta \operatorname{Rev}_{t}+\beta_{2} P P E_{t}+\varepsilon_{t}$ & $\begin{array}{l}\text { Accruals are a function of revenue growth and } \\
\text { depreciation is a function of PPE. All variables are } \\
\text { scaled by total assets. }\end{array}$ & $\begin{array}{l}\text { Correlation or error with firm performance can bias } \\
\text { tests. }\end{array}$ \\
\hline \multicolumn{3}{|c|}{ Modified Jones model (Dechow, Sloan and Sweeney, 1995) } \\
\hline$A c c_{t}=\alpha+\beta_{l}\left(\Delta \operatorname{Rev}_{t}-\Delta \operatorname{Rec}_{t}\right)+\beta_{2} P P E_{t}+\varepsilon_{t}$ & $\begin{array}{l}\text { Adjusts Jones model to exclude growth in credit sales in } \\
\text { years identified as manipulation years. }\end{array}$ & $\begin{array}{l}\mathrm{R}^{2} \text { around } 12 \% \text {. Residual is correlated with accruals, } \\
\text { earnings and cash flow. }\end{array}$ \\
\hline \multicolumn{3}{|c|}{ Performance matched (Kothari, Leone, and Wasley, 2005) } \\
\hline DisAcc $_{t}-$ Matched firm's DisAcc ${ }_{t}$ & $\begin{array}{l}\text { Matches firm-year observation with another from the } \\
\text { same industry and year with the closest ROA. } \\
\text { Discretionary accruals are from the Jones-model (or } \\
\text { Modified Jones model). }\end{array}$ & $\begin{array}{l}\text { Can reduce power of test. Apply only when } \\
\text { performance is an issue. }\end{array}$ \\
\hline \multicolumn{3}{|l|}{ Dechow and Dichev (2002) approach } \\
\hline $\begin{array}{c}\Delta W C=\alpha+\beta_{1} C F O_{t-1}+\beta_{2} C F O_{t}+ \\
\beta_{3} C F O_{t+1}+\varepsilon_{t}\end{array}$ & $\begin{array}{l}\text { Accruals are modeled as a function of past, present, and } \\
\text { future cash flows given their purpose to alter the timing } \\
\text { of cash flow recognition in earnings. }\end{array}$ & $\begin{array}{l}\sigma\left(\varepsilon_{t}\right) \text { or absolute } \varepsilon_{t} \text { proxies for accrual quality as an } \\
\text { unsigned measure of extent of accrual "errors." }\end{array}$ \\
\hline \multicolumn{3}{|c|}{ Discretionary estimation errors (Francis, LaFond, Olsson, Schipper, 2005) } \\
\hline $\begin{aligned} & T C A_{t}=\alpha+ \beta_{I} C F O_{t-1}+\beta_{2} C F O_{t}+ \\
& \beta_{3} C F O_{t+1}+\beta_{4} \triangle \text { Rev }_{t}+\beta_{5} P P E_{t}+\varepsilon_{t} \\
& \sigma\left(\varepsilon_{t}\right)=\alpha+\lambda_{I} \text { Size }_{t}+\lambda_{2} \sigma(C F O)_{t}+\lambda_{3} \sigma(\text { Rev })_{t}+ \\
& \lambda_{4} \log (\text { OperCycle })_{t}+\lambda_{5} \text { Loss }_{t}+v_{t}\end{aligned}$ & $\begin{array}{l}\text { Decomposes the standard deviation of the residual from } \\
\text { the accruals model into an innate component that reflects } \\
\text { the firm's operating environment and a discretionary } \\
\text { component }\left(v_{t}\right) \text { that reflects managerial choice. }\end{array}$ & $\begin{array}{l}\text { Innate estimation errors are the predicted component } \\
\text { from } \sigma(\varepsilon)_{\mathrm{t}} \text { regression. }\end{array}$ \\
\hline
\end{tabular}

